\title{
Application of Virtual Patients in Undergraduate Dental Education
}

Citation for published version (APA):

Marei, H. F. (2018). Application of Virtual Patients in Undergraduate Dental Education. [Doctoral Thesis, Maastricht University]. Maastricht University. https://doi.org/10.26481/dis.20180907hm

Document status and date:

Published: 01/01/2018

DOI:

10.26481/dis.20180907hm

Document Version:

Publisher's PDF, also known as Version of record

\section{Please check the document version of this publication:}

- A submitted manuscript is the version of the article upon submission and before peer-review. There can be important differences between the submitted version and the official published version of record.

People interested in the research are advised to contact the author for the final version of the publication, or visit the DOI to the publisher's website.

- The final author version and the galley proof are versions of the publication after peer review.

- The final published version features the final layout of the paper including the volume, issue and page numbers.

Link to publication

\footnotetext{
General rights rights.

- You may freely distribute the URL identifying the publication in the public portal. please follow below link for the End User Agreement:

www.umlib.nl/taverne-license

Take down policy

If you believe that this document breaches copyright please contact us at:

repository@maastrichtuniversity.nl

providing details and we will investigate your claim.
}

Copyright and moral rights for the publications made accessible in the public portal are retained by the authors and/or other copyright owners and it is a condition of accessing publications that users recognise and abide by the legal requirements associated with these

- Users may download and print one copy of any publication from the public portal for the purpose of private study or research.

- You may not further distribute the material or use it for any profit-making activity or commercial gain

If the publication is distributed under the terms of Article $25 \mathrm{fa}$ of the Dutch Copyright Act, indicated by the "Taverne" license above, 


\title{
Application of Virtual Patients in Undergraduate Dental Education
}

\author{
DISSERTATION \\ to obtain the degree of Doctor at Maastricht University, \\ on the authority of the Rector Prof. dr. Rianne M. Letschert, \\ in accordance with the decision of the Board of Deans,
} to be defended in public on Friday $7^{\text {th }}$ September 2018, at 12.00 hours

by

Hesham Fathi Marei 


\section{Supervisor}

Prof. dr. J.J.G. van Merrienboer

\section{Co-supervisor}

Dr. H.H.L.M. Donkers

\section{Assessment Committee}

Prof. dr. J.J. Rethans (chair)

Prof. dr. H. Hamdy, Gulf Medical University, Ajman, United Arab Emirates Prof. dr. S.E. Köhler

Dr. P.M. van Rosmalen

Dr. L.W.M. van der Sluis, UMCG, Groningen 


\section{Contents}

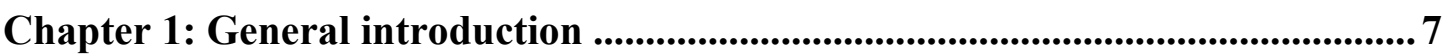

Chapter 2: Virtual patients and collaborative learning.....................................27

Chapter 3: Sequencing virtual patients with lectures ..........................................49

Chapter 4: Virtual patients and teaching professionalism ...................................69

Chapter 5: Virtual patients and cognitive load .....................................................93

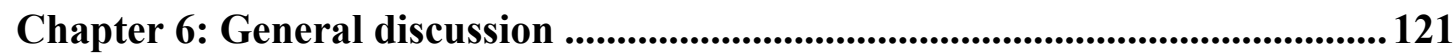

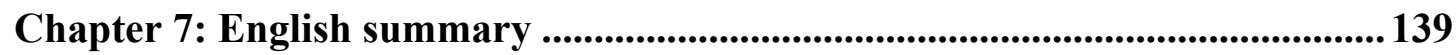

Hoofdstuk 8: Samenvatting ............................................................................................ 147

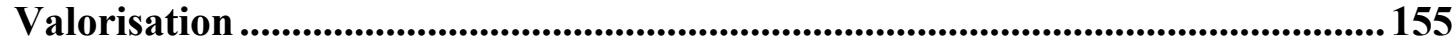

Acknowledgment ............................................................................................................... 159

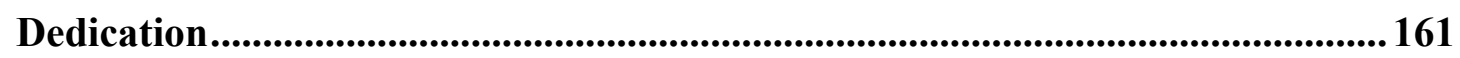

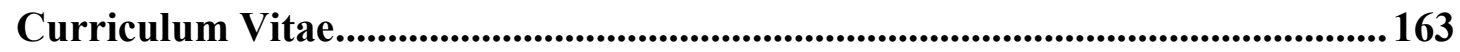

Marei HF Publications ....................................................................................... 165

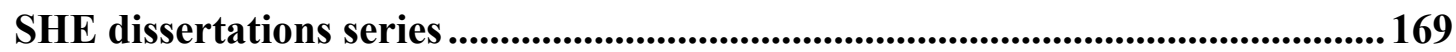


Chapter 1: General introduction

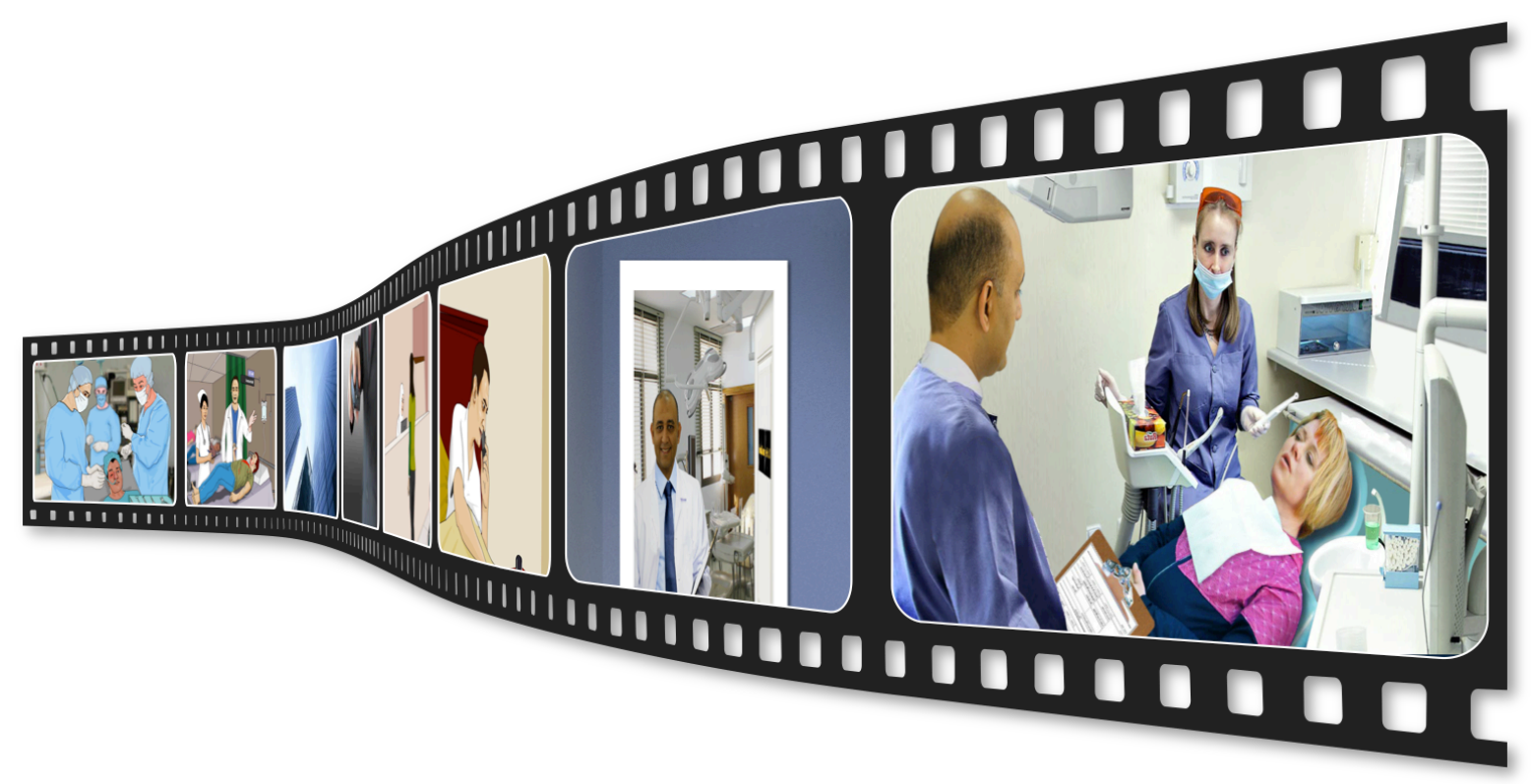


Virtual Patients (VPs) have been receiving considerable attention in medical education over the last decade, as evident from the growing number of published articles and reports in different medical education journals. The advancement in the fields of virtual reality and artificial intelligence may promote more use and extensive application of VPs in health profession education. Articles in the medical, dental and nursing literature refer to the term Virtual Patient or VP. Yet, we ponder: Do they talk about the same thing? Is the presentation of VPs consistent across different contexts? Do medical teachers with different backgrounds apply and use VPs in the same way? The aim of this chapter is to provide the readers with a background on VPs' description, VPs' design and main applications, leading to the presentation of the problem statement of the current thesis and the different research questions that will be answered by the studies presented in this thesis.

\section{What is a VP?}

A VP is recognized in the context of medical education as: "An interactive computer simulation of a real-life clinical scenario for the purpose of teaching, learning and assessment" (Ellaway, Candler, Greene, \& Smothers, 2006, p2). Yet, the American Association of Medical Colleges (AAMC) describes a VP as "A specific type of computer-based program that simulates real-life clinical scenarios; learners emulate the roles of health care providers to obtain a history, conduct a physical exam, and make diagnostic and therapeutic decisions" (AAMC, 2007, p7). Both definitions indicate that a VP is a clinical scenario that plays on a computer screen. In general, in using a VP, learners read or listen to the virtual patient's complain (on the screen) and request specific investigations (such as radiographs or lab tests) by selecting options from a drop-list or by entering text. Upon presenting the results of the requested investigations, learners are requested to interpret the findings and select from a list the most likely diagnosis and then suggest the most appropriate treatment plan. Within this general description of a VP, there is a wide room for variation in its design, use, and integration within a curriculum.

\section{What are the Different VP Designs?}

The instructional design of VPs depends mainly on the learner pathway from start till the end, use of images and videos within the VP, and how the story is being told (Huwendiek, de Leng, et al., 2009). The learner pathway of VPs can be either 
linear (passive or active) or in the form of a branching-tree. A classic example of a linear passive pathway is the paper case used in case-based learning, as it does not unfold during learner practice (Figure 1a). The VP in this design is mainly used as a trigger for discussion. A linear pathway can be made more interactive by using an active design, which is known as a 'string of pearls' (Figure 1b). It involves a single path through history, examination, diagnosis, and treatment planning. In this design, the learner has to finish one section (examination) in order to move to the next section (Ellaway, Poulton, Fors, McGee, \& Albright, 2008). The most sophisticated design is the branching-tree or network design, which involves multiple pathways leading to a common end point or multiple end points (Figure 2). In this design, the learner pathway is based on the decisions taken by the learner at every strategic node in the VP. The VP would branch in a divergent pattern to end in multiple end points or it may direct the learner back to the main stream to end in one end point (Ellaway et al., 2008).

In all VP designs, learners invariably interact with the VP by either selecting from a list of options or entering free text. The learner can follow the consequences of the decision taken as in branching-tree design, or directly be guided to the next stage as in linear active design. Moreover, VPs can be programed to provide immediate formative feedback as per the learners' choices, or it can generate a summative report at the end of the session (Huwendiek, Reichert, et al., 2009).

\section{a. Linear passive design}

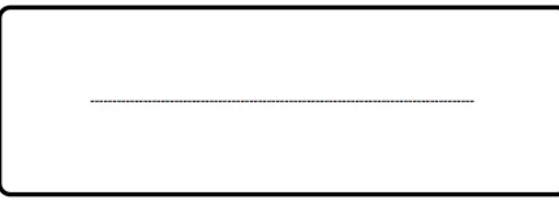

\section{b. Linear active design}

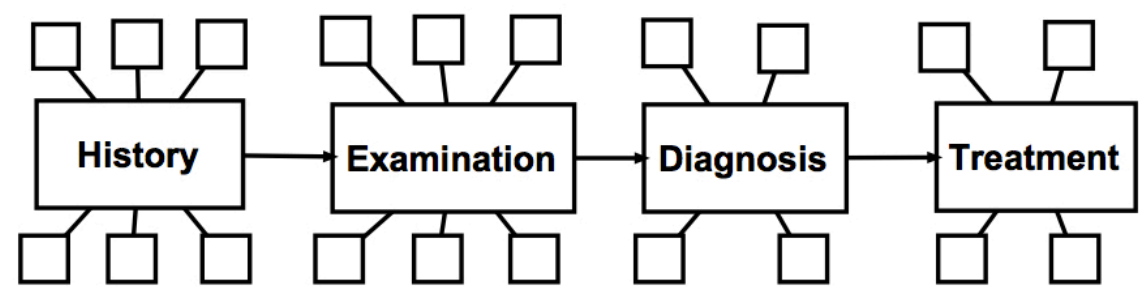

Figure 1: Linear VP designs 


\section{a. Branching tree design with one end node}

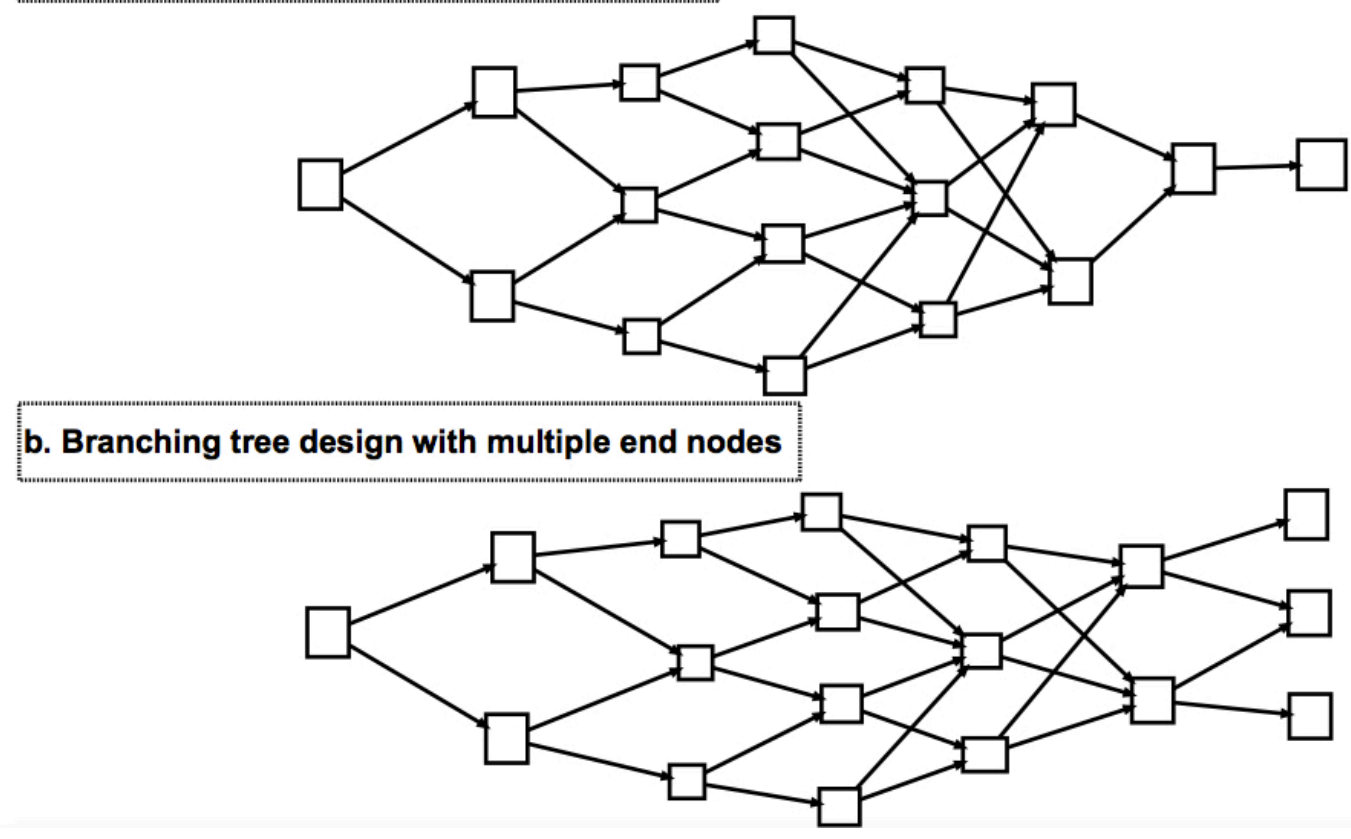

Figure 2: Branching Tree VP designs

Moreover, VP design varies according to the use of images and media. Research on the use of technology from a cognitive perspective advocates that elearning tools should ensure that the learner constructs optimal mental representations of the scenario (Dror, Schmidt, \& O'Connor, 2011). For the learner to construct such mental representations, the e-learning tool should consider in its design three different types of simulation fidelity, which should be optimal for the intended target group and the learning goal (Dankbaar et al., 2016). These types are functional, physical and psychological fidelity. Functional fidelity refers to how the learner interacts and controls the simulation, its behavior and responses to learner actions, while physical fidelity indicates tactile, visual, auditory, and olfactory features of the simulator to enhance its physical appearance (Hamstra, Brydges, Hatala, Zendejas, \& Cook, 2014). Psychological fidelity is the degree of reality in the thinking process perceived by the learner (Ker \& Bradley, 2014).

The same simulation principles apply to VPs. The VP scenario should present a valid and coherent representation of the real world analog to ensure that what is learnt is directly transferable to real-life scenarios (Ellaway et al., 2008). Multiple studies have investigated learners' perceptions of the ideal features of VP design that 
foster learning (Botezatu, Hult, \& Fors, 2010; Huwendiek, Reichert, et al., 2009). There is a general agreement on the importance of designing VPs that (a) target relevant real-life problems, (b) are highly interactive, (c) are of an appropriate level of difficulty, (d) involve an authentic interface that reflects the reality of clinical practice and provides feedback to the learner, and (e) shows the consequences of the decision taken during VP practice (e.g., actual clinical evolution and the effect of offered treatment through the case).

Finally, a student's persistent engagement in VPs depends on the balance between presenting data (reading a history, getting test results) and telling a story (engaging in conversation, character, narrative). Learners might lose themselves in a story whenever they experience a feeling of entering a world evoked by the narrative because of empathy for the story characters and imagination of the story plot (Van Laer, De Ruyter, Visconti, \& Wetzels, 2013). Presenting too much data might isolate the learner from getting immersed in the scenario, while too much conversation between characters might reduce the educational benefit due to a lesser scientific content (Huwendiek, de Leng, et al., 2009). The variability in VPs' designs has opened the gate for a wide range of uses and applications with different educational outcomes.

\section{What are the Main Uses and Benefits of VPs?}

VPs can offer a solution to the common dilemma of students' limited access to real patients (Ellaway et al., 2008; Johnson et al., 2014), which could be due to a real shortage in the number of patients or inability of students to access clinics in the most appropriate phase of their educational program. Curriculum designers advocate the importance of students' early clinical contacts (Manogue et al., 2011) and the necessity of integrating basic sciences with clinical sciences (Dahle, Brynhildsen, Behrbohm, Rundquist, \& Hammar, 2002; Manogue et al., 2011). However, it is not easy to implement such guidelines due to many reasons, such as a lack of clinical resources that can accommodate students at all levels and a shortage of clinical tutors. Finally, most healthcare systems prioritize patients' clinical service above students' clinical training. Therefore, curriculum designers can use VPs to link basic sciences and clinical training, by incorporating VPs within teaching sessions of basic sciences to show the relevance of basic concepts to clinical problems. It was reported that 
student acceptance of VPs is higher in novice students, which indicates its potential benefit early in the curriculum (Gesundheit et al., 2009; Gupta, Singh, Khaliq, Dhaliwal, \& Madhu, 2018).

VPs' use was prescribed earlier for the development of clinical reasoning skills (Cook \& Triola, 2009a). VPs can also be used to facilitate knowledge acquisition when used as stand-alone e-learning objects. Furthermore, VPs can be used to bridge the gap between low fidelity environments (e.g., paper cases) and high fidelity environments (e.g., manikins in a simulation lab), as it is advocated that the learning of complex tasks proceeds from simple to increasingly more complex learning tasks, and gradually increasing fidelity is one way to reach this goal (Van Merrienboer \& Sweller, 2010).

Moreover, it is better for the community and for patient safety that learners make mistakes on virtual patients rather than on real patients (Kononowicz et al., 2016), as the emotional negative impact of medical error is high for both patients and clinicians (Berlinger \& Wu, 2005; Marei, 2013). It is also better to receive individualized and timely feedback on incorrect answers rather than general feedback (Harden \& Laidlaw, 2013), which are opportunities that are offered by VPs. VPs can be standardized from one learner to the next and integrated into assessment activities to assess learner competence to begin working with real patients, which reduces medical errors (Berman, Durning, Fischer, Huwendiek, \& Triola, 2016). Furthermore, educational data retrieved from different VPs can be analyzed to predict future performance and to identify learners at risk of failure (Berman et al., 2016).

Ellaway et al. (2015) described a group of learning activities that can be constructed around VPs, which are bridging, reference, blended, independent and collaborative activities. In a bridging activity, VPs may be used to prepare for, and then follow up on, a manikin-based simulation task or educational game in order to add the psychosocial aspect of the real environment to the manikin-based activity (Ellaway, Topps, Lee, \& Armson, 2015). VPs can be used also as online reference materials (known as reference VPs). Reference VPs usually serve as wrappers for other material such as videos demonstrating clinical skills or quizzes, by providing a contextual framework, highlighting key points, and providing additional background material (Ellaway et al., 2015). 
VPs can also be incorporated in a flipped-classroom approach to promote deep learning, as learners can work on VPs independently at home and then come to the classroom prepared for a face-to face discussion of a problem relevant to the VPs (Berman et al., 2016). In such an approach, VPs are described as part of a blended learning activity, because the overall aim (deep learning) is achieved through a combination of face-to-face learning and online learning with VPs (Ellaway et al., 2015).

Learners can use VPs individually or in groups inside the classroom (Ellaway et al., 2015). Collaborative use of VPs is applied mainly to trigger students' interactions. A collaborative VP learning activity requires learners to work in groups of 3-5 members and to reach consensus on what their collaborative decisions for the VP should be. The role of a tutor in this activity is to control the session, guide the discussion around the VP, and provide feedback to the learners. In such an activity, most of the learning occurs as a result from the group discussion rather than from the interaction with the VP itself. In independent learning activities, the learner works individually with a VP, where learning depends mainly on the inherent characteristics incorporated in the VP design, such as: the quality of the provided problem, amount of interactive nodes, and the quality of feedback (Ellaway et al., 2015; Huwendiek, Reichert, et al., 2009).

\section{How to Use VPs Most Effectively?}

VP studies that explored students' learning concluded that learning from VPs is dependent on (a) what teachers and learners do with the VPs (Ellaway, 2014), (b) how VPs are aligned in the curriculum and sequenced with other instructional methods (Huwendiek et al., 2013), (c) how VPs are designed and perceived by the learners (Huwendiek, Reichert, et al., 2009), and (d) the students' knowledge and experience prior to interacting with the VPs (Bateman, Allen, Samani, Kidd, \& Davies, 2013).

Learners' use of VPs in the context of different learning activities and the teacher philosophy in aligning VP activities with other instructional methods are factors that are extraneous to VP design. Such factors could result in an impact on learning outcomes more than the design of VPs per se. Therefore, there was a call for more research to inform how to effectively use VPs (Cook \& Triola, 2009b). 
The alignment and sequence of VPs with other instructional methods can take several forms. VP activities can be sequenced before other instructional sessions such as a lecture or a small group discussion, so students can appreciate gaps in their knowledge, which raise their interest in the presented materials. Moreover, the VP activities can be sequenced after lectures or small group discussions, to serve as a context for knowledge application, which promotes deep learning. This way, both the VPs' session and the other instructional sessions are planned to augment each other and serve common educational objectives. A particular form of sequence of VPs with other instructional methods is called a VP integration scenario (Huwendiek et al., 2013).

Studies on the use of VPs and their effectiveness revealed venues for further research. For instance, in their critical review, Cook and Triola (2009b) concluded that VPs are "likely to play an important role in medical education, but its effective use requires evidence to guide design and integration" (Cook \& Triola, 2009a). A meta-analysis on VPs called for more research to clarify how they can be effectively implemented (Cook, Erwin, \& Triola, 2010). In the same vein, other studies recommended more quantitatively controlled studies to investigate the effects of different VP integration scenarios on different outcome variables (Huwendiek et al., 2013; Huwendiek, Reichert, et al., 2009).

\section{Problem Statement}

Although VPs are being applied at an increasing rate and with growing levels of success in developing clinical reasoning skills, and are generally positively perceived by both learners and medical teachers, there is still a call for more research to disclose how VPs can be effectively integrated into a curriculum.

Figure 3 summaries the four studies that will be presented in the following sections. Studies 1 and 2 involve comparisons between two different interventions in regard to the same dependent variables, which are knowledge acquisition, retention and transfer. Study 3 explores student perceptions in regard to the collaborative use of VPs in teaching and learning professionalism. Study 4 evaluates the different types of cognitive load that were imposed on students during the practice of different VPs interventions in Studies 1 and 2, and combines them with the students' scores to explore the efficiency of different instructional methods. The answers of the four 
research questions should give a rational on how to effectively integrate VPs into a curriculum.

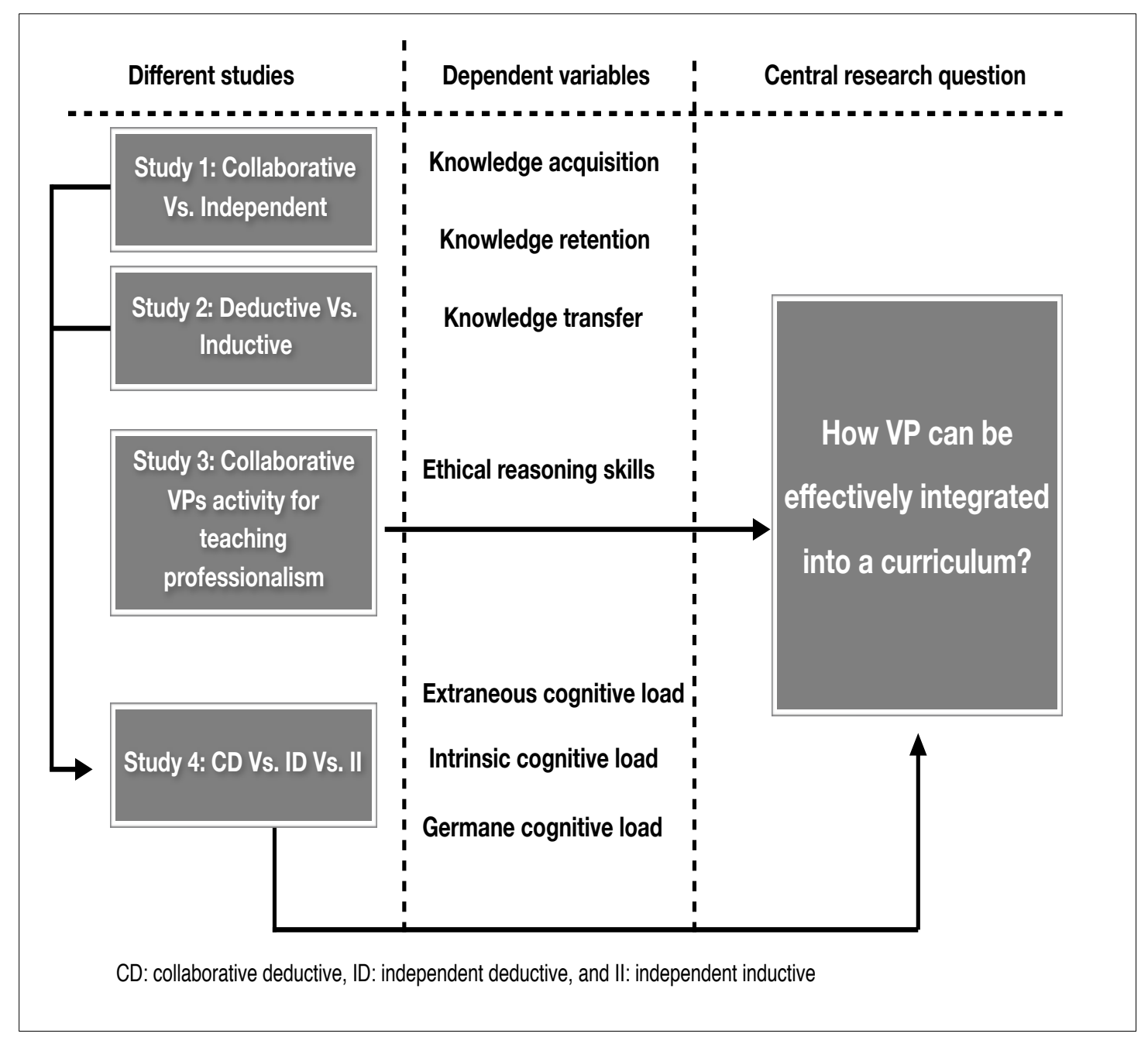

Figure 3: Outline of the four studies and the problem statement 


\section{Studies and Research Questions}

\section{Study 1: VPs Integration as a Collaborative Learning Activity}

Since collaborative learning is recognized in general as an effective learning method and there is a call for using VPs as a part of a whole activity, Study 1 (in Chapter 2) addresses the first research question: Would the use of virtual patients as a collaborative learning activity, when compared with their use as an independent learning activity, enhance students' knowledge acquisition, retention, and transfer? In Study 1, we are comparing between the effectiveness of two types of activities that were proposed by previous studies (Huwendiek et al., 2013). Study 1 hypothesized that the collaborative learning activity would be more effective than the independent learning activity. This hypothesis was based on the social constructivism learning theory, which acknowledges the dimension of collaboration, and interaction among students and their tutors, as important contributing factors for schema construction (Philpott \& Batty, 2009).

The study is conducted in two separate campuses (male and female). It involved randomization of both the male students and the female students into two groups. The interventions consisted of two parts: lecture sessions, which were the same for all four experimental groups, followed by VPs activities, which were either independent or collaborative. The study involved two topics so that students who practiced independently in the first topic became involved in a collaborative practice in the second topic and vice versa. The independent variables in Study 1 were the type of intervention (independent \& collaborative) and gender (male \& female), while the dependent variables were knowledge acquisition, retention and transfer. Knowledge acquisition was measured immediately after the VP sessions using MCQs. Knowledge retention is measured two weeks later using MCQs, while knowledge transfer is measured using two new VPs.

\section{Study 2: VPs and Lecture Integration Scenario}

Since there are multiple VP integration scenarios that are reported in the literature and some of them are perceived well by learners, Study 2 (in Chapter 3) aims to answer the second research question: Is sequencing VPs with lectures in a deductive approach (i.e. VP after lecture) more effective than sequencing them in an inductive approach (i.e. VP before lecture), on students' knowledge acquisition, 
retention, and transfer? Study 2 thus compares between two different VP integration scenarios, which are the independent use of VPs after the lecture (deductive learning) and before it (inductive learning) in respect to the same learning outcomes that were investigated in Study 1.

Our interventions were based on students' preference of a specific VP integration scenario that was presented in the literature. Students preferred the sequence of having a lecture followed by a VP, then a small group discussion, and finally a real patient (Huwendiek et al., 2013). Huwendiek et al. (2013) admitted that such preferred sequence requires further investigation to proof its effectiveness. It is well known that what students want is not always what they need (Kirschner \& Van Merrienboer, 2013). Therefore, we investigated two sequences of aligning VPs with lecture.

Exposing students to an authentic problem or a task after a lecture is regarded as a deductive learning approach (Prince \& Felder, 2006), which is appropriate when prior knowledge is not yet present to be retrieved from long-term memory and the instructions presented in a lecture format would be regarded as supportive information for task execution (Vandewaetere et al., 2014). It is typically argued that such learning approach might work better for learners with relatively high expertise that already have the prior knowledge necessary to understand the newly presented information (Van Merrienboer, 2013).

In the inductive approach, the problem is presented before any other form of instructions (Prince \& Felder, 2006), which might be more appropriate for learners with low expertise (Schmidt, Rotgans, \& Yew, 2011). Students, in the inductive approach, are expected to discover their knowledge gap that raises their situational interest and increases their desire to learn. VPs, as authentic clinical scenarios, present opportunities for students to discover their knowledge gaps in the inductive approach or a context for knowledge application in the deductive approach.

In Study 2, we followed the same randomization design of Study 1, but on a different batch of students. The interventions consisted of two parts: lecture sessions, which were either before or after independent VPs practice. The independent variables in Study 1 were the sequence of VPs with lecture (deductive \& inductive) and gender (male \& female), while the dependent variables were knowledge 
acquisition, retention and transfer. The same tests that were used in Study 1 are applied in Study 2.

Study 3: VPs Activity as a Vehicle for Teaching Professionalism

Knowledge retention and transfer are not the only intended learning outcomes. Professionalism is an essential competency that must be demonstrated by healthcare graduates. Study 3 (in Chapter 4) intended to answer the research questions: How can $V P s$ help students in developing their ethical reasoning skills, and what are the salient VP design features for teaching professionalism? The study aims to investigate students' perception about the effectiveness of integrating VPs in a collaborative learning activity for teaching ethical reasoning skills that are required in decision-making on a given professionalism dilemma. It explores students' perception about the ideal features of VP design that would contribute to effective teaching and learning of professionalism.

The design of the intervention was based on situated-learning theory, which is a cornerstone model in the medical literature for developing and designing instructions towards teaching professionalism. The theory argues that learning occurs as a result of a complex interaction between the participants (social context), their environment (physical context), and authentic activities that are led by a mentor or teacher (Birden et al., 2013). That said, we anticipated that the collaborative work of students (social context) with VPs based on authentic professionalism dilemmas, followed by a reflection session guided by faculty, could be an effective method for developing ethical reasoning skills that are required in decision-making on professionalism dilemmas.

The study addressed the research question using a questionnaire that was designed and used before by a group of medical education experts in evaluating students' perception toward VPs features that foster clinical reasoning skills (Huwendiek \& de Leng, 2010). The questions clustered into five main categories, which are the authenticity of the patient encounter, professional approach in consultation, coaching during consultation, learning effect and overall judgment. The adapted questionnaire contained 10 closed and three open- ended questions. For the closed questions, the students were asked to rank five VPs from 1 to 5 ; in which 1 is 
the best VP and 5 is the worse VP. For open-ended questions, thematic analysis was generated based on students' qualitative data.

Study 4: Instructional Efficiency of VPs Integration Scenarios

Different VP integration scenarios may impose a variable amount of cognitive load on learners. Ideally, VPs sessions should be designed to prevent cognitive overload. Study 4 (in Chapter 5) addressed the central research question from the perspective of cognitive load theory. The study investigated: Would the collaborative use of VPs after the lecture (i.e. deductive), be the most efficient instructional method, when compared with independent use of VPs either before (i.e. inductive) or after the lecture? Cognitive load theory advocates the significance of managing the capacity of working memory, so it can process novel information to construct schemas in longterm memory (Van Merrienboer \& Sweller, 2010). Managing the capacity of working memory requires attention to different types of cognitive load.

The complex nature of the VPs and / or their sequence with other instructional methods that do not respect the level of prior knowledge of the learners could result in cognitive overload (Kirschner, Sweller, \& Clark, 2006; Van Merrienboer \& Kirschner, 2018). The study combines the students' scores that were achieved in knowledge acquisition, retention and transfer tests in Studies 1 and 2 with the cognitive load measurements after practicing VPs in the relevant study. The study used the cognitive load questionnaire developed by Leppink, Paas, van Gog, van der Vleuten, and van Merrienboer (2014) for measuring the intrinsic, extraneous and germane load. Efficiency of a specific instructional method is higher when high performance is combined with low cognitive load, and efficiency is lower when low performance is combined with high cognitive load (Paas \& Van Merrienboer, 1993). 


\section{Overview of the Thesis}

To summarize, the research reported in this thesis will tackle the following four research questions that will be presented in Chapters 2, 3, 4 and 5:

1. Would the use of virtual patients as a collaborative learning activity, when compared with their use as an independent learning activity, enhance students' knowledge acquisition, retention, and transfer?

2. Does sequencing virtual patients with lectures through a deductive approach, when compared with an inductive approach, result in a difference in students' knowledge acquisition, retention, and transfer?

3. How can the use of VPs in the classroom help students in developing their ethical reasoning skills, and what are the VP design features that learners perceive as crucial for teaching professionalism?

4. Is the collaborative use of VPs after a lecture (i.e. deductive) the most efficient instructional method, when compared with independent use of VPs either before (i.e. inductive) or after the lecture?

Together, the answers to the four research questions will offer a basis that can guide medical teachers in an effective and efficient integration of VPs within a dental curriculum.

Chapter 6 (General Discussion) summarizes the answers of the four research questions in relevance to our stated theories and hypotheses. The discussion chapter provides also the key practical and theoretical implications in the form of messages to the different stakeholders. Finally, limitations and venues for further research are acknowledged along with concluding remarks as take home messages. 


\section{References}

AAMC. (2007). Effective Use of Educational Technology in Medical Education: Summary Report of the 2006 AAMC Colloquium on Educational Technology. Retrieved from https://www.aamc.org/initiatives/meded on 10/01/2018

Bateman, J., Allen, M., Samani, D., Kidd, J., \& Davies, D. (2013). Virtual patient design: exploring what works and why. A grounded theory study. Med Educ, 47(6), 595-606.

Berlinger, N., \& Wu, A. W. (2005). Subtracting insult from injury: addressing cultural expectations in the disclosure of medical error. J Med Ethics, 31(2), 106-108.

Berman, N. B., Durning, S. J., Fischer, M. R., Huwendiek, S., \& Triola, M. M. (2016). The Role for Virtual Patients in the Future of Medical Education. Academic Medicine, 91(9), 1217-1222.

Birden, H., Glass, N., Wilson, I., Harrison, M., Usherwood, T., \& Nass, D. (2013). Teaching professionalism in medical education: a Best Evidence Medical Education (BEME) systematic review. BEME Guide No. 25. Med Teach, $35(7)$, e1252-1266.

Botezatu, M., Hult, H., \& Fors, U. G. (2010). Virtual patient simulation: what do students make of it? A focus group study. BMC Med Educ, 10, 91.

Cook, D. A., Erwin, P. J., \& Triola, M. M. (2010). Computerized virtual patients in health professions education: a systematic review and meta-analysis. Academic Medicine, 85(10), 1589-1602.

Cook, D. A., \& Triola, M. M. (2009a). Virtual patients: a critical literature review and proposed next steps. Med Educ, 43(4), 303-311.

Cook, D. A., \& Triola, M. M. (2009b). Virtual patients: a critical literature review and proposed next steps. Med Educ., 43(4), 303-311.

Dahle, L., Brynhildsen, J., Behrbohm, M., Rundquist, I., \& Hammar, M. (2002). Pros and cons of vertical integration between clinical medicine and basic science within a problem-based undergraduate medical curriculum: examples and experiences from Linkoping, Sweden. Med Teach, 24(3), 280-285.

Dankbaar, M. E., Alsma, J., Jansen, E. E., van Merrienboer, J. J., van Saase, J. L., \& Schuit, S. C. (2016). An experimental study on the effects of a simulation game on students' clinical cognitive skills and motivation. Adv Health Sci Educ Theory Pract, 21(3), 505-521. 
Dror, I., Schmidt, P., \& O'Connor, L. (2011). A cognitive perspective on technology enhanced learning in medical training: great opportunities, pitfalls and challenges. Med Teach, 33(4), 291-296.

Ellaway, R. (2014). Virtual patients as activities: exploring the research implications of an activity theoretical stance. Perspect Med Educ, 3(4), 266-277.

Ellaway, R., Candler, C., Greene, P., \& Smothers, V. (2006). An architectural model for MedBiquitous virtual patients. Baltimore, MD: MedBiquitous.

Ellaway, R., Poulton, T., Fors, U., McGee, J. B., \& Albright, S. (2008). Building a virtual patient commons. Med Teach, 30(2), 170-174.

Ellaway, R., Topps, D., Lee, S., \& Armson, H. (2015). Virtual patient activity patterns for clinical learning. Clin Teach, 12(4), 267-271. doi:10.1111/tct.12302

Gesundheit, N., Brutlag, P., Youngblood, P., Gunning, W. T., Zary, N., \& Fors, U. (2009). The use of virtual patients to assess the clinical skills and reasoning of medical students: initial insights on student acceptance. Med Teach, 31(8), 739-742.

Gupta, A., Singh, S., Khaliq, F., Dhaliwal, U., \& Madhu, S. V. (2018). Development and validation of simulated virtual patients to impart early clinical exposure in endocrine physiology. Adv Physiol Educ, 42(1), 15-20.

Hamstra, S. J., Brydges, R., Hatala, R., Zendejas, B., \& Cook, D. A. (2014). Reconsidering fidelity in simulation-based training. Academic Medicine, 89(3), 387-392.

Harden, R. M., \& Laidlaw, J. M. (2013). Be FAIR to students: four principles that lead to more effective learning. Med Teach, 35(1), 27-31.

Huwendiek, S., \& de Leng, B. A. (2010). eViP Student questionnaire concerning the integration of virtual patients. eViP Evaluation Toolkit. Retrieved from http://www.virtualpatients.eu on 10/01/2018

Huwendiek, S., de Leng, B. A., Zary, N., Fischer, M. R., Ruiz, J. G., \& Ellaway, R. (2009). Towards a typology of virtual patients. Med Teach, 31(8), 743-748.

Huwendiek, S., Duncker, C., Reichert, F., de Leng, B. A., Dolmans, D., van der Vleuten, C. P., . . . Tonshoff, B. (2013). Learner preferences regarding integrating, sequencing and aligning virtual patients with other activities in the undergraduate medical curriculum: A focus group study. Med Teach, 35(11), 920-929. 
Huwendiek, S., Reichert, F., Bosse, H. M., de Leng, B. A., van der Vleuten, C. P., Haag, M., ... Tonshoff, B. (2009). Design principles for virtual patients: a focus group study among students. Med Educ, 43(6), 580-588.

Johnson, T., Lyons, R., Kopper, R., Johnsen, K., Lok, B., \& Cendan, J. (2014).

Virtual patient simulations and optimal social learning context: a replication of an aptitude-treatment interaction effect. Med Teach, 36(6), 486-494.

Ker, J., \& Bradley, P. (2014). Simulation in medical education. In T. Swanwick (Ed.), Understanding Medical Education-Evidence, Theory and Practice (2 ed., pp. 175-192): Wiley Blackwell.

Kirschner, P. A., Sweller, J., \& Clark, R. E. (2006). Why minimal guidance during instruction does not work: An analysis of the failure of constructivist, discovery, problem-based, experiential, and inquiry-based teaching. Educational Psychologist, 41(2), 75-86.

Kirschner, P. A., \& Van Merrienboer, J. J. (2013). Do Learners Really Know Best? Urban Legends in Education. Educational Psychologist, 48(3), 169-183.

Kononowicz, A. A., Woodham, L., Georg, C., Edelbring, S., Stathakarou, N., Davies, D., . . Car, J. (2016). Virtual patient simulations for health professional education. The Cochrane Library.

Leppink, J., Paas, F., van Gog, T., van der Vleuten, C. P. M., \& van Merrienboer, J. J. (2014). Effects of pairs of problems and examples on task performance and different types of cognitive load. Learning and Instruction, 30(Supplement C), $32-42$.

Manogue, M., McLoughlin, J., Christersson, C., Delap, E., Lindh, C., SchoonheimKlein, M., \& Plasschaert, A. (2011). Curriculum structure, content, learning and assessment in European undergraduate dental education - update 2010. European Journal of Dental Education, 15(3), 133-141.

Marei, H. F. (2013). Medical litigation in oral surgery practice: lessons learned from 20 lawsuits. J Forensic Leg Med, 20(4), 223-225.

Paas, F. G., \& Van Merrienboer, J. J. (1993). The efficiency of instructional conditions: An approach to combine mental effort and performance measures. Human factors, 35(4), 737-743.

Philpott, J., \& Batty, H. (2009). Learning best together: social constructivism and global partnerships in medical education. Med Educ, 43(9), 923-924. 
Prince, M. J., \& Felder, R. M. (2006). Inductive teaching and learning methods: Definitions, comparisons, and research bases. Journal of engineering education, 95(2), 123-138.

Schmidt, H. G., Rotgans, J. I., \& Yew, E. H. (2011). The process of problem-based learning: what works and why. Med Educ, 45(8), 792-806.

Van Laer, T., De Ruyter, K., Visconti, L. M., \& Wetzels, M. (2013). The extended transportation-imagery model: A meta-analysis of the antecedents and consequences of consumers' narrative transportation. Journal of Consumer research, 40(5), 797-817.

Van Merrienboer, J. J. (2013). Perspectives on problem solving and instruction. Computers \& Education, 64, 153-160.

Van Merrienboer, J. J., \& Kirschner, P. A. (2018). Ten steps to complex learning: A systematic approach to four-component instructional design: Routledge.

Van Merrienboer, J. J., \& Sweller, J. (2010). Cognitive load theory in health professional education: design principles and strategies. Med Educ, 44(1), 8593.

Vandewaetere, M., Manhaeve, D., Aertgeerts, B., Clarebout, G., Van Merrienboer, J. J., \& Roex, A. (2014). 4C/ID in medical education: How to design an educational program based on whole-task learning: AMEE Guide No. 93. Med Teach, 1-17. 


\section{Chapter 2: Virtual patients and collaborative learning}

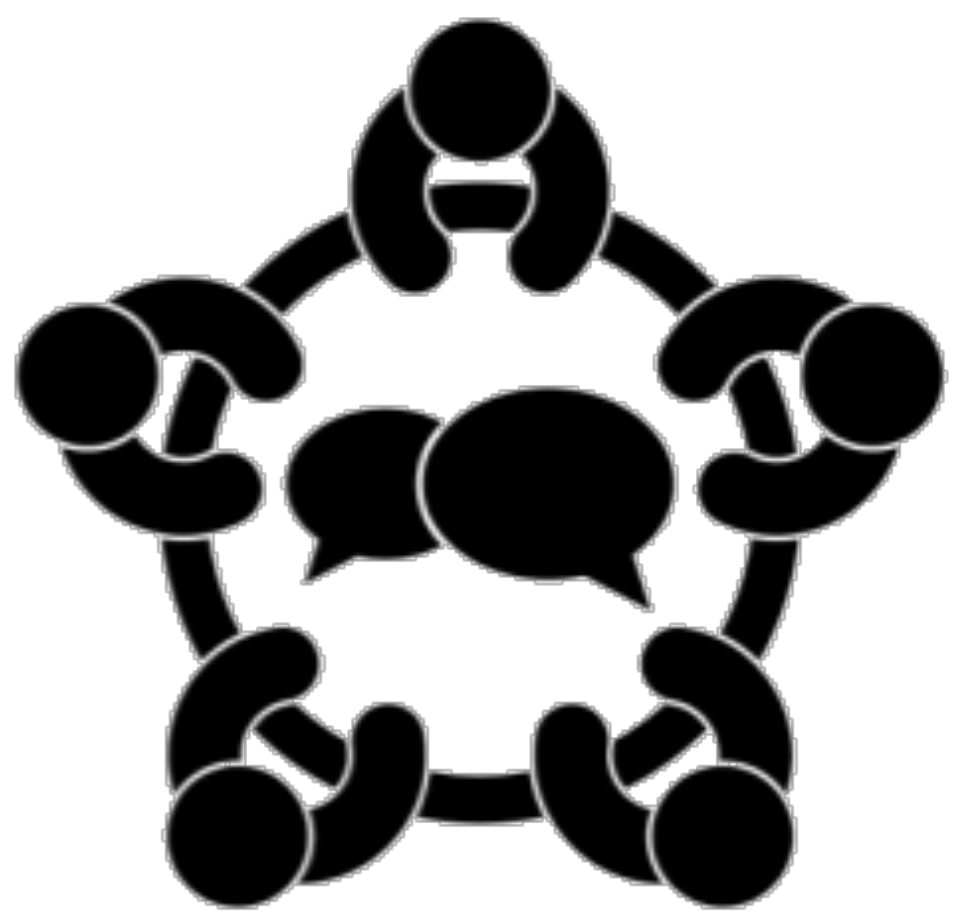

This chapter was published as:

Marei, H.F., Donkers, H.H.L.M., Van Merrienboer, J.J.G. (2018). The effectiveness of integration of virtual patients in a collaborative learning activity. Medical Teacher, May; 7:1-8. doi: 10.1080/0142159X.2018.1465534. [Epub ahead of print]. 


\begin{abstract}
Background: Virtual patients (VPs) have been recently integrated within different learning activities.

Aim: To compare between the effect of using VPs in a collaborative learning activity and using VPs in an independent learning activity on students' knowledge acquisition, retention and transfer.

Methods: For two different topics, respectively 82 and 76 dental students participated in teaching, learning and assessment sessions with VPs. Students from a female campus and from a male campus have been randomly assigned to condition (collaborative and independent), yielding four experimental groups. Each group received a lecture followed by a learning session using two VPs per topic. Students were administrated immediate and delayed written tests as well as transfer tests using two VPs to assess their knowledge in diagnosis and treatment.

Results: For the treatment items of the immediate and delayed written tests, females outperformed males in the collaborative VP group but not in the independent VP group.

Conclusion: On the female campus, the use of VPs in a collaborative learning activity is more effective than its use as an independent learning activity in enhancing students' knowledge acquisition and retention. However, the collaborative use of VPs by itself is not enough to produce consistent results across different groups of students and attention should be given to all the factors that would affect students' interaction.
\end{abstract}




\section{Introduction}

Virtual Patients (VPs) have been defined in the medical literature as a form of computer simulation of real-life clinical scenarios (Ellaway, Candler, Greene, \& Smothers, 2006). They can have a linear passive design that is similar to a paper case as used in case-based learning, a linear active design defined as a 'string of pearls' that involves a single path through history, examination, diagnosis, and treatment planning, or finally a branching-tree or network design that involves multiple pathways leading to a common end point or multiple end points (Ellaway, Poulton, Fors, McGee, \& Albright, 2008).

Different studies have shown that feedback to learners, deliberate practice, variability in practice and instructor training are some of the factors that dictate the effectiveness of the use of simulation in general (Cook et al., 2013; Motola, Devine, Chung, Sullivan, \& Issenberg, 2013). For VPs, it is advocated that the most important impact could come from features that are extraneous to the design of VPs such as how they are aligned with other instructional methods in the curriculum, and whether students should complete VPs in groups or individually. Therefore, there was a call for more research to inform how to effectively use VPs (Cook \& Triola, 2009). In the same context, Ellaway, Topps, Lee, and Armson (2015) indicated that the effectiveness of VPs depends on the activity design that is constructed around them, and the medical teachers should find the best ways to use them.

Recently, VPs have been introduced as an integrated part of a whole learning activity as one VP can be used in many different learning activities, and many VPs can be used in one activity (Ellaway \& Davies, 2011). A particular form of integration is called a VP integration scenario (Huwendiek et al., 2013) or VP activity (Ellaway \& Davies, 2011).

Different VP activity patterns have been presented by Ellaway et al. (2015). Two of which are collaborative learning and independent learning activities. In a collaborative learning activity, learners work in groups with VPs to reach consensus on what their collaborative decisions should be. The role of a tutor in this activity is to control the session, guide the discussion around the VPs and provide feedback to the learners. In an independent learning activity, the learners work individually with VPs, and the responsibility of the tutor is limited to reviewing learner performance at the 
end of the activity because the correct answers to questions, and the feedback in term of points and scores are already encoded in the software.

Using VPs individually has shown a positive impact on students' knowledge retention when compared with didactic lectures (Botezatu, Hult, Tessma, \& Fors, 2010), but working with VPs in a group might have more advantages because learners share their perspectives, observations, and previous experiences, which would allow knowledge to be analyzed, shaped and constructed into new structure.

Multiple studies have confirmed that knowledge acquisition and retention are facilitated by linking new knowledge to prior knowledge to construct meaningful knowledge in a process of elaboration (Dror, Schmidt, \& O'Connor, 2011; Schmidt, Rotgans, \& Yew, 2011), and it is well-known that the level of retention of meaningful knowledge is higher than that of meaningless knowledge (Schmidt \& Rikers, 2007; Schmidt et al., 2011). Moreover, presenting materials in the right context, and even better, in different contexts can lead to improved retention (Custers, 2010; Schmidt et al., 2011).

Linking new knowledge to prior knowledge is explained in the theoretical framework of constructivism, which attributes learning to the interaction between new knowledge and already existing schemas in long-term memory for the construction of new schemas in a process known as elaboration (Lau, 2014; Lunenberg, 1998; Tynjala, 1999). Social constructivism adds the dimension of students' collaboration with each other, and interaction with their tutors as important factors for promoting elaboration (Philpott \& Batty, 2009). Interacting with others helps to activate students' already existing knowledge and makes it available in short-term memory in order to connect new information from long-term memory to it (Kalyuga, 2009).

When students collaborate to apply their knowledge on patient problems, there will be a clustering of knowledge elements that often occur together such as specific history, signs and symptoms of a disease into cognitive schemas in a process of knowledge encapsulation, and involvement of other elements of knowledge such as treatment planning and its outcome will lead to the construction of a new knowledge structure that is known as an 'illness script'. Therefore, the growth of expertise would depend on the number and varieties of patients' problems or in another sense the number and varieties of constructed illness scripts (Schmidt \& Rikers, 2007). 
Based on this theoretical background, VPs could be seen as an educational tool that can facilitate schema construction, because it provides an authentic context for knowledge application that would allow for elaboration and re-clustering of knowledge relevant to diagnosis, treatment planning, and its outcome into an illness script. Moreover, VPs, especially in collaborative activities would also offer an opportunity for students to work, learn, and discuss dilemmas in groups toward a common goal, for instance, completing the VPs correctly.

Although constructing meaningful forms of knowledge can enhance knowledge retention, still the ultimate goal is enabling learners to transfer such knowledge to new situations, and to apply it on problems in the clinical setting. Knowledge transfer involves near transfer in which knowledge transfer occurs between different problems in the same context or two closely related contexts, and far transfer, that refers to the ability to solve new problems in unfamiliar contexts (Perkins \& Salomon, 1992; Van Merrienboer, 2013).

Research on knowledge transfer advocated that teaching for transfer requires curricula that are rich in authentic activities and full of a variety of problems (Gentile, 2000), which is an opportunity that can be offered by VPs (Ellaway et al., 2008). In a study by Botezatu, Hult, and Fors (2010), undergraduate medical students perceived VPs as an effective tool for both near transfer to other types of exams and far transfer to real patient settings.

Such prospect that can be obtainable by VPs for knowledge transfer and the current move from using VPs as an isolated e-learning artifact to a more holistic approach that focuses on the pedagogical aspects of VPs as a part of a whole activity triggered us to investigate the effectiveness of using virtual patients in a collaborative learning activity, when compared with their use as independent learning activity, with respect to students' knowledge acquisition, retention, and transfer.

\section{Method}

Participants

The study was conducted at a dental school that involves two separate campuses for male students and female students. All students who were registered for the first time in the oral and maxillofacial surgery course for the academic year 
$2015 / 2016$ ( $1^{\text {st }}$ semester $)$ were invited to participate voluntary in the study $(N=96)$. The study involved the use of eight VPs for teaching, learning and assessment purposes. It targeted two topics, which are impacted wisdom teeth (Topic 1) and maxillofacial trauma (Topic 2) within the same course.

All the dental students were at their $4^{\text {th }}$ academic year of a 6 -year disciplinebased dental program. Using a stratified random sampling method, male students were randomly distributed using their scores in the previous year as strata to have two comparable groups: male/collaborative group $(n=23)$ and male/independent group ( $n$ $=22$ ); female students were also distributed randomly exactly in the same way as male students over two comparable groups: female/collaborative group $(n=26)$, and female/independent group $(n=25)$. Up on implementation of the study, 14 students have not attended one or more sessions of Topic 1. Therefore, 82 out of 96 students have participated in Topic 1 as follows: male/collaborative group $(n=18)$, male/independent group $(n=17)$, female/collaborative group $(n=25)$, and female/independent group $(n=22)$.

For Topic 2, 20 students have not attended one or more sessions. Therefore, the total numbers of students were 76 out of 96 as follow: male/collaborative group ( $n$ $=20)$, male/independent group $(n=15)$, female/collaborative group $(n=21)$, and female/independent group $(n=20)$.

\section{Procedure}

The interventions consisted of two parts: lecture sessions, which were the same for all four experimental groups, and VP activities, which followed the lecture sessions and were different for the collaborative and independent groups. There were group activities for the male/collaborative and female/collaborative groups, and individual activities for the male/independent and female/independent groups (Figure $1)$.

Lecture session: All students received the same lecture that involved a PowerPoint presentation for 90 minutes that was interrupted by a 10-minutes break. The lecture followed a teacher-centered approach, and targeted the learning objectives of both topics. They were mainly related to diagnosis of specific conditions through identifying the relevant history, signs and symptoms, required investigations. The lecture also covered formulation of treatment plans through making the students 
aware of the indications and contra-indications of every treatment option, and factors that would affect the outcome of specific surgical procedures. Two subject-matter experts revised the lecture content and structure, and the lecture was delivered by a faculty member (first author) who has been delivering this lecture for the last 3 years to students similar to the participants in this study. After the lecture, the students had another 10-minute break, and then commenced the VP session based on their allocation to the experimental groups.

Collaborative VP learning activity session: The students were asked to work in groups of five students to reach consensus on what their collaborative decision should be for every question posed by the VPs, which were projected on the classroom screen using a data show projector. The role of the tutor (first author) was to facilitate the session by asking why specific decisions were taken, what the consequence would be of choosing other options, providing feedback, and finally operating the VP based on the decisions taken. The VP session lasted for one hour.

Independent VP learning activity session: The same VPs were used as in the collaborative session, but now as an independent learning activity. Each student accessed his/her own computer and worked individually on the VPs from the beginning till the end of the session, which lasted for one hour. The role of the tutor was limited to monitoring the students during their interaction with the VPs.

Since the lecture session for Topic 1 is identical in both interventions, all male students (independent and collaborative groups) have received the lecture in one lecture room at the same time, given by the same faculty member (first author), and then they practiced VPs in two classrooms based on the group they were assigned to, then they gathered again in the same lecture room for the immediate tests. The same procedure has been applied to female students, with the same faculty member (first author).

One month later, Topic 2 was presented in the same manner like the first topic. Student groups who have been involved in VPs collaborative activity session were asked to practice VPs independently and vice versa. 

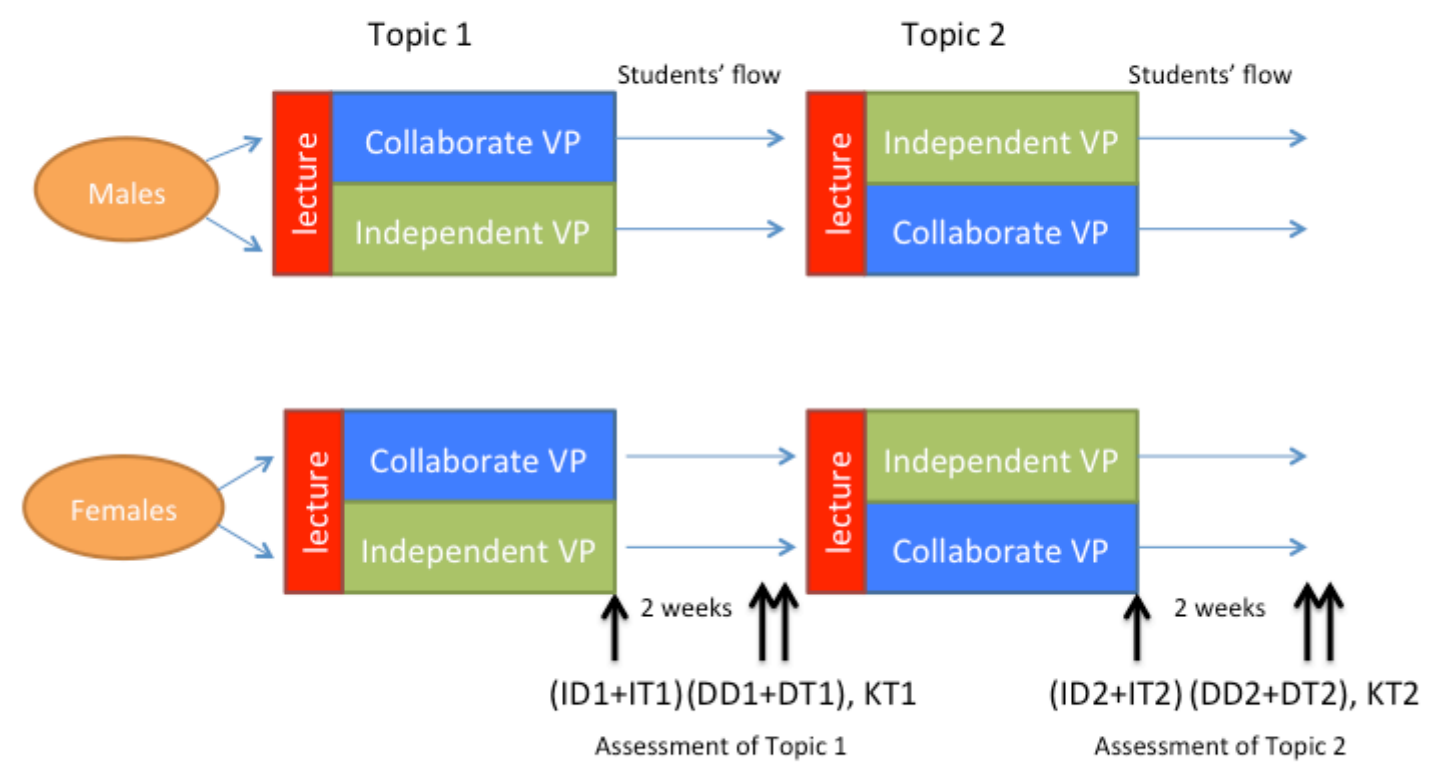

Figure 1: Flowchart showing the sequence of different interventions. ID1: immediate diagnosis 1, IT1: immediate treatment 1, DD1: delayed diagnosis 1, DT1: delayed treatment 1, KT1: knowledge transfer 1, ID2: immediate diagnosis 2, IT2: immediate treatment 2, DD2: delayed diagnosis 2, DT2: delayed treatment 2, KT2: knowledge transfer 2 .

Materials

\section{Virtual Patients}

For the teaching and learning sessions, four VPs (two VPs per topic) were used. They had a branched-tree dynamic design, and were based on real patient scenarios. Real patient radiographs, lab results, intra-oral photos, and records for other special investigations were used at different stages of VPs path, while twodimensional graphics were used to represent different clinical settings, and different characters within the VPs (Figure 2).

During practice, each VP branched based on student's choices on crucial decisions such as definitive diagnosis, selecting a specific surgical procedure, or admitting the 'patient' to a hospital. The students selected each decision from a shortlist of options. If correct, the student stayed in the main VP path, while if wrong, the student followed the consequences of the decision taken till the next node, where 
he/she was directed back to the main stream. Other than decision-making in crucial steps, the VP provided immediate feedback to the students on knowledge questions as either correct or incorrect, and briefly explained why an answer was incorrect, while the overall score, which was calculated based on the total number of correct answers, was displayed after the VP had been completed by students.

All VPs are designed, developed and validated, as a part of a research project on the application of VPs in dental education, by a team that involved subject matter experts, instructional designer, photographer, programmer, and animator. VPs development was a collaborative work between faculty members of the dental school and a private e-learning vendor, while partially funded by the Deanship of Scientific Research within our university.
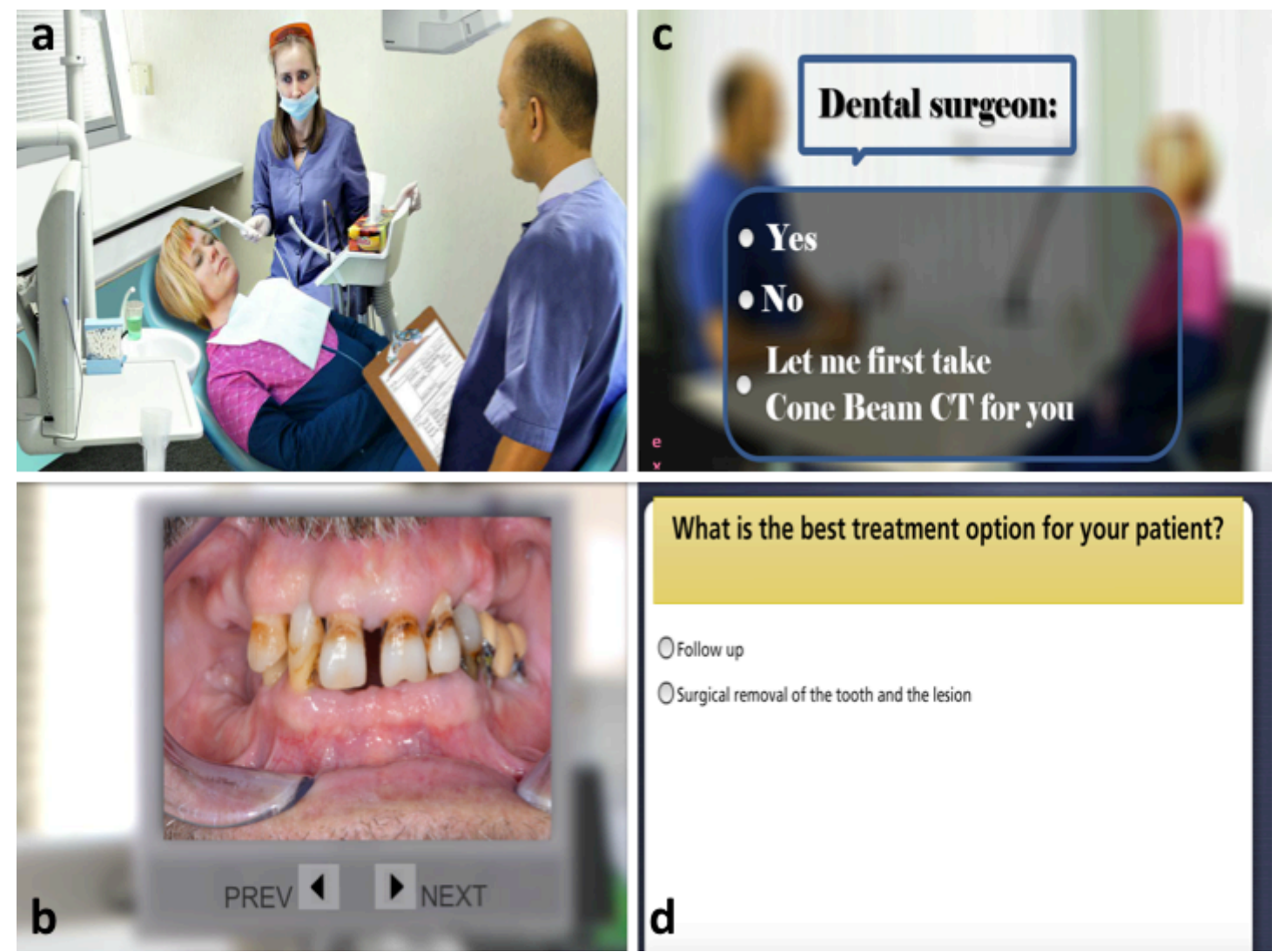

Figure 2: Screen shots a, b, c, d from different VPs. a: virtual characters (dentist, patient and dental assistant) in a dental office during history taking, b: the learner should navigate through the intra-oral photos of the VP, c: the learner should take a decision in response to an inquiry from the VP during diagnosis, $\mathrm{d}$ : the learner should take a decision in regard to the treatment plan. 


\section{Measurement instruments}

Five tests were constructed for each topic: an immediate diagnosis test (ID), an immediate treatment test (IT), a delayed diagnosis test (DD), a delayed treatment test (DT), and a knowledge transfer test (KT). All tests were paper-based except for the knowledge transfer tests, which were computer-based tests that involved the use of four new VPs (2 VPs for each topic).

The paper-based tests ID and DD are equivalent in format, difficulty and final scores, and the same is true for IT and DT. The immediate tests for Topic 1 (ID1 and IT1) are presented together in one sheet and delivered immediately after the teaching and learning session of Topic 1. They involved 18 Multiple Choice Questions (MCQs), in which each question involves 4 options. The same was true for the immediate tests ID2 and IT2 (18 MCQs), which were delivered immediately after the teaching and learning session for Topic 2. The unannounced delayed tests (DD1, DT1) and (DD2 and DT2) were delivered two weeks after the immediate tests of Topic 1 and 2 respectively. They involved the same number and type of items.

All questions were retrieved from the department item bank that contains questions that have been used before and showed a difficulty index of 0.2 to 0.8 and a discrimination index larger than 0.1. Two subject matter experts established the content validity of test items through test blueprint, and test revision. They also developed and agreed on the scoring key for all questions. The tests were scored electronically. All paper-based tests were constructed to measure factual knowledge (e.g., the complication associated with specific procedure, the risk of damage to certain vital structure, specific terms that describe certain phenomena, the signs and symptoms of specific conditions), conceptual knowledge (e.g., classify an impacted tooth or a specific fracture, estimate the degree of difficulty of specific surgical procedure based on the presented vignette), and strategic knowledge (e.g., request a specific investigation, reach a diagnosis, choose a specific treatment option, prescribe a specific medication based on the patients' condition in the presented vignette).

A factor analysis was performed on the combined paper-based tests to confirm relevant subscales. Two subscales were recognized and included in the analysis: "diagnosis" and "treatment". After deletion of bad items (those with low item-test correlation), the diagnosis scale for Topic 1 consisted of 5 items (Cronbach's alpha $=$ $0.64) ; 3$ were included in the immediate test (ID1) and 2 were included in the delayed 
test (DD1), while the diagnosis scale for Topic 2 consisted of 14 items (Cronbach's alpha $=0.66$ ); 7 were included in the immediate test (ID2) and 7 were included in the delayed test (DD2).

For the treatment scale, deletion of bad items resulted in 11 items for Topic 1 (Cronbach's alpha $=0.70) ; 6$ items were included in the immediate test (IT1) and 5 items were included in the delayed test (DT1), while the treatment scale for Topic 2 consisted of 10 items (Cronbach's alpha $=0.70) ; 6$ items were included in the immediate test (IT2) and 4 items were included in the delayed test (DT2).

The computer-based transfer tests KT1 and KT2 were delivered unannounced immediately after the delayed tests. Each test involved two new VPs. The tests targeted mainly strategic knowledge of the relevant topics. The student had to request the appropriate radiograph, interpret the relevant lab test, choose the correct diagnosis, admit the virtual patient to the hospital, select a specific surgical procedure, consent the patient before surgery, and finally recommend a management for a specific complication. The VPs' design was similar to the VPs that were used in the teaching and learning sessions but they provide only a summary report that shows the final score, which is the percentage of correct items to the total number of items in the test. All students worked individually in the transfer tests.

Data collection and analysis

Data were collected by the college's statistical unit then coded and analyzed using SPSS Software (SPSS 22.0, SPSS Inc., Chicago, IL, USA). For both Topic 1 and Topic 2, 2x2 ANOVAs with the factors campus (male, female) and condition (collaborative, independent) were applied to test for main effects and interactions on immediate diagnosis, delayed diagnosis, immediate treatment, delayed treatment, and transfer scores. A $p$-value less than 0.05 is considered significant.

Ethical approval

The study was reviewed and approved by the University Ethical Committee. IRB number: IRB-2015-02-099

\section{Results}

Eighty-two (47 females and 35 males) out of 96 students have participated in all the teaching, learning, and assessment sessions of Topic 1 while 76 students (41 
females and 35 males) have participated in Topic 2 sessions.

Table 1 provides the means and standard deviations for all scores, split out for condition (collaborative, independent) and campus (male, female). For the immediate and delayed diagnosis scores of Topic 1 and Topic 2, there were no significant effects of campus, condition, or their interaction. 
Table 1: Means and standard deviations for all scores in percentages, split out by condition and campus.

\begin{tabular}{|c|c|c|c|c|c|c|c|c|}
\hline & \multicolumn{8}{|c|}{ Topic 1} \\
\hline & \multicolumn{4}{|c|}{ Female Campus } & \multicolumn{4}{|c|}{ Male Campus } \\
\hline & \multicolumn{2}{|c|}{$\begin{array}{c}\text { Collaborative } \\
\qquad(n=25)\end{array}$} & \multicolumn{2}{|c|}{$\begin{array}{l}\text { Independent } \\
\qquad(n=22)\end{array}$} & \multicolumn{2}{|c|}{$\begin{array}{l}\text { Collaborative } \\
\qquad(n=18)\end{array}$} & \multicolumn{2}{|c|}{$\begin{array}{l}\text { Independent } \\
\quad(n=17)\end{array}$} \\
\hline & $M$ & $S D$ & $M$ & $S D$ & $M$ & $S D$ & $M$ & $S D$ \\
\hline $\begin{array}{l}\text { Immediate } \\
\text { diagnosis }\end{array}$ & 58.6 & 37.6 & 62.1 & 44.0 & 51.8 & 43.1 & 47.0 & 45.7 \\
\hline $\begin{array}{l}\text { Delayed } \\
\text { diagnosis }\end{array}$ & 58.0 & 49.3 & 63.6 & 46.7 & 47.2 & 43.6 & 52.9 & 44.9 \\
\hline $\begin{array}{l}\text { Immediate } \\
\text { treatment }\end{array}$ & 74.0 & 27.2 & 55.3 & 28.8 & 53.7 & 39.8 & 65.6 & 34.5 \\
\hline $\begin{array}{l}\text { Delayed } \\
\text { treatment }\end{array}$ & 72.8 & 22.2 & 54.5 & 32.7 & 58.8 & 30.2 & 54.1 & 28.9 \\
\hline \multirow[t]{4}{*}{ Transfer 1} & 74.5 & 8.09 & 76.7 & 8.5 & 67.3 & 11.7 & 69.8 & 8.4 \\
\hline & \multicolumn{8}{|c|}{ Topic 2} \\
\hline & \multicolumn{4}{|c|}{ Female Campus } & \multicolumn{4}{|c|}{ Male Campus } \\
\hline & \multicolumn{2}{|c|}{$\begin{array}{c}\text { Collaborative } \\
(n=21)\end{array}$} & \multicolumn{2}{|c|}{$\begin{array}{c}\text { Independent } \\
(n=20)\end{array}$} & \multicolumn{2}{|c|}{$\begin{array}{l}\text { Collaborative } \\
\qquad(n=20)\end{array}$} & \multicolumn{2}{|c|}{$\begin{array}{c}\text { Independent } \\
\quad(n=15)\end{array}$} \\
\hline $\begin{array}{l}\text { Immediate } \\
\text { diagnosis }\end{array}$ & 57.8 & 20.9 & 61.4 & 15.4 & 57.8 & 27.9 & 62.8 & 11.8 \\
\hline $\begin{array}{l}\text { Delayed } \\
\text { diagnosis }\end{array}$ & 50.3 & 21.4 & 39.2 & 24.0 & 40.7 & 31.5 & 52.3 & 24.5 \\
\hline $\begin{array}{l}\text { Immediate } \\
\text { treatment }\end{array}$ & 82.5 & 17.8 & 57.5 & 27.8 & 65.8 & 19.0 & 61.1 & 14.9 \\
\hline $\begin{array}{l}\text { Delayed } \\
\text { treatment }\end{array}$ & 83.3 & 29.9 & 36.2 & 30.8 & 48.7 & 23.6 & 55.0 & 16.9 \\
\hline Transfer 2 & 55.3 & 11.2 & 59.7 & 12.4 & 62.8 & 14.6 & 62.4 & 11.5 \\
\hline
\end{tabular}

For the immediate treatment score for Topic 1, a significant interaction between condition and campus was found, $F(1,78)=4.51, p<.05$. As shown in the 
left upper graph of Figure 3a, females $(M=74.0, S D=27.2)$ do better than males $(M$ $=53.7, S D=39.8)$ in the collaborative condition, but females $(M=55.3, S D=28.2)$ are not superior to males $(M=65.6, S D=34.5)$ in the independent condition. Thus, females are superior to males only in the collaborative condition. The main effect of campus is not significant, $F(1,78)=0.47, p=0.49$, and the main effect of the condition is also not significant $F(1,78)=0.21, p=0.64$.

A similar pattern was found for the immediate treatment score for Topic 2; again, a significant interaction between condition and campus was found. As shown in the right upper graph of Figure 3c, females $(M=82.5, S D=17.8)$ do better than males $(M=65.8, S D=19.0)$ in the collaborative condition, but females $(M=57.5, S D$ $=27.8)$ are not superior to males $(M=61.1, S D=14.9)$ in the independent condition. This interaction effect is significant, $F(1,72)=4.45, p<.05$. The main effect of campus is not significant, $F(1,72)=1.84, p=0.17$, while the main effect of condition is significant, $F(1,72)=9.55, p<.05$. However, as can be seen in the right upper graph of Figure 3, this main effect of condition cannot be interpreted due to the disordinal interaction.

For the delayed treatment score of Topic 1, there was a similar trend of results. As shown in the left lower graph of Figure $3 \mathrm{~b}$, females $(M=72.8, S D=22.2)$ seemed to score somewhat higher than males $(M=58.8, S D=30.2)$ in the collaborative condition but not in the independent condition, but this interaction was not statistically significant, $F(1,78)=1.11, p=.293$. The main effects of campus ( $p=$ $0.26)$ and condition $(p=0.07)$ are also not significant.

For the delayed treatment score of Topic 2, again a significant interaction between campus and condition was found. As shown in the right lower graph of Figure $3 \mathrm{~d}$, females $(M=83.3, S D=29.9)$ do better than males $(M=48.7, S D=23.6)$ in the collaborative condition, but they $(M=36.2, S D=30.8)$ are not superior to males $(M=55.0, S D=16.9)$ in the independent condition. This interaction effect is significant, $F(1,72)=18.8, p<.001$. The main effect of campus is not significant, $F$ $(1,72)=1.6, p=0.2$, while the main effect of condition is significant, $\mathrm{F}(1,72)=11.0$, $p<.05$. But as for the immediate treatment score of Topic 2 , the main effect of condition cannot sensibly be interpreted because there is a disordinal interaction.

For knowledge transfer, a significant main effect was found for campus on 
students' scores in Topic 1. Females $(M=75.5, S D=8.31)$ do better than males $(M=$ $68.5, S D=10.1), F(1,78)=11.5, p<.05$. There were no significant effects for condition $(p=0.25)$ or the interaction between campus and condition on student scores. The same is true for Topic 2 as there were no significant effects of campus, condition, or their interaction.
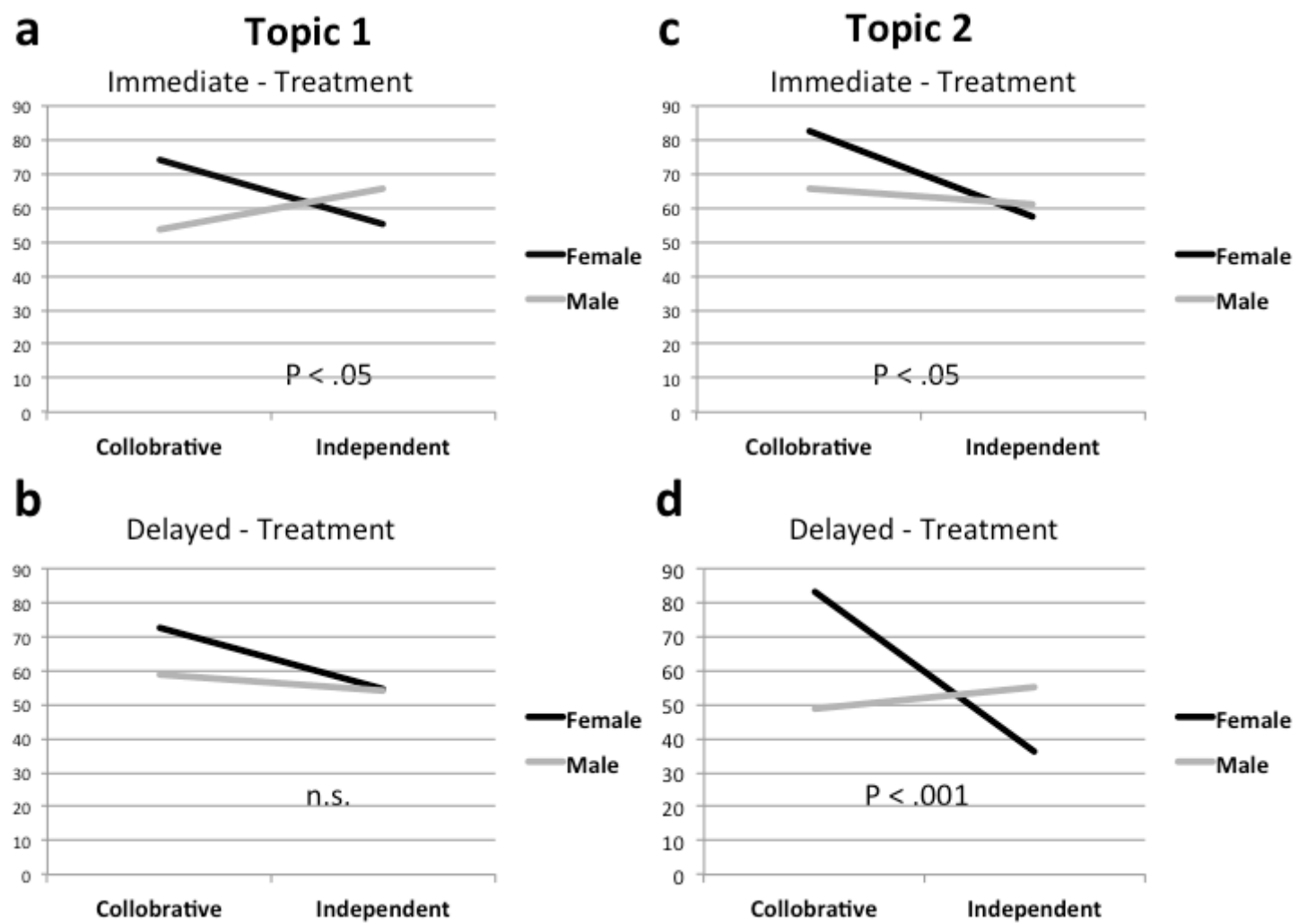

Figure 3: Students' scores in the treatment tests of topic 1 and 2 per condition and campus.

\section{Discussion}

This study compared the effect of collaborative and independent use of VPs on students' knowledge acquisition, retention and transfer across two campuses, namely, a male and female campus. Our hypothesis was partially supported, as the impact of collaborative use of VPs was clear in the female campus only and mainly along knowledge acquisition and retention of treatment items.

As shown in Figure 3, females who worked collaboratively with the VPs were better on the treatment tests than females who worked independently, but these results were not attained on the male campus. This finding could possibly be attributed to a higher amount of discussion and interaction occurring between females. It was shown 
by Adrianson (2001) that females have a tendency to produce more messages in faceto-face communication, and there were also more opinion changes from females than from males in collaborative learning. The same conclusion was drawn in asynchronized online communication by Savicki, Kelley, and Lingenfelter (1996), as the authors found that female groups were the most satisfied by the group process and changed their opinions most as a result of group activity. Moreover, it was shown that gender grouping mainly influences students' attitudes toward collaborative learning as female students perform better in single gender grouping, while males perform better in mixed gender grouping (Zhan, Fong, Mei, \& Liang, 2015).

Moreover, the division of students in male and female campuses could have created conditions in the female campus that are more conductive to collaboration and peer interaction. As groups' creation for the collaborative activities was constructed randomly by the students themselves by forming smaller groups of 5 students each. Therefore, we suspect that the construction of these small groups has created a more favorable mixture in the female campus than in the male campus. In other words, female collaborative small groups might have involved a mixture of high aptitude students with one or more low aptitude students. Such mixture allowed high aptitude students to provide scaffolding to lower aptitude students. It has been documented that low aptitude students can cross the zone of proximal development (ZPD) when help and scaffolding are provided in the appropriate time. ZPD is the difference between what a learner can do without help and what he or she can do with help (Vygotsky, 1980). Dde Leng, Muijtjens, and van der Vleuten (2009) showed that for achieving effective use of computer-based simulated cases, it is important to introduce scaffolding strategies such as guided peer interaction.

The question that requires an answer now is why the superiority of collaborative performance was evident only in treatment scores and such effect was absent in diagnosis and transfer scores. This could be explained based on the nature of the content that was provided to the students. In Topics 1 and 2, each topic presented one main dental problem that involved different treatment options, and surgical approaches based on different inputs such as the age of the patients and their underlying medical history. That is to say, it was easy for the students to construct their own diagnosis knowledge structure independently as it was only one problem per topic. But in knowledge that is relevant to treatment, where there were high 
amounts of interrelating elements, the interaction between students facilitated the elaboration, therefore, the collaborative performance showed its impact.

This study has provided a preliminary conclusion about the effectiveness of collaborative use of VPs on knowledge acquisition and retention. Future studies could investigate the effect of multiple and longer exposure to collaborative VPs activities, for instance at the end of a whole semester. Such context might allow defining and assessing specific metrics of student performance, which could clarify when and how the learner moves from novice to expert.

The study had limitations in terms of the amount of exposure of our students to learning using VPs, as it was only one session for one hour, but it was necessary to standardize the time of exposure across different groups and eliminate any bias that might occur as a result of studying at home especially before the immediate test. Another important limitation is that the results provide little input to universities with gender mixed groups of students but we suspect that our results might be generalized to educational situations, where there are gender-separated groups of students.

\section{Conclusion}

On the female campus, the use of VPs in a collaborative learning activity is more effective than its use in an independent learning activity in enhancing students' knowledge acquisition and retention related to treatment decisions. However, the collaborative use of VPs by itself is not enough to produce consistent results across different groups of students and attention should be given to all the factors that would affect students' interaction.

\section{Practice Points}

1. On a female campus, the use of VPs in a collaborative learning activity could enhance students' knowledge acquisition and retention.

2. Collaborative learning activities might require a customized VP design that enhances students' interaction.

3. The effect of collaborative use of VPs would be more obvious in difficult topics that involve interaction between multiple elements. 


\section{References}

Adrianson, L. (2001). Gender and computer-mediated communication: Group processes in problem solving. Computers in Human Behavior, 17(1), 71-94.

Botezatu, M., Hult, H., \& Fors, U. G. (2010). Virtual patient simulation: what do students make of it? A focus group study. BMC Med Educ, 10, 91.

Botezatu, M., Hult, H., Tessma, M. K., \& Fors, U. (2010). Virtual patient simulation: knowledge gain or knowledge loss? Med Teach, 32(7), 562-568.

Cook, D. A., Hamstra, S. J., Brydges, R., Zendejas, B., Szostek, J. H., Wang, A. T., . . . Hatala, R. (2013). Comparative effectiveness of instructional design features in simulation-based education: systematic review and meta-analysis. Med Teach, 35(1), e867-898.

Cook, D. A., \& Triola, M. M. (2009). Virtual patients: a critical literature review and proposed next steps. Med Educ., 43(4), 303-311.

Custers, E. J. (2010). Long-term retention of basic science knowledge: a review study. Adv Health Sci Educ Theory Pract, 15(1), 109-128.

de Leng, B. A., Muijtjens, A. M., \& van der Vleuten, C. P. (2009). The effect of faceto-face collaborative learning on the elaboration of computer-based simulated cases. Simulation in Healthcare, 4(4), 217-222.

Dror, I., Schmidt, P., \& O'Connor, L. (2011). A cognitive perspective on technology enhanced learning in medical training: great opportunities, pitfalls and challenges. Med Teach, 33(4), 291-296.

Ellaway, R., Candler, C., Greene, P., \& Smothers, V. (2006). An architectural model for MedBiquitous virtual patients. Baltimore, MD: MedBiquitous.

Ellaway, R., \& Davies, D. (2011). Design for learning: deconstructing virtual patient activities. Med Teach, 33(4), 303-310.

Ellaway, R., Poulton, T., Fors, U., McGee, J. B., \& Albright, S. (2008). Building a virtual patient commons. Med Teach, 30(2), 170-174.

Ellaway, R., Topps, D., Lee, S., \& Armson, H. (2015). Virtual patient activity patterns for clinical learning. Clinical Teacher, 12(4), 267-271.

Gentile, J. R. (2000). Learning, transfer of. In A. E. Kazdin \& A. E. Kazdin (Eds.), Encyclopedia of psychology, Vol. 5. (pp. 13-16). Washington, DC, US; New York, NY, US: American Psychological Association, Oxford University Press. 
Huwendiek, S., Duncker, C., Reichert, F., de Leng, B. A., Dolmans, D., van der Vleuten, C. P., . . Tonshoff, B. (2013). Learner preferences regarding integrating, sequencing and aligning virtual patients with other activities in the undergraduate medical curriculum: A focus group study. Med Teach, 35(11), 920-929.

Kalyuga, S. (2009). Knowledge elaboration: A cognitive load perspective. Learning and Instruction, 19(5), 402-410.

Lau, K. H. (2014). Computer-based teaching module design: principles derived from learning theories. Med Educ, 48(3), 247-254.

Lunenberg, F. C. (1998). Constructivism and technology: Instructional designs for successful education reform. Journal of instructional psychology, 25(2), 7582.

Motola, I., Devine, L. A., Chung, H. S., Sullivan, J. E., \& Issenberg, S. B. (2013). Simulation in healthcare education: a best evidence practical guide. AMEE Guide No. 82. Med Teach, 35(10), e1511-1530.

Perkins, D. N., \& Salomon, G. (1992). Transfer of learning. International encyclopedia of education, 2, 6452-6457.

Philpott, J., \& Batty, H. (2009). Learning best together: social constructivism and global partnerships in medical education. Med Educ, 43(9), 923-924.

Savicki, V., Kelley, M., \& Lingenfelter, D. (1996). Gender and group composition in small task groups using computer-mediated communication. Computers in Human Behavior, 12(2), 209-224.

Schmidt, H. G., \& Rikers, R. M. (2007). How expertise develops in medicine: knowledge encapsulation and illness script formation. Med Educ., 41(12), 1133-1139.

Schmidt, H. G., Rotgans, J. I., \& Yew, E. H. (2011). The process of problem-based learning: what works and why. Med Educ, 45(8), 792-806.

Tynjala, P. (1999). Towards expert knowledge? A comparison between a constructivist and a traditional learning environment in the university. International Journal of Educational Research, 31, 357-442.

Van Merrienboer, J. J. (2013). Perspectives on problem solving and instruction. Computers \& Education, 64, 153-160.

Vygotsky, L. S. (1980). Mind in society: The development of higher psychological processes: Harvard university press. 
Zhan, Z., Fong, P. S., Mei, H., \& Liang, T. (2015). Effects of gender grouping on students' group performance, individual achievements and attitudes in computer-supported collaborative learning. Computers in Human Behavior, 48, 587-596. 
Chapter 3: Sequencing virtual patients with lectures

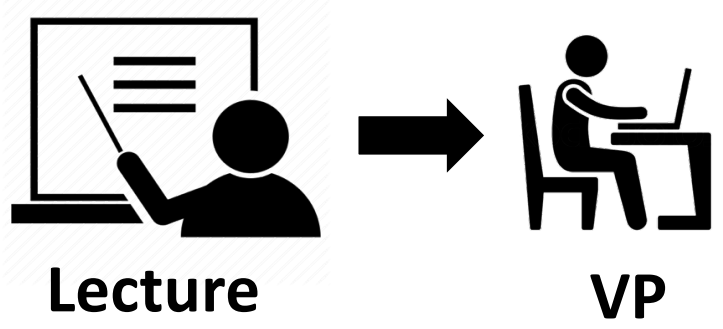

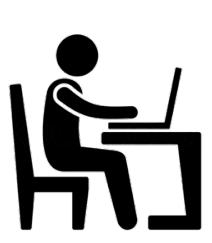

VP

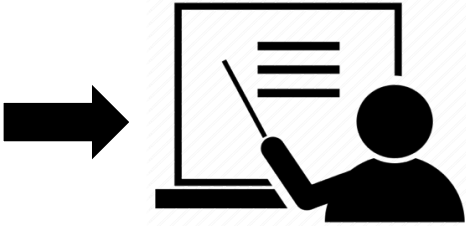

Lecture

This chapter was published as:

Marei, H.F., Donkers, H.H.L.M., Al-Eraky, M.M., Van Merrienboer, J.J.G. (2017).

The effectiveness of sequencing virtual patients with lectures in a deductive or inductive learning approach. Medical Teacher, 39(12), pp. 1268-1274. 


\begin{abstract}
Background: Virtual patients (VPs) can be sequenced with other instructional methods in different ways.

Aim: To investigate the effect of sequencing VPs with lectures in a deductive approach, in comparison with an inductive approach, on students' knowledge acquisition, retention, and transfer.

Methods: For two different topics, 84 out of 87 students have participated in the lecture and VP sessions. Students from female and male campuses have been randomly assigned to one of the two learning approaches (deductive and inductive), yielding four experimental groups. Each group received a lecture session and an independent VP learning activity, which either followed the lecture session in the deductive group or preceded it in the inductive group. Students were administrated knowledge acquisition and retention written tests as well as transfer tests using two new VPs.

Results: There was no significant effect for the learning approach on knowledge acquisition or retention, while for knowledge transfer, males have benefited from the inductive approach in Topic 1 while in the more complex Topic 2 , they have benefited from the deductive approach. On the other hand, females seem to be largely unaffected by learning approach.

Conclusion: Sequencing virtual patients in inductive and deductive learning approaches leads to no significant differences on students' performance when full guidance is offered in the inductive approach.
\end{abstract}




\section{Introduction}

Virtual Patients (VPs) are specific types of computer-programs that simulate real-life clinical scenarios; learners imitate the roles of health care providers to obtain a history, conduct a clinical examination, and make diagnostic and therapeutic decisions (Cook \& Triola, 2009).

The potentials of VPs in promoting deep learning, reducing medical errors, knowledge gain and transfer (Berman, Durning, Fischer, Huwendiek, \& Triola, 2016) have motivated educators to question how to use and sequence VPs with other instructional methods in order to have tangible effects on learning outcomes (Cook, Erwin, \& Triola, 2010; Cook \& Triola, 2009; Ellaway, Topps, Lee, \& Armson, 2015) and positive influence on students' perceptions (Huwendiek et al., 2013).

VPs can be sequenced with other instructional methods in different ways (Huwendiek et al. (2013), as they can be presented either before the lecture (inductive approach) or after the lecture (deductive approach). A deductive learning approach refers to introducing theoretical knowledge followed by its practical applications and examples (Gavriel, 2015). In such an approach, the students attend a lecture before handling an authentic problem or a task (Prince \& Felder, 2006). The instructions presented in the lecture serve as supportive information for task execution or problem solving (Vandewaetere et al., 2014).

On the other hand, the inductive approach refers to the process of moving from real practical situations towards theoretical and generalized concepts (Gavriel, 2015). In such an approach, the student is confronted by a problem followed by another form of instruction (Prince \& Felder, 2006). The problem stimulates the students to discover their knowledge gap, which first raises their situational interest and increases their desire to learn. Once students get saturated with knowledge through other forms of instruction, their desire to learn decreases (H. G. Schmidt, Rotgans, \& Yew, 2011). Situational interests are interests that are triggered temporarily by environmental factors such as task instructions or an engaging text, thus these interests are more or less under the direct control of educators (Schraw, Flowerday, \& Lehman, 2001).

A deductive learning approach is more applicable in situations that involve large group teaching, and it is the dominant instructional approach in a discipline- 
based curriculum (Harden, Sowden, \& Dunn, 1984). It might work better for learners with previous experience, as they already have knowledge structures (schema) relevant to the topic in their long-term memory. Therefore, the process of associating new knowledge elements with each other (schema construction) or with prior knowledge (schema elaboration) results in a germane cognitive load on working memory which enhances learning (Van Merrienboer \& Sweller, 2010). Although this learning approach is criticized for being more teacher-centered (Harden et al., 1984), it still can positively influence student achievement in an active-learning classroom, provided that teachers are experts, can express themselves in clear language and show their concerns for their students (Rotgans \& Schmidt, 2011).

On the other hand, the inductive approach works well in small group settings (like Problem-based learning), is more appropriate for learners with relative low expertise who are eager to learn more about the topic and, therefore, it provokes their situational interest (H. G. Schmidt et al., 2011). Although it is considered as a studentcentered learning approach, as students have to construct their own knowledge by selecting and integrating information across multiple literature resources, still the role of the tutor is crucial in such an approach. The tutor provides scaffolding to the learners by guiding them to the relevant learning resources, facilitating the discussion and creating a learning environment in the classroom that leads to exchange of ideas (H. G. Schmidt et al., 2011).

In a deductive approach, VPs can be used as an authentic context for knowledge application in an independent learning activity that follows, for instance, a lecture. In an inductive approach, VPs can be used as a trigger for students to be aware of their knowledge gap. In both approaches, presenting the students with problems through VPs gives more meaning or relevance to the acquired knowledge (Fyrenius, Bergdahl, \& Silen, 2005), and it is determined that the level of acquisition and retention of meaningful knowledge is higher than that of meaningless knowledge (Fyrenius et al., 2005; H. G. Schmidt \& Rikers, 2007). Students store their own interpretation of what is lectured rather than store information as taught. Therefore, when students apply what they learned, acquisition, retention and transfer are enhanced (Henk G Schmidt, Wagener, Smeets, Keemink, \& van der Molen, 2015). Knowledge transfer to new settings or problems, different from the original learning context, requires variability in practicing authentic problems in a real or simulated 
environment to increase the number and complexity of schemata in long-term memory (Gentile, 2000; Van Merrienboer \& Sweller, 2010).

Jones, Holland, and Oldmeadow (2008) evaluated students' perception toward both deductive and inductive learning approaches. They stated that the inductive approach is better than the deductive approach for generating students' interest, remembering facts, and comprehension, while the deductive approach enabled a greater content coverage in a given time. Others argued that solving complex problems without any prior knowledge of the topic or appropriate support or guidance by a tutor imposes high load on working memory and leads to slow and inefficient learning (Clark, Kirschner, \& Sweller, 2012; Kirschner, Sweller, \& Clark, 2006). Wijnia, Loyens, van Gog, Derous, and Schmidt (2014) found that studying integrated model answers during self-study in a PBL setting (inductive approach) is more effective than letting students construct their own answers by selecting and integrating information across multiple literature resources. Such result was accompanied by equal investment of mental effort during the study phase of both groups, which indicates that even within an inductive learning approach, still there is an effective role for direct instructions.

Although Huwendiek et al. (2013) reported a qualitative analysis of students' perceptions toward the optimal sequence of VPs with other instructional methods, still such sequence might not be the most effective one. Our study aimed to investigate the effect of sequencing virtual patients with lectures on students' knowledge acquisition, retention and transfer, leading to the research question: Is sequencing virtual patients with lectures in a deductive approach (i.e. VP after lecture) more effective than sequencing them in an inductive approach (i.e. VP before lecture), on students' knowledge acquisition, retention, and transfer?

\section{Method}

Participants

The study was conducted at a dental school that involves two separate campuses for male students and female students. For the purpose of this study, both male and female students were invited to attend the teaching, learning and assessment sessions in the same classroom but at different times for the two genders. All students who were registered for the first time in the oral and maxillofacial surgery course for 
the academic year 2016/2017 ( $1^{\text {st }}$ semester $)$ were invited to participate voluntary in the study $(N=87)$. The study involved the use of eight VPs for learning and assessment purposes. It targeted two topics, which are impacted wisdom teeth (Topic 1) and maxillofacial trauma (Topic 2) within the same course.

The male students were randomly assigned into two groups as follow: Male /inductive $(\mathrm{n}=22)$ and male/deductive $(\mathrm{n}=21)$. The same was true for the female students, who were randomly assigned into female/inductive $(\mathrm{n}=22)$ and female/deductive $(n=22)$ groups.

\section{Materials}

\section{Virtual Patients}

Eight virtual patients were used. Four of which (two VPs per topic) were used in the VP learning activity sessions, while the other four (two VPs per topic) were used for assessment purpose. They have been delivered as computer-based transfer tests two weeks after the lecture and VP learning sessions.

For the VP sessions, the VPs had a branched-tree dynamic design, and were based on real patient scenarios. Real patient radiographs, lab results, intra-oral photos, and records for other special investigations were used at different stages of VPs path, while two-dimensional graphics were used to represent different clinical settings, and different characters within the VPs.

During practice, each VP branched based on student's choices on crucial decisions such as definitive diagnosis, selecting a specific surgical procedure, or admitting the patient to a hospital. The students selected each decision from a shortlist of options. If correct, the student stayed in the main VP path, while if wrong, the student followed the consequences of the decision taken till the next node, where he/she was directed back to the main stream. The VP provided immediate feedback to the students on knowledge questions as either correct or incorrect, while the overall score, which was calculated based on the total number of correct answers, was displayed after the VP had been completed by students.

For assessment, the VPs' design was similar to the VPs that were used in the VP sessions but they provide only a summary report that shows the final score, which is the percentage of correct items to the total number of items. 


\section{Measurement instruments}

Three tests were constructed for each topic: A Knowledge acquisition test (KA), a knowledge retention test (KR), and a knowledge transfer test (KT). KA and KR were paper-based tests that are similar in format, difficulty and number of items, while KT was a computer-based test that involved the use of four VPs (2 VPs for each topic).

The KA tests for Topics 1 and 2 were delivered immediately after the lecture and VP sessions of Topic 1 and 2 respectively. Each test involved 25 Multiple Choice Questions (MCQs), in which each question involves 4 options. The KR tests were unannounced and delivered two weeks after the immediate KA tests of Topic 1 and 2 respectively.

All questions were retrieved from the department item bank that contains questions that have been used before and showed a difficulty index of 0.2 to 0.8 and a discrimination index larger than 0.1 . Two subject matter experts established the content validity of test items through test blueprint, and test revision. They also developed and agreed on the scoring key for all questions. The tests were scored electronically. All paper-based tests were constructed to measure factual knowledge (e.g., the complication associated with specific procedure, the risk of damage to certain vital structure, specific terms that describe certain phenomena, the signs and symptoms of specific conditions), conceptual knowledge (e.g., classify an impacted tooth or a specific fracture, estimate the degree of difficulty of specific surgical procedure based on the presented vignette), and strategic knowledge (e.g., request a specific investigation, reach a diagnosis, choose a specific treatment option, prescribe a specific medication based on the patients' condition in the presented vignette). For the KA and KR tests, we used the same blueprint and difficulty selection. The reliability (Cronbach's alpha) of items of Topic 1 and 2 was 0.73 and 0.72 respectively.

The computer-based transfer tests (KT) for Topic 1 and 2 were delivered unannounced immediately after the retention tests. Each test involved two new VPs. Two independent subject matter experts have validated the new VPs to ensure that they present new situations that are relevant to the VPs used in the learning sessions. The students took the transfer test independently by logging in to their account on the 
university learning management system. The VP software did all scoring automatically. The final score equals the percentage of correct answers. The results of the tests were displayed on the final screen of the VP and were collected by the tutor. A copy of students' scores was recorded on the university learning management system for future feedback. The tests targeted mainly strategic knowledge of the relevant topics. The student had to request the appropriate radiograph, interpret the relevant lab test, choose the correct diagnosis, admit the virtual patient to the hospital, select a specific surgical procedure, consent the patient before surgery, and finally recommend the clinical management for a specific complication.

Procedure

The interventions consisted of two parts: a lecture session, which was the same per topic for all experimental groups, and an independent VP learning activity, which either followed the lecture session in the deductive group or preceded it in the inductive group (Figure 1).

Lecture session: All students received the same lecture that involved a PowerPoint presentation for 90 minutes with a 10-minutes break halfway. The lecture was designed and presented to target predefined learning objectives of both topics. The objectives were mainly related to diagnosis of specific conditions through identifying the relevant history, signs and symptoms, required investigations. The lecture also covered formulation of treatment plans through making the students aware of the indications and contra-indications of every treatment option, and factors that would affect the outcome of specific surgical procedures. Two subject-matter experts revised the lecture content and structure, and the same faculty member delivered the lecture to both the male and female groups.

VP session: Each student accessed a computer in the computer Lab and worked individually on two different VPs from the beginning till the end of the session, which lasted for one hour. The role of the tutor was limited to helping the students with any technical problems during their interaction with the VPs.

One month later, Topic 2 was presented in the same manner as the first topic. Student groups who have practiced the VPs after the lecture session (deductive) in Topic 1 were now asked to practice the VPs before the lecture session (inductive) in Topic 2 and vice versa. 

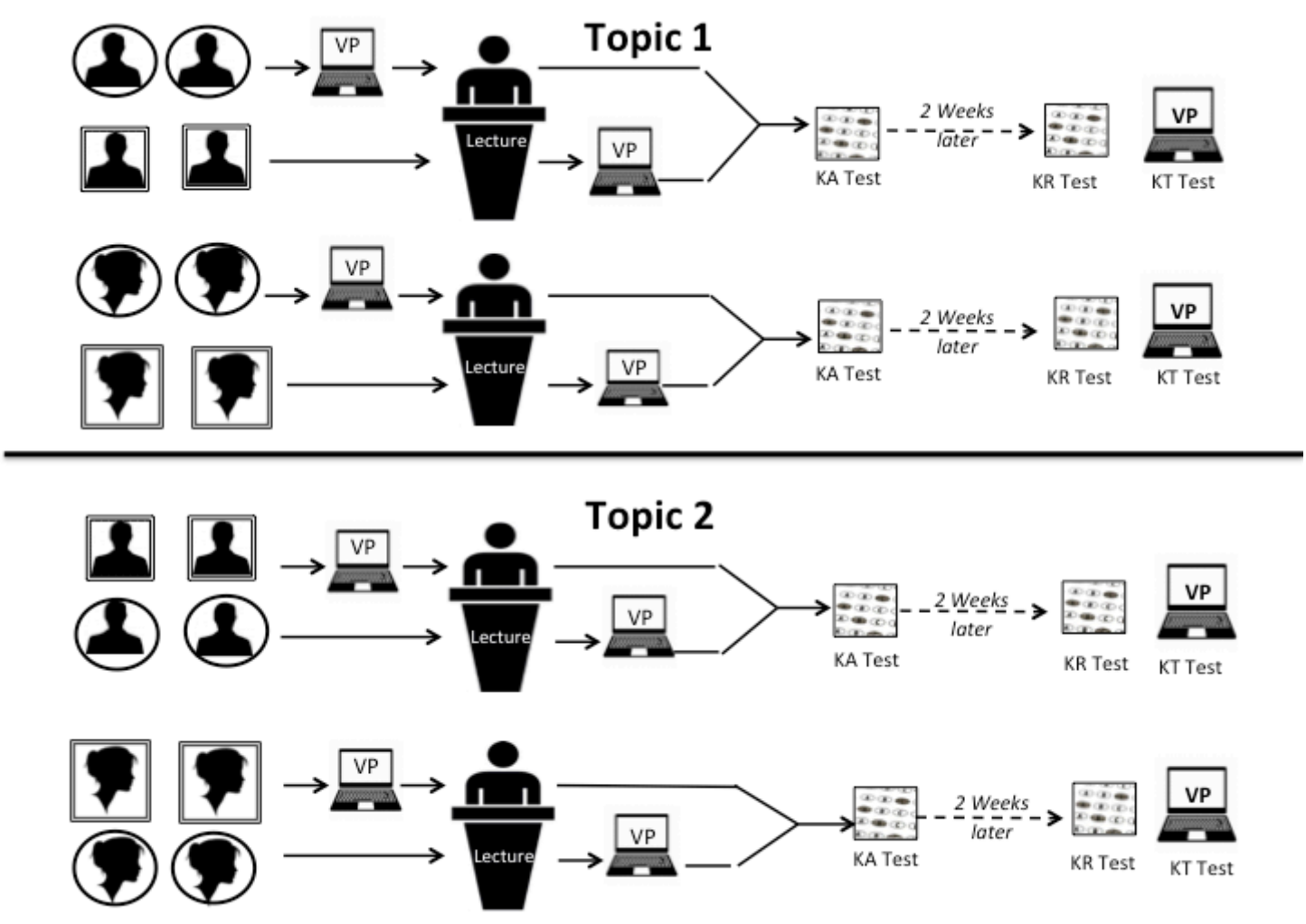

Figure 1. The process of using VPs in both inductive and deductive approaches followed by three tests for: knowledge acquisition (KA), knowledge retention (KR) and knowledge transfer (KT). One month later, student groups who have been involved in VPs after the lecture in topic 1 were asked to practice VPs before the lecture in topic 2 and vice versa.

Data collection and analysis

Data were collected by the college's statistical unit then coded and analyzed using SPSS Software (SPSS 22.0, SPSS Inc., Chicago, IL, USA). For both Topic 1 and Topic 2, two-way ANOVA was used to measure the influence of the learning approach (deductive/inductive) and gender (male/female) on the scores for KA, KR, and KT (dependent variables). A $p$-value less than 0.05 is considered significant.

Ethical approval

The study was reviewed and approved by the University Ethical Committee. IRB number: IRB-2015-02-099

\section{Results}

Eighty-four out of 87 students have participated in the lecture and VP sessions of Topic 1 (43 females and 41 males) and Topic 2 (44 females and 40 males). 
Table 1 provides the means, standard deviations for all scores of Topics 1 and 2 per learning approach (deductive, inductive) and gender (males, females). KA1 is the knowledge acquisition test, KR1 is the knowledge retention test, and KT1 is the knowledge transfer test in Topic 1. KA2, KR2, and KT2 are the same tests for Topic 2. 
Table 1: Means and standard deviations for all scores of Topics 1 and 2 per learning approach (deductive, inductive) and gender (males \& females)

\begin{tabular}{|c|c|c|c|c|c|c|c|c|c|}
\hline & \multicolumn{9}{|c|}{ Topic 1} \\
\hline & \multicolumn{4}{|c|}{ Males } & \multicolumn{4}{|c|}{ Females } & \\
\hline & \multicolumn{2}{|c|}{$\begin{array}{l}\text { Inductive } \\
(n=20)\end{array}$} & \multicolumn{2}{|c|}{$\begin{array}{l}\text { Deductive } \\
(n=21)\end{array}$} & \multicolumn{2}{|c|}{$\begin{array}{l}\text { Inductive } \\
(n=22)\end{array}$} & \multicolumn{2}{|c|}{$\begin{array}{c}\text { Deductive } \\
(n=21)\end{array}$} & \multirow[t]{2}{*}{$\begin{array}{c}p- \\
\text { value }\end{array}$} \\
\hline & $M$ & $S D$ & $M$ & $S D$ & $M$ & $S D$ & $M$ & $S D$ & \\
\hline KA1 & 78.2 & 9.4 & 75.8 & 9.2 & 87.8 & 9.1 & 87.4 & 10.0 & $>.05$ \\
\hline KR1 & 59.6 & 16.0 & 55.2 & 10.7 & 68.9 & 11.9 & 63.6 & 12.5 & $>.05$ \\
\hline \multirow[t]{4}{*}{ KT1 } & 72.8 & 10.7 & 66.4 & 8.0 & 73.5 & 10.8 & 77.6 & 10.5 & $<.05^{*}$ \\
\hline & \multicolumn{9}{|c|}{ Topic 2} \\
\hline & \multicolumn{4}{|c|}{ Males } & \multicolumn{4}{|c|}{ Females } & \\
\hline & \multicolumn{2}{|c|}{$\begin{array}{l}\text { Inductive } \\
(n=20)\end{array}$} & \multicolumn{2}{|c|}{$\begin{array}{l}\text { Deductive } \\
(n=20)\end{array}$} & \multicolumn{2}{|c|}{$\begin{array}{l}\text { Inductive } \\
(n=22)\end{array}$} & \multicolumn{2}{|c|}{$\begin{array}{c}\text { Deductive } \\
(n=22)\end{array}$} & $\begin{array}{c}p- \\
\text { value }\end{array}$ \\
\hline KA2 & 68.0 & 13.8 & 71.8 & 13.0 & 72.0 & 10.7 & 64.3 & 10.1 & $<.05^{*}$ \\
\hline KR2 & 53.0 & 12.0 & 55.4 & 13.6 & 71.6 & 10.0 & 67.0 & 9.7 & $>.05$ \\
\hline KT2 & 39.0 & 9.6 & 50.2 & 9.1 & 49.3 & 9.9 & 47.9 & 14.7 & $<.05^{*}$ \\
\hline
\end{tabular}

KA1 is knowledge acquisition test, KR1 is knowledge retention test, and KT1 is knowledge transfer test in Topic 1. KA2, KR2, and KT2 are the same tests for Topic 2. * A $p$-value less than 0.05 is considered significant

For Topic 1, there was no significant effect of learning approach on scores of different tests (Figure 2a). However, there was a significant effect for gender $F(1,83)$ $=26.4, p<0.05, \eta p^{2}=0.24$, as females $(M=87.6, S D=9.4)$ scored significantly higher than males $(M=76.9, S D=9.2)$ in KA1. The same was true for KR1; $F(1,83)$ $=9.8, p<0.05, \eta p^{2}=0.10$, and KT1; $F(1,83)=7.9, p<0.05, \eta p .{ }^{2}=0.09$. However, the main effect of gender on KT1 cannot be sensibly interpreted because there is a disordinal interaction. 

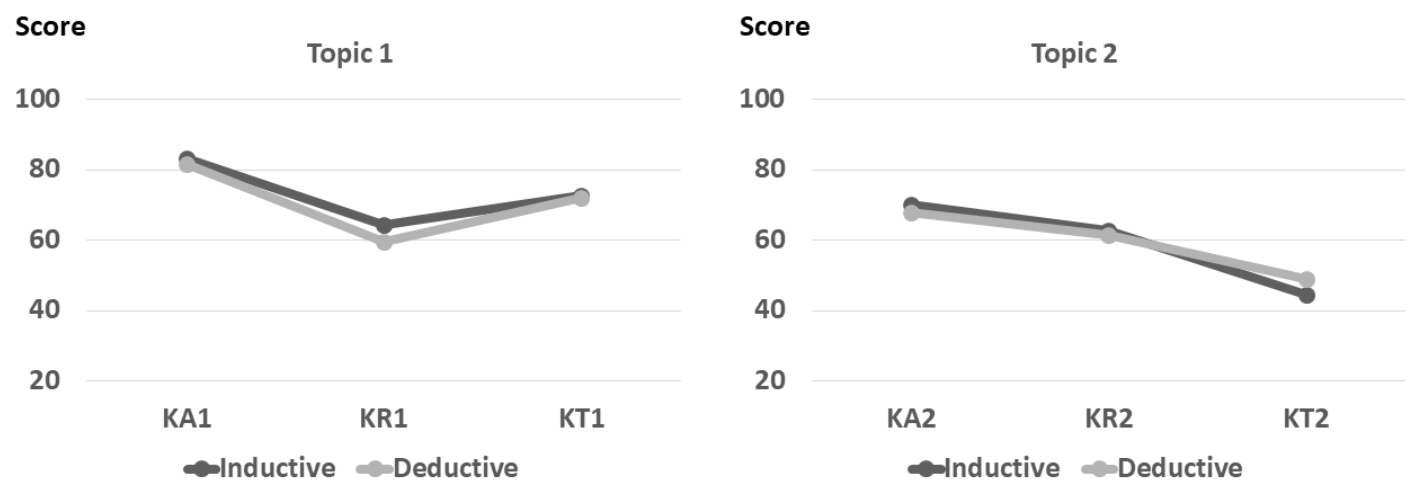

Figure 2. Students' scores in different tests of topics 1 (a) and 2 (b) per learning approach.

There was a significant effect for the interaction between gender and learning approach on KT1; $F(1,83)=4.9, p<0.05, \eta$. $^{2}=0.05$, The males do better in the inductive strategy $(\mathrm{M}=72.8, \mathrm{SD}=10.7)$ than in the deductive strategy $(\mathrm{M}=66.4, \mathrm{SD}$ $=8.0)$, but the opposite is true for the females, who do somewhat better in the deductive strategy $(\mathrm{M}=77.6, \mathrm{SD}=10.5)$ than in the inductive strategy $(\mathrm{M}=73.5, \mathrm{SD}$ $=10.8)$.

For Topic 2, there was no significant effect of the learning approach on KA2 and KR2 (Figure 2b). However, there was a significant effect for learning approach on $\mathrm{KT} 2 ; F(1,83)=4.0, p<0.05, \eta$. $^{2}=0.04$ as the deductive group $(M=49.0, S D=$ 12.3) scored significantly higher than the inductive group $(M=44.4, S D=10.9)$.

However such effect cannot be sensibly interpreted because, again, there is a disordinal interaction. As shown in table 1, there is a significant effect for the interaction between gender and learning approach on $\mathrm{KT} 2 ; F(1,83)=6.6, p<0.05$, $\eta$. $^{2}=0.07$, the females $(\mathrm{M}=49.3, \mathrm{SD}=9.9)$ outperform the males $(\mathrm{M}=39.0, \mathrm{SD}=$ 9.6) in the inductive approach, but in the deductive approach, the females $(\mathrm{M}=47.9$, $\mathrm{SD}=14.7)$ do not score higher than the males $(\mathrm{M}=50.2, \mathrm{SD}=9.1)$. Therefore, males profit more from a deductive approach $(\mathrm{M}=50.2, \mathrm{SD}=9.1)$ compared to an inductive approach $(\mathrm{M}=39.0, \mathrm{SD}=9.6)$. 
In regard to the effect of gender, there was a significant effect $F(1,83)=36.8$, $p<0.05, \eta p^{2}=0.31$; as females $(M=69.3, S D=10.0)$ scored significantly higher than males $(M=54.2, S D=12.7)$ in KR2. There was also a significant effect for the interaction between gender and learning approach on $\mathrm{KA} 2 ; F(1,83)=4.7, p<0.05$, $\eta p^{2}=0.05$, the females profit from an inductive approach $(\mathrm{M} 72.0, \mathrm{SD}=10.7)$ compared to a deductive approach $(\mathrm{M}=64.3, \mathrm{SD}=10.1)$, while the males, in contrast, profit somewhat from a deductive approach $(\mathrm{M}=71.8, \mathrm{SD}=13.8)$ compared to an inductive approach $(\mathrm{M}=68.0, \mathrm{SD}=13.8)$.

\section{Discussion}

The current study explored the effects of sequencing VP with lecture, in two different learning approaches, on students' knowledge acquisition, retention, and transfer. The study showed no significant difference between students' scores in knowledge acquisition and retention in both topics when the VP is sequenced in an inductive or a deductive approach. In regard to knowledge transfer, there was no significant difference between both learning approaches on students' scores in topic 1, while for topic 2 , the deductive group scored significantly higher than the inductive group. We could, however, not sensibly interpret such effect due to a disordinal interaction between gender and learning approach.

We attribute the lack of difference between both learning approaches on students' performance to the level of guidance in both approaches. The deductive approach moved from theory to application using the VPs and the inductive approach presented the problem then the theory, yet direct instruction was provided in both approaches. In instructional design, the level of guidance could vary from totally unguided discovery to full guidance through direct instruction. Our study might have shown a difference in favor of the inductive approach if the students were given an opportunity and enough time to explore learning resources to find answers for questions presented in the VPs.

Yet, when we consider gender as an independent variable, males scored higher in the inductive approach in topic 1 and in the deductive approach in topic 2 on the knowledge transfer tests. Females, however, seem to be largely unaffected by learning approach. We attribute the differences in the male results to the nature of the contents provided in Topics 1 and 2. 
In Topic 1, the VP session addressed one specific condition (impacted wisdom teeth). Students interpreted signs and symptoms, requested the relevant investigations and formulated a treatment plan that is relevant to one condition only in a purely convergent type of thinking. Therefore, students were able to manage the cognitive load of Topic 1 that was most likely within the capacity of working memory because it was only one condition.

There are different types of cognitive loads that can collectively impair learning if they overload working memory capacity (Young, Van Merrienboer, Durning, \& Ten Cate, 2014). Intrinsic load, which is relevant to the given content, is a function of the complexity of the material, that is, the number of elements presented (amount of given content) and the interaction between such elements (similarities in signs and symptoms, investigations, treatment plans of different conditions) (Young et al., 2014). The extraneous load depends on the quality of instruction and the surrounding physical environment (Choi, Van Merrienboer, \& Paas, 2014; Young et al., 2014). In our study, all groups received the instructions in the same classrooms, so we assume that the physical environment effect was the same.

On the other hand, Topic 2 (maxillofacial trauma) was relatively more challenging because it addressed multiple conditions. During the VP session, students had to interpret signs and symptoms that are relevant to fracture mandible, mid-face, zygoma and orbit and then formulate a treatment plan based on different clinical and radiographic findings. Such conditions involved interactions between multiple elements. In other words, there were overlaps between signs, symptoms, radiographic investigations and methods of fixations of different fractures. Such interactivity resulted in a high intrinsic cognitive load.

The male/inductive group might not be able to handle the intrinsic load of Topic 2 when exposed to the VP before the lecture. The knowledge gap could have been big enough to hinder rather than stimulate students' situational interest. Previous studies showed that complex problems without any prior knowledge of the topic imposes high load on working memory and leads to slow and inefficient learning (Clark et al., 2012), and the situation could be even worse if minimal guidance is provided to novice students working on complex problems (Kirschner et al., 2006), as was the case in the current study. On the other hand, the male/deductive group was able to process and store some information in long-term memory during the lecture, 
which resulted in attaining higher scores for the males/deductive than the male/ inductive group in Knowledge transfer test of Topic 2.

The high intrinsic load of Topic 2 did not only hinder the ability of the male/inductive group to construct a well organized knowledge schema, but it affected generally knowledge acquisition, retention and transfer of both groups as there was a trend of lower scores for Topic 2 when compared with students scores in Topic 1. Both groups had to deal with the full complex problems in VPs during one learning session, however managing the intrinsic cognitive load requires dealing with isolated elements (low element interactivity) first and then gradually works up to the tasks in their full complexity (Van Merrienboer \& Sweller, 2010).

In Topic 1, students in both approaches attained high scores in KA and KT. We may consider such results as a form of productive success. Productive success is the ability of students to perform well in the shorter term (KA) in combination with effective learning (solving real problems) in the longer term (KT) (Kapur, 2016). The main reason behind such performance is the appropriate correlation between the amounts of guidance (direct instructions before or after the VP in our study), complexity of the presented problems (VPs), and the students' prior knowledge (Kapur, 2016).

In Topic 2, there was a drop in scores in KT when compared to KA for all groups. We consider the low achievement in KT a form of unproductive success. Unproductive success is the ability of students to perform well on the shorter term (KA) without effective learning in the longer term (KT) (Kapur, 2016). The main reason behind such phenomena is that students get benefit from the direct instructions without any added value for the given problems (VPs). In direct instructions, novice students do not have the necessary prior knowledge differentiation to be able to notice and encode critical features of domain knowledge, which might lead to underperformance that is not so much in terms of acquisition but more in conceptual understanding and transfer (Kapur, 2016).

Our study has provided a practical implication for the use and sequence of VPs with lectures. The study suggests that sequencing VPs in either an inductive or deductive approach does not make a significant difference on students' performance when full guidance is offered in the inductive approach. Moreover, we imply that 
complex topics are preferably presented using VPs in a deductive learning approach, which is aligned with students' preferences in Huwendiek et al. (2013) study. However our suggestion would profit from future studies that use larger number of VPs.

Our study is not without limitations. It has abstracted the inductive learning approach to presenting the VP (problem) before the lecture (direct instruction) without allowing the students to search and integrate information independently across multiple learning resources. In our view, sequencing VP in an inductive or deductive approach should carry differences in the amount of guidance and complexity of both the VP and the lecture to optimally scaffold learning (e.g. more guidance and possibly less complex VP needed if prior to lecture). However, our aim was to ensure that there is no variability in the presented content between the inductive and deductive groups. Therefore, direct instruction (lecture) was provided in the inductive approach to cover exactly the same content as in the deductive approach. The study has also involved gender as a factor in its design, which was mainly due to cultural factors as males and females are separated in two different campuses. Future research would benefit from exploring the effect of sequencing VP and lecture with different amount of guidance and complexity using large number of VPs on other outcomes variables such as performance on real patients.

\section{Conclusion}

Sequencing virtual patients in inductive and deductive learning approaches leads to no significant difference on students' performance when full guidance is offered in the inductive approach.

\section{Practice Points}

1. Sequencing virtual patients after lectures in a deductive approach could facilitate knowledge transfer when complex topics are taught.

2. Sequencing VP in an inductive or deductive approach should carry differences in the amount of guidance based on students' prior knowledge and complexity of VPs.

3. VPs' typology should be followed in describing their features to allow better comparison between the effects obtained in different VPs' studies. 


\section{References}

Berman, N. B., Durning, S. J., Fischer, M. R., Huwendiek, S., \& Triola, M. M. (2016). The Role for Virtual Patients in the Future of Medical Education. Academic Medicine, 91(9), 1217-1222.

Choi, H., Van Merrienboer, J. J., \& Paas, F. (2014). Effects of the Physical Environment on Cognitive Load and Learning: Toward a New Model of Cognitive Load. Educ Psychol Rev, 26, 225-244.

Clark, R., Kirschner, P. A., \& Sweller, J. (2012). Putting students on the path to learning: The case for fully guided instruction. American Educ. 36(1), 6-11.

Cook, D. A., Erwin, P. J., \& Triola, M. M. (2010). Computerized virtual patients in health professions education: a systematic review and meta-analysis. Academic Medicine, 85(10), 1589-1602.

Cook, D. A., \& Triola, M. M. (2009). Virtual patients: a critical literature review and proposed next steps. Med Educ., 43(4), 303-311.

Ellaway, R., Topps, D., Lee, S., \& Armson, H. (2015). Virtual patient activity patterns for clinical learning. Clinic Teach., 12(4), 267-271.

Fyrenius, A., Bergdahl, B., \& Silen, C. (2005). Lectures in problem-based learning-why, when and how? An example of interactive lecturing that stimulates meaningful learning. Med Teach., 27(1), 61-65.

Gavriel, J. (2015). Tips on inductive learning and building resilience. Educ Prim Care., 26(5), 332-334.

Gentile, J. R. (2000). Learning, transfer of. In A. E. Kazdin \& A. E. Kazdin (Eds.), Encyclopedia of psychology, Vol. 5. (pp. 13-16). Washington, DC, US; New York, NY, US: American Psychological Association, Oxford University Press.

Harden, R. M., Sowden, S., \& Dunn, W. R. (1984). Educational strategies in curriculum development: the SPICES model. Med Educ., 18(4), 284-297.

Huwendiek, S., Duncker, C., Reichert, F., de Leng, B. A., Dolmans, D., van der Vleuten, C. P., . . . Tonshoff, B. (2013). Learner preferences regarding integrating, sequencing and aligning virtual patients with other activities in the undergraduate medical curriculum: A focus group study. Med Teach, 35(11), 920-929.

Jones, V. S., Holland, A. J., \& Oldmeadow, W. (2008). Inductive teaching method-an alternate method for small group learning. Med Teach., 30(8), e246-249. 
Kapur, M. (2016). Examining productive failure, productive success, unproductive failure, and unproductive success in learning. Educ. Psychol, 51(2), 289-299.

Kirschner, P. A., Sweller, J., \& Clark, R. E. (2006). Why minimal guidance during instruction does not work: An analysis of the failure of constructivist, discovery, problem-based, experiential, and inquiry-based teaching. Educational Psychologist, 41(2), 75-86.

Prince, M. J., \& Felder, R. M. (2006). Inductive teaching and learning methods: Definitions, comparisons, and research bases. Journal of engineering education, 95(2), 123-138.

Rotgans, J. I., \& Schmidt, H. G. (2011). The role of teachers in facilitating situational interest in an active-learning classroom. Teaching and Teacher Education, $27(1), 37-42$.

Schmidt, H. G., \& Rikers, R. M. (2007). How expertise develops in medicine: knowledge encapsulation and illness script formation. Med Educ., 41(12), 1133-1139.

Schmidt, H. G., Rotgans, J. I., \& Yew, E. H. (2011). The process of problem-based learning: what works and why. Med Educ, 45(8), 792-806.

Schmidt, H. G., Wagener, S. L., Smeets, G. A., Keemink, L. M., \& van der Molen, H. T. (2015). On the use and misuse of lectures in higher education. Health Prof Educ., 1(1), 12-18.

Schraw, G., Flowerday, T., \& Lehman, S. (2001). Increasing situational interest in the classroom. Educ Psychol Rev., 13(3), 211-224.

Van Merrienboer, J. J., \& Sweller, J. (2010). Cognitive load theory in health professional education: design principles and strategies. Med Educ, 44(1), 8593.

Vandewaetere, M., Manhaeve, D., Aertgeerts, B., Clarebout, G., Van Merrienboer, J. J., \& Roex, A. (2014). 4C/ID in medical education: How to design an educational program based on whole-task learning: AMEE Guide No. 93. Med Teach, 1-17.

Wijnia, L., Loyens, S. M., van Gog, T., Derous, E., \& Schmidt, H. G. (2014). Is there a role for direct instruction in problem-based learning? Comparing studentconstructed versus integrated model answers. LEARN INSTR., 34, 22-31. 
Young, J. Q., Van Merrienboer, J. J., Durning, S., \& Ten Cate, O. (2014). Cognitive Load Theory: implications for medical education: AMEE Guide No. 86. Med Teach., 36(5), 371-384. 


\section{Chapter 4: Virtual patients and teaching professionalism}

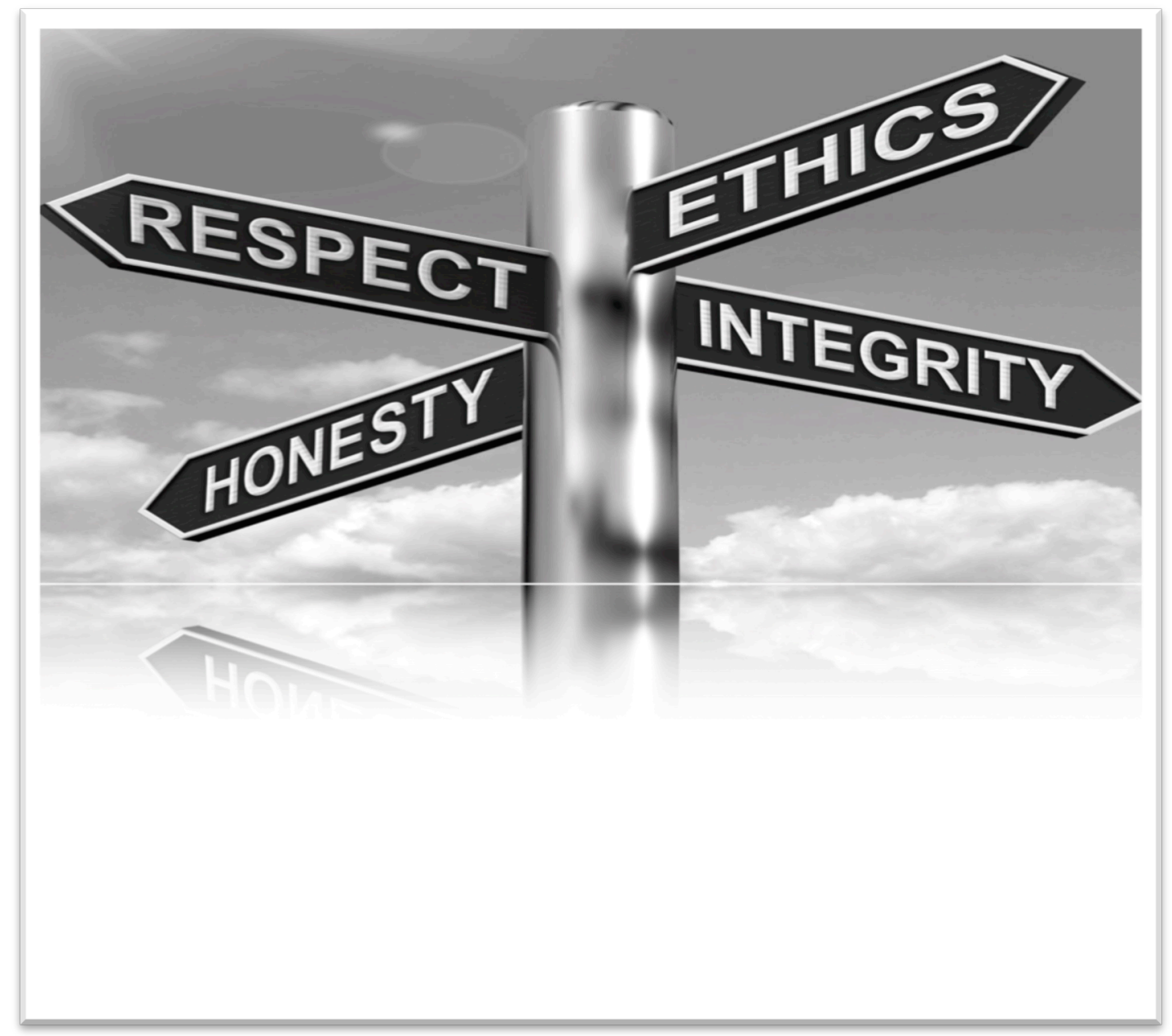

This chapter was published as:

Marei, H.F., Al-Eraky, M.M., Almasoud, N.N., Donkers, H.H.L.M., Van Merrienboer, J.J.G. (2018). The use of virtual patient scenarios as a vehicle for teaching professionalism. European Journal of Dental Education, May; 22(2): e253-e260. 


\begin{abstract}
Objectives: This study aimed to measure students' perceptions of virtual patient scenarios (VPs) for developing ethical reasoning skills and to explore features in VP design that are necessary to promote professionalism.

Methods: 65 dental students participated in learning sessions that involved collaborative practice with 5 VPs (4 high-fidelity and 1 low-fidelity), followed by reflection sessions. Students' perceptions toward the use of VPs in developing ethical reasoning skills were assessed using a questionnaire that involved 10 closed and 3 open-ended questions.

Results: High-fidelity VPs were perceived as significantly better for developing ethical reasoning skills than low-fidelity VPs. Analyses of answers to open-ended questions revealed two new features that are specific for VPs intended for teaching professionalism, which are VP dramatic structure and how it should end.

Conclusion: VPs intended for teaching professionalism need to have high fidelity, follow a specific dramatic structure and should include multiple plausible endings. The use of VPs as part of a collaborative activity that is followed by a reflection session is perceived as an effective tool for the development of ethical reasoning skills in dental education.
\end{abstract}




\section{Introduction}

Professionalism is an essential competency that must be demonstrated by healthcare graduates. Unprofessional behavior of students during medical schools is correlated with disciplinary action among practicing physicians during working life (Papadakis et al., 2005). In the same vein, analysis of medical litigations in dental practice showed that the majority of lawsuits was filed due to unprofessional conduct, such as violation in the scope of practice, negligence during the consenting process, lack of respect to patients' choices, and absence of support to patients when complications arise (Krause, Bremerich, \& Rustemeyer, 2001; Marei, 2013). Therefore, the Association of Dental Education in Europe recommended that dental schools should put strategies into place for teaching professionalism, and referred to simulation as one of the teaching methods that can be used for reaching this goal (Manogue et al., 2011).

Simulation varies in its complexity and ability to represent real-patient situations. It could be in the form of physical simulation such as a mannequin head for training students on local anesthetic injection, teeth extraction and cavity preparation (Marei \& Al-Jandan, 2013; Perry, Bridges, \& Burrow, 2015). Computer software programs are other tools that are used for simulating the clinical encounter, patients' problems and/or the consequences of the decision taken by the learner (Cook \& Triola, 2009; Schittek Janda et al., 2004; Zary, Johnson, \& Fors, 2009). Furthermore, simulation could involve recruiting standardized and/or simulated patients (SP) for teaching and assessing students' skills in history taking, breaking bad news and obtaining an informed consent (Carey, Madill, \& Manogue, 2010). However, the costly process of recruitment, selection and retention of suitable and credible SP is critical to running a SP program (Cleland, Abe, \& Rethans, 2009).

One of the currently available forms of computer simulation is provided by Virtual Patient Scenarios (VPs). These are computer simulations of real-life clinical scenarios that have been used effectively for enhancing knowledge retention (Botezatu, Hult, Tessma, \& Fors, 2010) and for teaching clinical reasoning skills (Cook \& Triola, 2009; Huwendiek, Reichert, et al., 2009). The use of VPs has been perceived well by students in various medical and dental studies (Botezatu, Hult, Kassaye Tessma, \& Fors, 2010; Schittek Janda et al., 2004), because they offer students the opportunity to take decisions in a safe environment and to contemplate 
consequences of their actions as if they are doctors in charge (Botezatu, Hult, \& Fors, 2010; Huwendiek, Reichert, et al., 2009).

Different studies that investigated learners' perceptions toward VPs showed that learners prefer specific features in VP design such as realism, relevance, appropriate level of difficulty, high interactivity, and feedback (Botezatu, Hult, \& Fors, 2010; Huwendiek, Reichert, et al., 2009). Although VPs have been used in different contexts, little seems to be known about their potential for teaching professionalism in health professions education and whether their use in teaching professionalism requires specific design features.

Teaching professionalism is challenging for many reasons. There is no conclusive definition of professionalism (Birden et al., 2014; Trathen \& Gallagher, 2009; Zijlstra-Shaw, Robinson, \& Roberts, 2012). Most professionalism dilemmas do not have a clear cut between correct and wrong answers (Sternszus, 2016). In learning professionalism, students are confronted with different plausible options for decisionmaking and they need to learn ethical reasoning skills. The variety of options might dictate specific features in VP design to accommodate the complexity of professionalism dilemmas. Furthermore, professionalism needs to be understood and interpreted in view of the social contract (Cruess \& Cruess, 2006), which means VPs that have been designed for a specific context may not work in a different context or culture.

Professionalism is culture-specific. Western frameworks on professionalism were found inappropriate to other context, which drives researchers to embrace other cultural perspectives on the attributes and behaviors of health professionals (AlEraky, Donkers, Wajid, \& van Merrienboer, 2014; Tsai, Lin, Harasym, \& Violato, 2007). Some of the universally acknowledged humanistic attributes are: respect, excellence (aspiring to perfection), confidentiality, accountability, and honesty (AlEraky et al., 2014; Hilton \& Slotnick, 2005; Steinert, Cruess, Cruess, Boudreau, \& Fuks, 2007). The progress in operationalizing the professionalism concept into workable attributes and behaviors unlocked the gate for clinical teachers in different cultures to plan what they should teach and therefore, think about how to use the currently available instructional methods in teaching the underlying cognitive base and developing the required attributes. 
Situated learning theory was described by Birden et al. (2013) as the most relevant model that can be followed for developing and designing instructions toward teaching professionalism. The theory argues that learning occurs as a result of a complex interaction between the participants (social context), their environment (physical context), and authentic activities that are led by a mentor or teacher (Durning \& Artino, 2011). In the same vein, role modelling in a clinical context, where there is interaction between dentists, patients, and nurses in situations creating real dilemmas was considered as an effective method in teaching professionalism (Birden et al., 2013). However, standardization of clinical rotations across the wide spectrum of patients, tutors and colleagues poses a challenge for educators. Moreover, the medical profession has a wide range of roles and practices in systems that put great limits on personal autonomy, making role modelling problematic (Cruess, 2006).

This problem has resulted in teachers using conventional teaching methods such as lectures in conveying the intended messages, which are usually in the form of 'DOs and DON'Ts (Field, Ellis, Abbas, \& Germain, 2010). Others used problems and writing exercises to stimulate students' reflection (Lantz, Bebeau, \& Zarkowski, 2011), but still such practice may result in isolation of the cognitive base of professionalism from clinical practice, which could make the acquired knowledge difficult to transfer to the workplace. Therefore, simulation might better help learners to internalize the cognitive base of professionalism by allowing them to situate it within the clinical context (Sternszus, 2016).

In a recent study, Hooper, Jivram, Law, Michell, and Somasunderam (2012) mentioned that $85 \%$ of students perceived VPs as an effective way for gaining knowledge relevant to medical ethics, but still more research is required to find out its potential in ethical reasoning and decision-making skills (Hooper, 2015). To the best of our knowledge, there is no existing evaluation instrument that is designed specifically for measuring the perception of using VPs in developing ethical reasoning skills. However, Huwendiek and de Leng (2010) have developed and used a questionnaire assessing students' experiences with VPs for learning clinical reasoning skills. The development of this questionnaire was based on literature about strategies to teach clinical reasoning, the design of teaching cases, and the results of a focus 
group study exploring students' perceptions of the ideal design of VPs for learning clinical reasoning skills.

Currently, there are different ways for using VPs within the classroom (Ellaway, Topps, Lee, \& Armson, 2015). However, situated learning theory resonates well with the latest paradigm shift from independent learning using VPs to integrating VPs in whole learning activities such as a VP collaborative learning activity. In such activity, learners work in groups with the virtual patient, discussing their options at each step, and reaching consensus on what their collective action will be. Therefore, the VP in such an activity acts mainly as a trigger for students' discussion and debate. Learning would depend on students' interactions with each other more than their direct interaction with the VP itself (Ellaway et al., 2015). That said, the collaborative work of students (social context) with VPs based on authentic professionalism dilemmas, followed by a reflection session guided by faculty, could be an effective method for developing ethical reasoning skills that are required in decision making on professionalism dilemma. Moreover, a collaborative learning activity could also fulfill two main requirements that are proposed for teaching professionalism: Creating learning opportunities that are appropriate to the level of the learners and allowing structured time for guided reflection (Al-Eraky, 2015). Guided reflection in such a context might enable students to discuss with their faculty the suboptimal answers. On the other hand, the faculty would be able to investigate why specific answers have been chosen and why the other options are not correct.

The physical environment of these learning activities is actually formed by the classroom and the VPs, so it is not as situated as in the clinical setting and real patients. Therefore, the current study investigates how using VPs in the classroom can help students in developing their ethical reasoning skills, and what are the VP design features that learners perceive as crucial for teaching professionalism?

\section{Methods}

\section{Participants}

Sixty-seven students who were registered in an oral and maxillofacial surgery course for the academic year 2015/2016 ( $2^{\text {nd }}$ semester) agreed to participate in the study. All students were in their $5^{\text {th }}$ academic year of a 6 -year discipline-based dental program. Two students did not attend the learning sessions in the study, therefore the 
total number of participants was 65 students $(N=65)$ in two main groups: males $(n=$ $36)$ and females $(n=29)$. Each main group of students was divided into small groups of 5 to 6 students each.

Materials

\section{Classroom}

The classroom contains six interactive multi-touch tables that are connected to 5-6 headphones to allow the students in the small groups to listen to the different VPs without having a sound collision from the neighboring table, while during discussion students can take the headphone off so they can listen to each other.

\section{Virtual Patients}

The study involved the use of five virtual patients, tackling four professionalism dilemmas, namely: privacy, confidentiality, excellence (aspiring to perfection), and honesty (Table 1). The virtual patients were different in their physical fidelity levels as four VPs (VP 1, 2, 4, 5) had a high-fidelity design, in which twodimensional graphics were used to represent different clinical settings and different characters within the VPs (Figure 2). Real human photos with a real human sound were used to project the different characters in the VPs. The VPs display real patient radiographs, lab results, intra-oral photos, and records for other special investigations at different stages of VPs path. VP 3 has low fidelity and presents the storyboard of the clinical scenario in a text format using PowerPoint. The PowerPoint slides are hyperlinked to each other in order to allow the students to follow the consequences of the decisions taken, therefore both designs have the same functional fidelity, which is how they respond to students' choices.

Table 1: The five VPs per topic and fidelity

\begin{tabular}{|l|l|l|l|l|l|}
\hline VP & VP1 & VP2 & VP3 & VP4 & VP5 \\
\hline Topic & Privacy & Confidentiality & Confidentiality & Excellency & Honesty \\
\hline Fidelity & High & High & Low & High & High \\
\hline
\end{tabular}




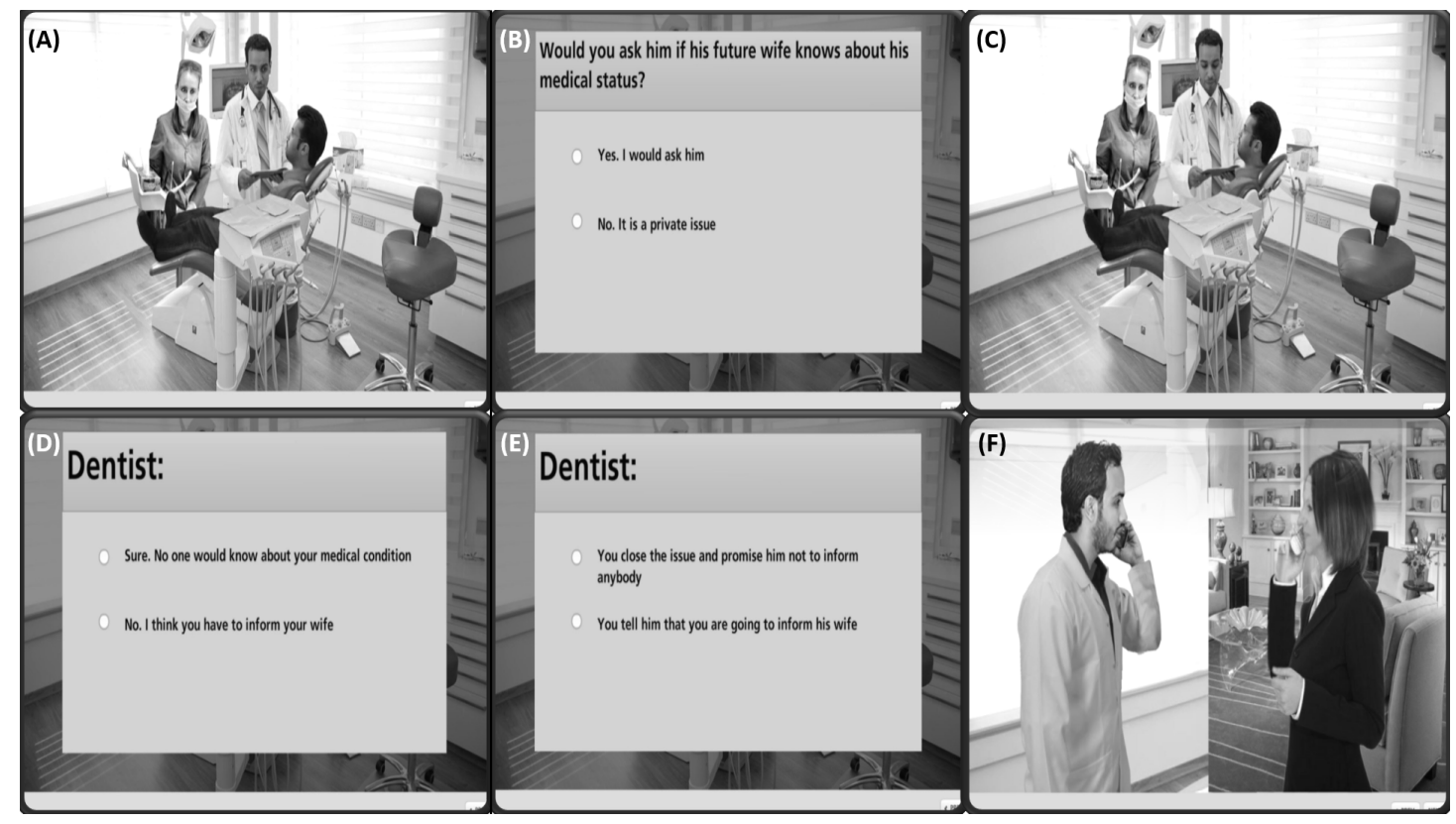

Figure 1: Multiple screenshots from VP2. The learner takes the role of the dentist in dealing with a patient with hepatitis $\mathrm{C}$ virus. The patient is going to get married to a lady who had wisdom teeth taken out within the same dental office. The ethical dilemma is about breaching the confidentiality of patient information if a third party could be at risk. (A) Dentist takes full medical and dental history, (B) The VP branches based on learner selection, (C) The dentist is asking the patient if his future wife knows about his medical status based on learner selection in the previous screen, (D, E) The VP branches based on the learner selection, (F) The patient wife phoned the dentist telling him that she is aware of the medical condition of her future husband because the learner decided to enforce the patient to inform his future wife.

\section{Measuring instruments}

A questionnaire that was developed by Huwendiek and de Leng (2010) for measuring students' perceptions of the development of clinical reasoning skills was adapted for the present study. The reliability of different subscales of the original questionnaire ranged from 0.74 to 0.82 (Huwendiek et al., 2014). The questionnaire is adapted by paraphrasing items to address perception of ethical reasoning using high and low fidelity VPs (For instance item number 1: While working on this case, I felt I had to make the same decisions a doctor would make in real life is paraphrased to Which of these virtual patients, you had the same decisions a doctor would make in real life?).

The adapted questionnaire contained 10 closed and 3 open-ended questions (Table 2). The questions clustered into five main categories, which are the 
authenticity of the patient encounter, professional approach in consultation, coaching during consultation, learning effect and overall judgment. For the closed questions, the students were asked to rank the five VPs from 1 to 5; in which 1 is the best VP and 5 is the worse VP. The open-ended questions required the students to reflect on special strengths and weaknesses regarding VP designs and to comment on the overall learning session. All the students filled the questionnaire immediately after the learning session. 
Table 2: The measuring instrument (Questionnaire)

\begin{tabular}{|c|c|c|c|c|c|c|}
\hline \# & Question & VP1 & VP2 & VP3 & VP4 & VP5 \\
\hline 1 & $\begin{array}{l}\text { Which of these virtual patients, you had } \\
\text { the same decisions a doctor would make in } \\
\text { real life? }\end{array}$ & & & & & \\
\hline 2 & $\begin{array}{l}\text { Which of these virtual patients, you felt } \\
\text { you were really the doctor caring for this } \\
\text { patient? }\end{array}$ & & & & & \\
\hline 3 & $\begin{array}{l}\text { Which one was informative enough and } \\
\text { you were aware of the required patient } \\
\text { information (e.g., history questions, } \\
\text { clinical exams, lab tests) to characterize the } \\
\text { ethical dilemma? }\end{array}$ & & & & & \\
\hline 4 & $\begin{array}{l}\text { Which of these virtual patients, you were } \\
\text { able to easily indicate the ethical dilemma? }\end{array}$ & & & & & \\
\hline 5 & $\begin{array}{l}\text { Which one you were actively engaged in } \\
\text { thinking about which findings supported or } \\
\text { refuted your decision? }\end{array}$ & & & & & \\
\hline 6 & $\begin{array}{l}\text { Which one was at the appropriate level of } \\
\text { difficulty for your training? }\end{array}$ & & & & & \\
\hline 7 & $\begin{array}{l}\text { Which of these virtual patients enhanced } \\
\text { your ethical reasoning skills? }\end{array}$ & & & & & \\
\hline 8 & $\begin{array}{l}\text { Which one provides better feedback for } \\
\text { your reasoning? }\end{array}$ & & & & & \\
\hline 9 & $\begin{array}{l}\text { Which of these virtual patients made you } \\
\text { feel better prepared to deal with similar } \\
\text { real patients in your future practice? }\end{array}$ & & & & & \\
\hline 10 & $\begin{array}{l}\text { Which one you think it was a worthwhile } \\
\text { learning experience? }\end{array}$ & & & & & \\
\hline 11 & \multicolumn{6}{|l|}{ Special Strengths in VP design and activity? } \\
\hline 12 & \multicolumn{6}{|l|}{ Special weaknesses in VP design and activity? } \\
\hline 13 & \multicolumn{6}{|c|}{ Additional comments and suggestions in regard to the whole activity? } \\
\hline
\end{tabular}


Procedure

The study involved two identical sessions, one for male and one for female students. Both sessions were conducted in the same classroom, used the same VPs and were facilitated by the same two faculty members, but at different points in time. Every learning session lasted for almost three hours and involved three parts: introduction, VP collaborative practice, and reflection.

Introduction: Lasted 10 minutes, in which an overview was provided about the VPs and how they respond to students' selections of different options. It involved also assigning a leader to every small group. He/she would operate the touch screen after the whole group discussed together the different questions and choices in the VP path.

VP collaborative practice: Lasted for nearly one hour. All students practiced the five VPs simultaneously in small groups (5-6 students each). During collaborative practice, the students listened, watched, and then discussed together in groups before taking a collective decision in different VPs. Two faculty members were moving between the tables to observe students' practice and respond to any questions.

Reflection part: Two-faculty members facilitated five reflection periods (one after each VP). Each reflection period lasted for about 20 minutes and was based on 7 pre-defined questions that were used as triggers for reflection on professionalism dilemmas (Al-Eraky, Donkers, Wajid, \& Van Merrienboer, 2015) (Table 3). Furthermore, students were allowed to provide their opinion on the different characters and to describe any relevance to previous experiences with real patients.

Table 3: Triggers/ questions to guide reflection on professionalism dilemmas

\begin{tabular}{|l|l|}
\hline 1 & Describe your feelings, if you were in that situation. \\
\hline 2 & What is the professionalism dilemma of the given scenario? \\
\hline 3 & What would you do in that situation? and why? \\
\hline 4 & What are the expected consequences of your decision? \\
\hline 5 & What if you were in the shoes of the colleague or the patient? (Swapping roles) \\
\hline 6 & What did you learn from discussing this scenario? \\
\hline 7 & $\begin{array}{l}\text { Do you feel more prepared in case if you encounter a similar situation in } \\
\text { reality? }\end{array}$ \\
\hline
\end{tabular}


Data collection and analysis

The college's statistical unit collected the filled questionnaires. The quantitative data were analyzed using SPSS Software (SPSS 22.0, SPSS Inc.,

Chicago, IL, USA). ANOVA was used to find any significant differences between the low-fidelity and high-fidelity VPs. Post Hoc Tukey HSD was performed for multiple pairwise comparisons. The $p$-value for statistical significance was set at $5 \%$.

Thematic analysis was generated based on students' qualitative data (openended questions) using Excel. We followed the conventional approach to content analysis. The response from each student was considered the unit of analysis. Meaning units represented features of ideal VP design and varied in length, ranging from one word, e.g. "realism" and "interactivity" to one or multiple statements, e.g. "I want to see a VP that is similar to a movie'. Short meaning units were condensed and coded as such, but longer ones were shortened with the preservation of their gist to form condensed meaning units. One code was given to them. Codes were then grouped under higher headings (categories), which were eventually clustered in themes.

\section{Ethical approval}

The study was reviewed and approved by the University Ethical Committee (IRB number: 2015-02-099) and all participants gave informed consent before the beginning of the study. It was clearly announced that the session is optional and students' attendance does not contribute to their grades or evaluation.

\section{Results}

All participants $(N=65)$ filled out the questionnaire. The mean rating scores for the high fidelity VPs was $31.9 \pm 7.5$ for VP1, 32.9 \pm 8.0 for VP2, 32.6 \pm 6.8 for VP4, and 31.4 \pm 8.2 for VP5, while for the low fidelity VP (VP3), it was 27.2 \pm 8.0 (Table 4). Reliability statistics showed a Cronbach's alpha of 0.75 for the 10 items.

For the influence of different designs on students' perceptions of ethical reasoning, there was a significant difference between the five VPs, $F(1,65)=5.47, p$ $=0.00$. Tukey HSD showed that the main difference was between VP 3 (low fidelity design) and VP1, VP2, VP4, and VP5, as the mean of any of the high fidelity VPs was higher than the low fidelity VP $(p=0.007,0.001,0.001,0.023$ respectively). There was no significant difference between the different high fidelity VPs in 
pairwise comparison. Furthermore, there was no significant difference between learning perception of male and female students for the different VPs.

Table 4: Mean, standard deviation, and pairwise comparison between high and low fidelity VPs

\begin{tabular}{|c|c|c|c|c|c|}
\hline & VP1 & VP2 & VP3 & VP4 & VP5 \\
\hline Mean +/_SD & $31.9 \pm 7.5$ & $32.9 \pm 8.0$ & $27.2 \pm 8.0$ & $32.6 \pm 6.8$ & $31.4 \pm 8.2$ \\
\hline VP 3 & $p=0.007$ & $p=0.001$ & - & $p=0.001$ & $p=0.023$ \\
\hline
\end{tabular}

$p$-value for statistical significance was set at $5 \%$.

Analysis of students' responses to open questions showed three main themes with nine categories as shown in Table 5. The main findings that were extracted from students' responses confirmed that the use of VPs was perceived as an effective tool in learning ethical reasoning skills (e.g., "I think I can weigh between different decisions"). However, the use of audio-visual effects was considered as a crucial element in VP design (e.g., "The audiovisual effects have added more reality to the VP"). The students acknowledged the reality of the problems that they encountered (e.g., "The problems that we have experienced were very real"), and preferred to see the arrangement of events in the VP similar to that seen in a movie (e.g., "I want to see a VP that is similar to a movie"). They have also requested to have links inside the VP to rules, regulation and reference materials that are relevant to the encountered problem (e.g., "We need to have links to rules and regulations in our country"). Furthermore, they considered group practice and having a reflection session as key elements during VP implementation (e.g., "The feedback session was as important as practicing with the VPs"). 
Table 5: Synopsis of themes, categories and examples of students' input

\begin{tabular}{|c|c|c|}
\hline Theme & Categories & Citations of students' answers to open questions \\
\hline \multirow[t]{6}{*}{ Design } & $\begin{array}{l}\text { Real life } \\
\text { scenarios }\end{array}$ & $\begin{array}{l}\text { - The problems that we have experienced } \\
\text { were very real } \\
\text { - The dialogue between the doctor and patient } \\
\text { was very realistic } \\
\text { - Ifelt like immersed in the story }\end{array}$ \\
\hline & Storyboard & $\begin{array}{l}\text { - I liked the VPS because it enhanced the } \\
\text { discussion about right and wrong decisions } \\
\text { - I want to see a VP that is similar to a movie } \\
\text { - I will not forget that I have been taken to the } \\
\text { court at the end of the VP } \\
\text { - Unforgettable experience as my stress went } \\
\text { up while I am taking some difficult } \\
\text { decisions. } \\
\text { Some problems could have two correct } \\
\text { answers at the end of the VP } \\
\text { Being not sure about the answer increased } \\
\text { my engagement }\end{array}$ \\
\hline & $\begin{array}{l}\text { Difficulty } \\
\text { of the } \\
\text { content }\end{array}$ & $\begin{array}{l}\text { - It was at a good level of understanding } \\
\text { - The VPs were clear }\end{array}$ \\
\hline & Interactivity & $\begin{array}{l}\text { - Very entertaining and interactive } \\
\text { - VP responding to my choices was good }\end{array}$ \\
\hline & $\begin{array}{l}\text { Audio- } \\
\text { visual } \\
\text { effects }\end{array}$ & $\begin{array}{l}\text { - The animations were very nice } \\
\text { - The audiovisual effects have added more } \\
\text { reality to the VP } \\
\text { - Use of media was very effective } \\
\text { - I wants to see the characters moving in next } \\
\text { VPS }\end{array}$ \\
\hline & $\begin{array}{l}\text { Link to } \\
\text { external }\end{array}$ & $\begin{array}{l}\text { - I would expect to have links to reference } \\
\text { materials relevant to the problems }\end{array}$ \\
\hline
\end{tabular}




\begin{tabular}{|c|c|c|}
\hline & resources & $\begin{array}{l}\text { - We need to have links to rules and } \\
\text { regulations in our country }\end{array}$ \\
\hline \multirow[t]{2}{*}{$\begin{array}{l}\text { Implementatio } \\
\mathrm{n}\end{array}$} & Practice & $\begin{array}{l}\text { - Group practice were very helpful } \\
\text { - I liked thinking together in a group } \\
\text { - The available resources facilitated working } \\
\text { as a group }\end{array}$ \\
\hline & Reflection & $\begin{array}{l}\text { - The feedback session was as important as } \\
\text { practicing with the VPs } \\
\text { - Discussion in the feedback sessions resolved } \\
\text { all my inquires } \\
\text { - The feedback sessions added to my ability to } \\
\text { take correct decisions } \\
\text { - I was not sure about the most appropriate } \\
\text { answer in some VP till the reflection session }\end{array}$ \\
\hline Learning & $\begin{array}{l}\text { Ethical } \\
\text { reasoning }\end{array}$ & $\begin{array}{l}\text { - I think I can weigh between different } \\
\text { decisions } \\
\text { - Now I can think more in depth in ethical } \\
\text { dilemmas } \\
\text { - The VP let me think like a dentist }\end{array}$ \\
\hline
\end{tabular}

\section{Discussion}

The current study measured the perception of students' toward five VPs that targeted ethical reasoning skills and explored features in VP design that make VPs suitable for teaching and learning professionalism in dental education.

The study showed that VPs with high fidelity were perceived as significantly better for developing ethical reasoning skills than the one with low fidelity design. Although all the designs were similar in their functional fidelity, which is how the VP responds to students' choices, still the appearance of the different characters, their sound, and the projection of the clinical setting had a great impact on students' perceptions. Our students' preferences were consistent with students' preferences in previous studies (Huwendiek, Reichert, et al., 2009), which showed that students 
prefer VPs that are interactive, rich in media, authentic, have appropriate difficulty and are based on real-life scenarios relevant to their future practice.

Although students' preference is crucial in designing specific instructional methods to make learning enjoyable and attractive to them, still the preferred way of learning does not need to be the most effective way of learning (Kirschner \& van Merriënboer, 2013). Moreover, learner preference for selecting particular instructional methods could be uncorrelated or negatively correlated to learning outcomes (Clark, 1982). Therefore, students' preference of high fidelity VPs is only one aspect of evaluation, which stands at the first level of Kirkpatrick model, while the other aspect would be evaluation of students' actual performance and learning outcomes (second level of Kirkpatrick model), which was not within the scope of our study.

Two features in the VP design theme have emerged in our study, and were not mentioned by students in previous VP studies. The first is the dramatic structure that is relevant to the storyboard. Students have commented on the necessity of building and arranging the incidents in the VP storyboard as in the movies. Furthermore, they said it is important to extend the uncertainty about the correct answer to increase engagement in the VP. Students' views are consistent with what Reeve (2009) advocated in developing serious games. This author stated that a good story is recognized as a highly efficient motivator for the learners. A good narrative gives a game a level of sophistication that promotes greater engagement and encourages longer involvement. The emotional attachment manifests itself in the desire to know what would happen if a specific option is selected. Therefore, it is crucial to maintain the correct mix between storytelling and the free exploratory activity in order to keep the learner actions as a part of the story.

In real moviemaking, it is stated that the arrangement of the incidents that take place in a dramatic work such as a play or film should pass through different stages namely exposition, conflict, rising action, climax, falling action, and resolution (Laurel, 1986). Although watching a movie is different from practicing a VP that requires active participation from the learners, still based on students' perception, building the storyboard to pass through the different movie stages could be possible. Exposition could be achieved by introducing the main characters in the VP during history taking; conflict can be presented through questions that are relevant to the professionalism dilemma; rising action till climax can be projected by directing the 
students (based on their choices) to different screens that complicate the dilemma and finally falling action and resolution could be fulfilled by the reflection session, in which the students discuss the advantages and disadvantages of every decision and what would support one decision over the others.

The second feature is how VPs should end. In general, VPs have either one end node, or multiple end nodes. In the first design, the VP branches or not based on learners' decisions to end in one end node. The second is more complex in branching and involves multiple end nodes. One of them represents the correct pathway that should be taken, while the other nodes represent the different consequences of wrong decisions (Huwendiek, De leng, et al., 2009).

Transferring these designs to complex professionalism dilemmas might require the VP to end with multiple correct end nodes because the real world contains situations that are complex enough to end with multiple correct answers. Sternszus (2016) stated that students do not need to understand medical professionalism in order to know how to react to scenarios that have clear right and wrong answers and such simple scenarios might make the students disengage from professionalism education. Furthermore, it was indicated that it is important to put all the efforts that promote positive professional behavior rather than providing curricula that focus on ensuring that the students do not behave unprofessionally (Al-Eraky, 2015; Sternszus, 2016). Although such design may create a form of uncertainty among students because they are used to one correct answer, their doubt can be resolved during the reflection session that should not be separated from the VP activity.

In regard to the VP implementation, students acknowledged that collaborative practice was conductive to learning. Such perception may be due to two main reasons. One is relevant to the scenario, which involved challenging questions that have highly plausible options, therefore students had to go in intense discussions to agree on a specific answer. Secondly, the student arrangements in 5-6 participants around the interactive tables have facilitated their discussion. Our results is consistent with Ellaway et al. study (Ellaway et al., 2015), who stated that in VP collaborative activities, much of the learning value is generated by the discussion and debate rather than by direct interactions with the VP. 
The second feature that is relevant to VP implementation is the reflection sessions. The students have recognized them as important as the VP practice. The reflection session prepared students to deal with uncertainty, as we asked them to acknowledge the complexity of real-life situations and embrace more than one plausible option based on many variables. Secondly, the facilitator's negotiation of the students' answer opened the students' mind to new perspectives so they were able to see the whole picture. We advocate that the aim of such reflection session is not to dictate or enforce specific answers, but to teach the students how to think and react to future similar dilemmas if some of the data have changed. We consider reflection as a central part of VP practice sessions. It allows students to analyze, question, and reframe (real or simulated) experiences to make an assessment of it for the purposes of learning (reflective learning) and/or to improve practice (reflective practice) (Aronson, 2011). Furthermore, authors advocated that teaching professionalism in general (without VP) requires structured time for guided reflection (Al-Eraky, 2015; Al-Eraky et al., 2015).

This study is not without limitations. It measured the perception for learning ethical reasoning skills; while there is a need to objectively assess students' abilities for reasoning skills after using VPs. Also there is a wide spectrum of VP designs that needed to be explored in relation to ethical reasoning skills and professionalism. The VP can be further used in different integration models such as a stand-alone or as a blended activity, not only as a collaborative learning activity. The study has provided two main practical implications. First, the design of VPs that are intended for developing professionalism should be centered on a well-written storyboard that follows a recognized dramatic structure. Secondly, the VPs should be designed to have multiple correct end nodes to enhance positive professional behavior.

\section{Conclusion}

VPs that are intended for teaching professionalism need to have high fidelity, follow a specific dramatic structure and should include multiple plausible endings. The use of VPs as a part of a collaborative activity that is followed by a reflection session has been perceived as an effective tool for developing ethical reasoning skills in dental education. 


\section{References}

Al-Eraky, M. M. (2015). Twelve Tips for teaching medical professionalism at all levels of medical education. Med Teach, 37(11), 1018-1025.

Al-Eraky, M. M., Donkers, J., Wajid, G., \& van Merrienboer, J. J. (2014). A Delphi study of medical professionalism in Arabian countries: the Four-Gates model. Med Teach, 36 Suppl 1, S8-16. doi:10.3109/0142159x.2014.886013

Al-Eraky, M. M., Donkers, J., Wajid, G., \& Van Merrienboer, J. J. (2015). Faculty development for learning and teaching of medical professionalism. Med Teach, 37 Suppl 1, S40-46.

Aronson, L. (2011). Twelve tips for teaching reflection at all levels of medical education. Med Teach, 33(3), 200-205.

Birden, H., Glass, N., Wilson, I., Harrison, M., Usherwood, T., \& Nass, D. (2013). Teaching professionalism in medical education: a Best Evidence Medical Education (BEME) systematic review. BEME Guide No. 25. Med Teach, 35(7), e1252-1266.

Birden, H., Glass, N., Wilson, I., Harrison, M., Usherwood, T., \& Nass, D. (2014). Defining professionalism in medical education: a systematic review. Med Teach, 36(1), 47-61.

Botezatu, M., Hult, H., \& Fors, U. G. (2010). Virtual patient simulation: what do students make of it? A focus group study. BMC Med Educ, 10, 91.

Botezatu, M., Hult, H., Kassaye Tessma, M., \& Fors, U. G. (2010). As time goes by: Stakeholder opinions on the implementation and use of a virtual patient simulation system. Med Teach, 32(11), e509-516.

Botezatu, M., Hult, H., Tessma, M. K., \& Fors, U. (2010). Virtual patient simulation: knowledge gain or knowledge loss? Med Teach, 32(7), 562-568.

Carey, J. A., Madill, A., \& Manogue, M. (2010). Communications skills in dental education: a systematic research review. Eur J Dent Educ, 14(2), 69-78.

Clark, R. E. (1982). Antagonism between achievement and enjoyment in ATI studies. Educational psychologist, 17(2), 92-101.

Cleland, J. A., Abe, K., \& Rethans, J. J. (2009). The use of simulated patients in medical education: AMEE Guide No 42. Med Teach, 31(6), 477-486.

Cook, D. A., \& Triola, M. M. (2009). Virtual patients: a critical literature review and proposed next steps. Med Educ, 43(4), 303-311. 
Cruess, R. L. (2006). Teaching professionalism: theory, principles, and practices. Clin Orthop Relat Res, 449, 177-185.

Cruess, R. L., \& Cruess, S. R. (2006). Teaching professionalism: general principles. Med Teach, 28(3), 205-208.

Durning, S. J., \& Artino, A. R. (2011). Situativity theory: a perspective on how participants and the environment can interact: AMEE Guide no. 52. Med Teach, 33(3), 188-199.

Ellaway, R., Topps, D., Lee, S., \& Armson, H. (2015). Virtual patient activity patterns for clinical learning. Clinical Teacher, 12(4), 267-271.

Field, J., Ellis, J., Abbas, C., \& Germain, P. (2010). Teaching and assessment of professional attitudes in UK dental schools - commentary. Eur J Dent Educ, 14(3), 133-135.

Hilton, S. R., \& Slotnick, H. B. (2005). Proto-professionalism: how professionalisation occurs across the continuum of medical education. Med Educ, 39(1), 58-65.

Hooper, C. (2015). Ethics virtual patients: a new pedagogical tool for educators? $J$ Med Ethics, 41(7), 549-552.

Hooper, C., Jivram, T., Law, S., Michell, A., \& Somasunderam, A. (2012). Using virtual patients to teach medical ethics, medical law and medical professionalism. Med Teach, 34(8), 674-675.

Huwendiek, S., \& de Leng, B. A. (2010). Virtual patient design and curricular integration evaluation toolkit. Med Educ, 44(5), 519.

Huwendiek, S., de Leng, B. A., Kononowicz, A. A., Kunzmann, R., Muijtjens, A. M., Van Der Vleuten, C. P., . . . Dolmans, D. H. (2014). Exploring the validity and reliability of a questionnaire for evaluating virtual patient design with a special emphasis on fostering clinical reasoning. Med Teach, 1-8.

Huwendiek, S., De leng, B. A., Zary, N., Fischer, M. R., Ruiz, J. G., \& Ellaway, R. (2009). Towards a typology of virtual patients. Med Teach, 31(8), 743-748.

Huwendiek, S., Reichert, F., Bosse, H. M., de Leng, B. A., van der Vleuten, C. P., Haag, M., . . . Tonshoff, B. (2009). Design principles for virtual patients: a focus group study among students. Med Educ, 43(6), 580-588.

Kirschner, P. A., \& van Merriënboer, J. J. (2013). Do learners really know best? Urban legends in education. Educational psychologist, 48(3), 169-183. 
Krause, H. R., Bremerich, A., \& Rustemeyer, J. (2001). Reasons for patients' discontent and litigation. J Craniomaxillofac Surg, 29(3), 181-183. doi:10.1054/jcms.2001.0212

Lantz, M. S., Bebeau, M. J., \& Zarkowski, P. (2011). The status of ethics teaching and learning in U.S. dental schools. J Dent Educ, 75(10), 1295-1309.

Laurel, B. K. (1986). Toward the design of a computer-based interactive fantasy system. The Ohio State University. Retrieved from Retrieved from https://etd.ohiolink.edu/ on 10/02/207

Manogue, M., McLoughlin, J., Christersson, C., Delap, E., Lindh, C., SchoonheimKlein, M., \& Plasschaert, A. (2011). Curriculum structure, content, learning and assessment in European undergraduate dental education - update 2010. Eur J Dent Educ, 15(3), 133-141.

Marei, H. F. (2013). Medical litigation in oral surgery practice: lessons learned from 20 lawsuits. J Forensic Leg Med, 20(4), 223-225.

Marei, H. F., \& Al-Jandan, B. A. (2013). Simulation-based local anaesthesia teaching enhances learning outcomes. Eur J Dent Educ, 17(1), e44-48.

Papadakis, M. A., Teherani, A., Banach, M. A., Knettler, T. R., Rattner, S. L., Stern, D. T., .. . Hodgson, C. S. (2005). Disciplinary action by medical boards and prior behavior in medical school. N Engl J Med, 353(25), 2673-2682.

Perry, S., Bridges, S. M., \& Burrow, M. F. (2015). A review of the use of simulation in dental education. Simul Healthc, 10(1), 31-37.

Reeve, C. (2009). Narrative-Based Serious Games. In O. Petrovic \& A. Brand (Eds.), Serious Games on the Move (pp. 73-89). Vienna: Springer Vienna.

Schittek Janda, M., Mattheos, N., Nattestad, A., Wagner, A., Nebel, D., Farbom, C., . .. Attstrom, R. (2004). Simulation of patient encounters using a virtual patient in periodontology instruction of dental students: design, usability, and learning effect in history-taking skills. Eur J Dent Educ, 8(3), 111-119.

Steinert, Y., Cruess, R. L., Cruess, S. R., Boudreau, J. D., \& Fuks, A. (2007). Faculty development as an instrument of change: a case study on teaching professionalism. Acad Med, 82(11), 1057-1064.

Sternszus, R. (2016). Developing a professional identity: a learner's perspective. In R. L. Cruess, S. R. Cruess, \& Y. Steinert (Eds.), Teaching Medical Professionalism: Supporting the Development of a Professional Identity (pp. 26 - 33): Cambridge University Press. 
Trathen, A., \& Gallagher, J. E. (2009). Dental professionalism: definitions and debate. Br Dent J, 206(5), 249-253.

Tsai, T. C., Lin, C. H., Harasym, P. H., \& Violato, C. (2007). Students' perception on medical professionalism: the psychometric perspective. Med Teach, 29(2-3), 128-134.

Zary, N., Johnson, G., \& Fors, U. (2009). Web-based virtual patients in dentistry: factors influencing the use of cases in the Web-SP system. Eur J Dent Educ, 13(1), 2-9.

Zijlstra-Shaw, S., Robinson, P. G., \& Roberts, T. (2012). Assessing professionalism within dental education; the need for a definition. Eur J Dent Educ, 16(1), e128-136. 


\section{Chapter 5: Virtual patients and cognitive load}
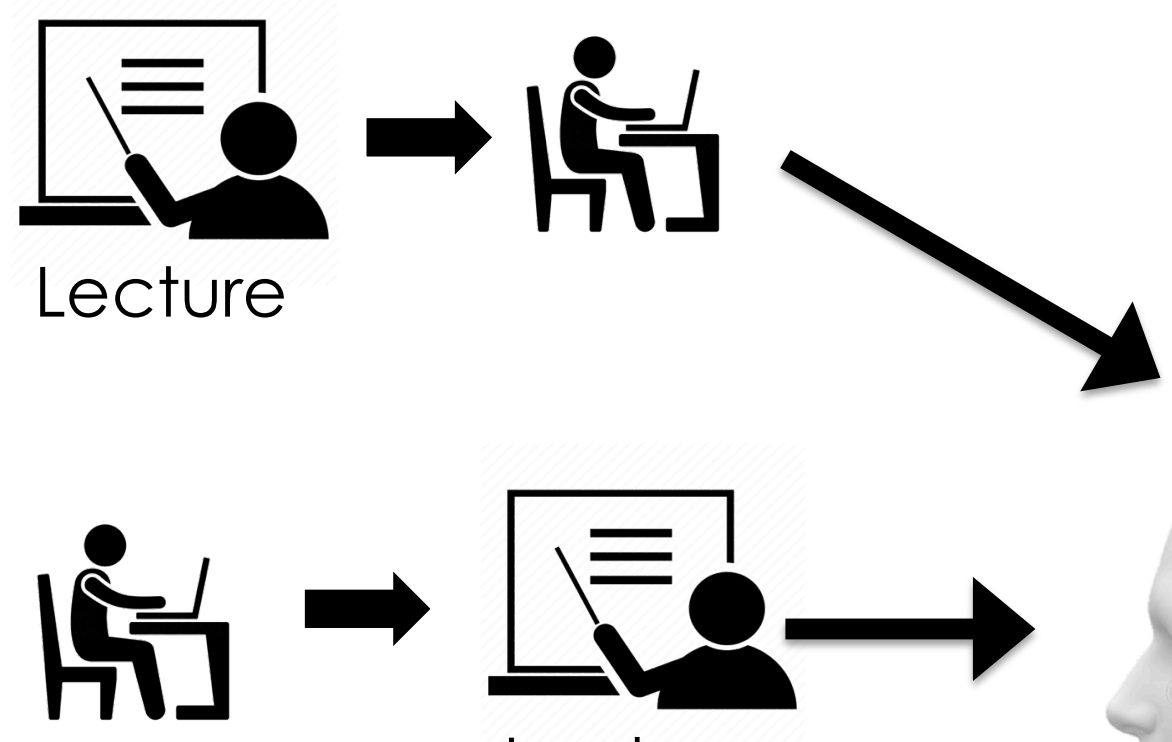

\section{Lecture}
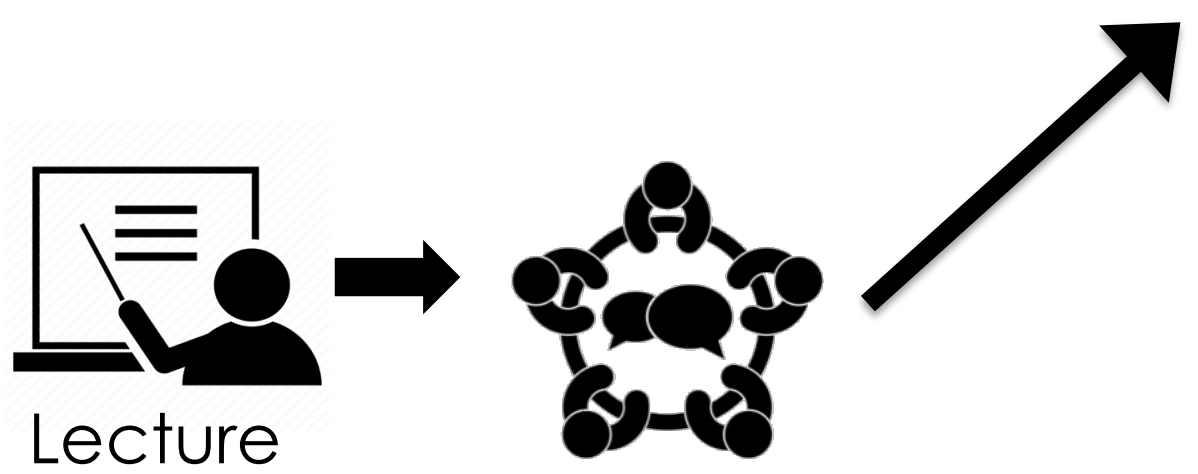

This chapter was published as:

Marei, H.F., Donkers, H.H.L.M., Al-Eraky, M.M., Van Merrienboer, J.J.G. (2018). Collaborative use of virtual patients after a lecture enhances learning with minimal investment of cognitive load. Medical Teacher, May 25:1-8. doi: 10.1080/0142159X.2018.1472372. [Epub ahead of print] 


\begin{abstract}
Background: The use of Virtual Patients (VPs), due to their high complexity and/or inappropriate sequencing with other instructional methods, might cause a high cognitive load, which hampers learning.

Aim: To investigate the efficiency of instructional methods that involved three different applications of VPs combined with lectures.

Method: From two consecutive batches, 171 out of 183 students have participated in lecture and VPs sessions. One group received a lecture session followed by a collaborative VPs learning activity (collaborative deductive). The other two groups received a lecture session and an independent VP learning activity, which either followed the lecture session (independent deductive) or preceded it (independent inductive). All groups were administrated written knowledge acquisition and retention tests as well as transfer tests using two new VPs. All participants completed a cognitive load questionnaire, which measured intrinsic, extraneous and germane load. Mixed effect analysis of cognitive load and efficiency using the $\mathrm{R}$ statistical program was performed.

Results: The highest intrinsic and extraneous load was found in the independent inductive group, while the lowest intrinsic and extraneous load was seen in the collaborative deductive group. Furthermore, comparisons showed a significantly higher efficiency, that is, higher performance in combination with lower cognitive load, for the collaborative deductive group than for the other two groups.

Conclusion: Collaborative use of VPs after a lecture is the most efficient instructional method, of those tested, as it leads to better learning and transfer combined with lower cognitive load, when compared with independent use of VPs, either before or after the lecture.
\end{abstract}




\section{Introduction}

A Virtual Patient (VP) is a computer simulation of a real-life clinical scenario for the purpose of teaching, learning and assessment (Ellaway et al. 2006). Originally, VPs were seen as a standalone e-learning tool that can be accessed by students via an e-learning management system (Berman et al. 2009). Learning from VPs, as a standalone activity, depends on the inherent characteristics that are embedded in their design, and on the time devoted by students to use them (Bateman et al. 2013; Huwendiek et al. 2009). Recently, more emphasis has been given to the value of VPs when they are integrated and sequenced with other instructional methods such as collaborative learning or lecturing (Edelbring et al. 2012; Ellaway and Davies 2011; Ellaway et al. 2015).

The use of VPs, due to their high complexity or element interactivity, might cause a high intrinsic cognitive load. In case of cognitive overload due to the complexity of the learning materials, learning is impaired (Van Merrienboer and Sweller 2010). Moreover, the sequence of complex VPs with other instructional methods that do not respect the level of prior knowledge of the learners could result in poor instructions, which is another potential source of cognitive load known as extraneous cognitive load (Kirschner et al. 2006).

Ideally, VPs sessions should be designed in such a way that cognitive overload is prevented. This can be reached by reducing extraneous load (which is always desirable) and/or intrinsic load (which might be necessary when learning tasks are too complex given the prior knowledge of the learners). By preventing cognitive overload, germane processing is facilitated, meaning that learners can optimally allocate their available working memory resources to deal with learning processes such as schema construction and schema automation (Van Merrienboer and Sweller 2010).

The extraneous cognitive load refers to the cognitive load that is not necessary for learning and / or execution of the task (Young et al. 2014). PowerPoint presentations that use slides full of texts and written descriptions of images is an example of poor instruction that causes high extraneous load (Van Merrienboer and Sweller 2010). On the other side, intrinsic cognitive load is the load necessary for executing the learning tasks and it increases with the increase in the number of information elements and the extent to which these elements interact with each other 
(Young et al. 2014). Novice students approaching a surgical problem for a patient with multiple interacting systematic diseases before facing it on a medically fit patient is an example of imposing (too) high intrinsic cognitive load on students. Therefore, it is important to adapt the complexity of the problem to the prior knowledge of the learners by sequencing the problems from simple to complex (Van Merrienboer and Sweller 2010).

To reduce intrinsic cognitive load, the four components instructional design model (4C/ID; Van Merrienboer \& Kirschner, 2018) suggests that supportive information (theoretical information that is relevant to performing the learning task) should be tailored and provided before executing specific learning tasks for learners, who already have some relevant prior knowledge in the domain. This deductive approach helps the learner to construct the cognitive schemata that are necessary to carry out problem solving, reasoning and decision making while completing the learning tasks (Vandewaetere et al. 2014).

The sequence of VPs (learning task) and lecture (supportive information) has been evaluated with respect to students' preference and effectiveness (Huwendiek et al. 2013; Marei et al. 2017). Huwendiek et al. (2013) showed that fifth-year students preferred having a lecture that is followed by VPs, a small group discussion, and then a real patient session. Marei et al. (2017) reported no significant difference between sequencing VPs before the lecture (inductive learning approach) or after it (deductive learning approach) on students' performance when direct instruction is offered in the inductive approach to novice learners.

Collaborative learning represents one form of scaffolding that is offered by group members to each other during the execution of learning tasks. Kirschner et al. (2009a) argued that assigning high complexity tasks to groups of learners allows information to be divided across a larger reservoir of cognitive capacity and might result in more effective and efficient learning than assigning them to an individual learner. However, if the task is simple, learning might be impaired as a result of group members' interaction as the discussion might impose an extraneous load that is not necessary for execution of a task that can be accomplished easily by independent work (Kirschner et al. 2009a). 
The current development of instruments that can be used at the end of teaching and learning sessions to measure the different types of cognitive load (Brunken et al. 2003; Leppink et al. 2013) has made the practice of exposing the students to cognitive overload educationally unjustified. Cognitive load measurements could be even of higher priority when new instructional methods like VPs are implemented or whenever there is a curriculum change that involves a new learning content. Therefore, it is important to investigate the most efficient way to integrate VPs in educational practice. Such practice would be most effective at managing learners' cognitive load and at the same time has the maximum effect on learner's performance.

Van Gog and Paas (2008) advocated that drawing conclusions about the efficiency of instructional methods emerges not only from test performance but also from cognitive load measurements during learning. In the same context, Leppink (2016) stated that interpretation of cognitive load measures in isolation from learning outcomes has no meaning in advocating specific instructional methods because lower cognitive load is not a goal in itself, but it should be reflected in better learning thus higher learning outcomes. Multiple studies used instructional efficiency measures to examine instructional efficiency in terms of the learning process, that is, combining the cognitive load investment during instructions with the test performance attained as a result of these instructions (Van Gog and Paas 2008).

The purpose of this study is to investigate the efficiency of instructional methods that involved three different applications of VPs combined with lectures. Our hypothesis is that collaborative use of VPs after the lecture (i.e. deductive) would be the most efficient instructional method when compared with independent use of VPs either before (i.e. inductive) or after the lecture.

\section{Method}

The study was conducted in a dental school over two consecutive academic years. The dental school involves two separate campuses for male students and female students. However, in the current study, all the teaching and learning sessions were conducted in the same classroom but at different times for the male and female students. The teaching and learning sessions targeted two topics, which are impacted wisdom teeth (Topic 1) and maxillofacial trauma (Topic 2) within the same course. 


\section{Participants}

All students who were registered in the oral and maxillofacial surgery course for the academic years commenced on 2015 (year 1) and 2016 (year 2) were invited to participate voluntary in the study $(N=183)$. The students were randomly assigned in year 1 into two different interventions, which are collaborative deductive $(n=49)$ and independent deductive year $1(n=47)$, while in year 2 ; they were randomly assigned into independent deductive $(n=43)$ and independent inductive $(n=44)$. Thus, for both years combined, $n=49$ for the collaborative deductive group, $n=90$ for the independent deductive group, and $n=44$ for the independent inductive group. The students are familiar with problem based learning as an instructional method. They practiced it along different courses in the curriculum. However, the most dominant instructional method in our curriculum is lectures.

\section{Materials}

\section{Teaching and learning sessions}

The teaching and learning sessions consisted of two parts: a lecture session, which was the same per topic for all groups, and a VP learning session which lasted for one hour and differs per group as follow:

Collaborative Deductive (CD) VP session: After the lecture, the students of year 1 were asked to work in groups of five students (single-gender groups) to discuss and take a collective decision for every question posed by the VPs, which were projected on the classroom screen using a data show projector. The role of the tutor was to facilitate the session by asking why specific decisions were taken, providing feedback, and finally operating the VP based on the decisions taken.

Independent Deductive (ID) VP session: After the lecture, each student of year 1 and 2 accessed the university E-learning management system and worked individually on the VPs. The role of the tutor was limited to monitor the students during their interaction with the VPs.

Independent Inductive (II) VP session: Before the lecture, each student of year 2 accessed the university E-learning management system and worked individually on the VPs in the same manner as in the independent deductive group. 
Lecture session: The same lecture was presented to all students. It was in the form of a PowerPoint presentation for 90 minutes with a 10-minutes break halfway. The lecture was designed to target diagnosis and treatment of different conditions including management of complications that might arise as a result of different surgical procedures. The lecture content and structure was revised by two subjectmatter experts, and was delivered by an expert faculty member to both the male and female groups.

\section{Virtual Patients}

Four VPs (two VPs per topic) were used in the VP learning activity sessions. The VPs had a branched-tree dynamic design, and were based on real patient scenarios. Real patient radiographs, lab results, intra-oral photos, and records for other special investigations were used at different stages of VPs path, while twodimensional graphics were used to represent different clinical settings, and different characters within the VPs (Appendix 1).

During practice, each VP branched based on student's choices on crucial decisions such as definitive diagnosis, selecting a specific surgical procedure, or admitting the patient to a hospital. The students selected each decision from a shortlist of options. If correct, the student (in ID and II) or students (in CD) stayed in the main VP path, while if wrong, the student/s followed the consequences of the decision taken till the next node and were then directed back to the main stream. The VP provided immediate feedback to the students on knowledge questions as either correct or incorrect, while the overall score, which was calculated based on the total number of correct answers, was displayed after the VP had been completed by students.

\section{Questionnaire}

The study applied the cognitive load questionnaire (Table 1) developed by Leppink et al. (2014). The questionnaire was applied in multiple previous studies to measure intrinsic, extraneous, and germane cognitive load (Tremblay et al. 2017). The questionnaire involves 13 items with 11-point (0-10) rating scales. The first 4 items measure intrinsic cognitive load (IL), items 5 to 8 measure extraneous cognitive load (EL), while the last 5 items measure germane load (GL). The items were adapted to our study by changing the word "activity" in the original questionnaire into "virtual 
patient activity" to refer specifically to the use of VPs. The scores for the three types of load were scaled so that each type of load ranged between 0 and 1 . 
Table 1: Cognitive load questionnaire by Leppink et al. (2014). All of the following questions refer to the VP activity that just finished. Please take your time to read each of the questions carefully and respond to each of them on a scale from 0 to 10 , in which " 0 " means not at all and " 10 " means completely the case.

1. The content of this VP activity was very complex.

2. The problem/s covered in this VP activity was/were very complex.

3. In this VP activity, very complex terms were mentioned.

4. I invested a very high mental effort in the complexity of this VP activity.

5. The explanations and instructions in this VP activity were very unclear.

6. The explanations and instructions in this VP activity were full of unclear language.

7. The explanations and instructions in this VP activity were, in terms of learning, very ineffective.

8. I invested a very high mental effort in unclear and ineffective explanations and instructions in this VP activity.

9. This VP activity really enhanced my understanding of the content that was covered.

10. This VP activity really enhanced my understanding of the problem/s that was/ were covered.

11. This VP activity really enhanced my knowledge of the terms that were mentioned.

12. This VP activity really enhanced my knowledge and understanding of how to deal with the problem/s covered.

13. I invested a very high mental effort during this VP activity in enhancing my knowledge and understanding.

\section{Knowledge Tests}

Three tests were delivered for each topic: A Knowledge Acquisition test (KA), a Knowledge Retention test (KR), and a Knowledge Transfer test (KT). KA and KR were paper-based tests that are similar in format, difficulty and number of items, while KT was a computer-based test that involved the use of four VPs (2 VPs for each of the two topics). Each test consisted of 18 to 25 Multiple Choice Questions (MCQs), in which each question involved 4 answer options. For the KA and KR tests, 
we used the same blueprint and difficulty selection. The items were retrieved from an item bank that involve items that were tested and used before. Furthermore, the tests as a whole were piloted on a group of similar students before using it in the study. Then, the items are subjected to improvement and revision (content validation) by a group of subject matter experts (Appendix 2). The internal consistency (Cronbach's alpha) of items of Topic 1 and 2 over the two years was higher than 0.7 .

The computer-based transfer tests KT involved two new VPs for each topic. Two independent subject matter experts validated the new VPs to ensure that they presented new situations that are relevant to the VPs used in the learning sessions. The students have independently taken the transfer test by logging in to their account on the university learning management system. The VP software did all scoring automatically.

\section{Procedure}

For Topic 1, the study involved the implementation of the lecture and VPs session as per the assigned groups. One month later, Topic 2 was presented in the same manner as the first topic. Student groups of year 1 that have been involved in CD session were asked to practice VPs independently and vice versa. The same applied to student groups of year 2, as those who have been involved in ID session in Topic 1 were now asked to practice the VPs before the lecture session in Topic 2 and vice versa.

Immediately after each VP session, participants were asked to complete the cognitive load questionnaire over 20 minutes. The questionnaire was delivered in its own original English version. The students handed the questionnaire back immediately after completing it. Confirmatory Factor Analysis (CFA) was applied to check to what extent the pre-validated questionnaire fits to the current context. It showed the following measures: $\mathrm{SRMR}=0.058, \mathrm{RMSEA}=0.071, \mathrm{CFI}=0.980, \mathrm{TLI}$ $=0.974$, which indicates a reasonable fit.

The KA tests for Topics 1 and 2 were delivered immediately after the lecture and VP sessions of Topic 1 and 2 respectively. The KR tests were unannounced and delivered two weeks after the immediate KA tests of Topic 1 and 2 respectively. The computer-based transfer tests KT for Topic 1 and 2 were delivered unannounced 
immediately after the retention tests. The results of the tests were displayed on the last screen at the end of the VP and were collected by the tutor.

Data collection and analysis

The college's statistical unit collected and tabulated the data in an Excel sheet. An expert biostatistician (second author) analyzed the data with the R statistical program (R Core Team 2017).

Mixed effect analysis of cognitive load and efficiency: In the linear mixed effect analyses using R (R Core Team 2017) and lme4 (Bates et al. 2014), group (treatment) and gender were taken as fixed effects, and the intercepts of topic (per study) and student as random effects. Interactions between gender and group were only included when significant. P-values were obtained by likelihood ratio tests of the full model with the effect in question against the model without the effect in question. Normality and homoscedasticity were checked for each model. AIC, conditional $\mathrm{R}^{2}$ and marginal $\mathrm{R}^{2}$ were obtained as measures of fit.

Efficiency (E) is computed by first computing z-scores of cognitive load (IL and EL) and test scores (KA, KR, KT) per study $\mathrm{x}$ topic (so in four parts). Z-scores are computed by taking the mean and SD and computing ( $\mathrm{x}-$ mean)/SD for each $\mathrm{x}$. The efficiency of each group is then computed by taking ( $z P-z L) /$ sqrt (2), where $z P$ is the z-score of the performance (test score) and $\mathrm{zL}$ is the $\mathrm{z}$-score of the cognitive load. In a system of axes, the efficiency of each group is thus computed as the shortest distance from a point in space to the line $\mathrm{zP}=\mathrm{zL}$ : if performance is higher than can be expected on the basis of cognitive load, efficiency is positive; if performance is lower than can be expected on the basis of cognitive load, efficiency is negative (for a full description of the computations, see Paas and Van Merriënboer 1993).

This resulted in 6 efficiency measures for the three different instructions (CD, ID, II) as follows: Efficiency intrinsic load \& KA (EILKA) = z KA - z IL/ sqrt (2). The same was applied to calculate the other efficiency measures: EELKA (extraneous load \& KA), EILKR (intrinsic load \& KR), EELKR (extraneous load \& KR), EILKT (intrinsic load \& KT), and EELKT (extraneous load \& KT). 


\section{Ethical approval}

The study was reviewed and approved by the University Ethical Committee. IRB number: IRB-2015-02-099.

\section{Results}

The study involved the participation of 171 out of 183 invited students (91 females, 80 males) yielding 320 data records (173 females, 147 males) as follow: 80 records in group $\mathrm{CD}, 156$ records in group ID, and 84 records in group II. The data record is the students' scores of KA, KR and KT tests of Topic 1 and/or Topic 2 in addition to a completely filled cognitive load questionnaire. There was a dropout of 22 data records due to incomplete data. There was no significant effect of the gender on students' scores and cognitive load scores.

The study showed that the highest IL and EL was found in the II group, while the lowest IL and EL was seen in the CD group (Figure 1). In regard to germane load, the highest was in the CD group, while the lowest was found in the II group. There was also a high correlation between IL and EL (0.704), and medium negative correlations between IL and GL (-0.491). The same was true for EL and GL (-0.422). The correlations between IL, EL and KA, KR scores are close to zero. IL correlates medium with KT (0.45), while EL has a lower correlation with KT (0.31). GL has medium correlation with KA (0.56) and KT (0.45) and lower correlation with KR $(0.22)$. 
IL, EL GL per Group
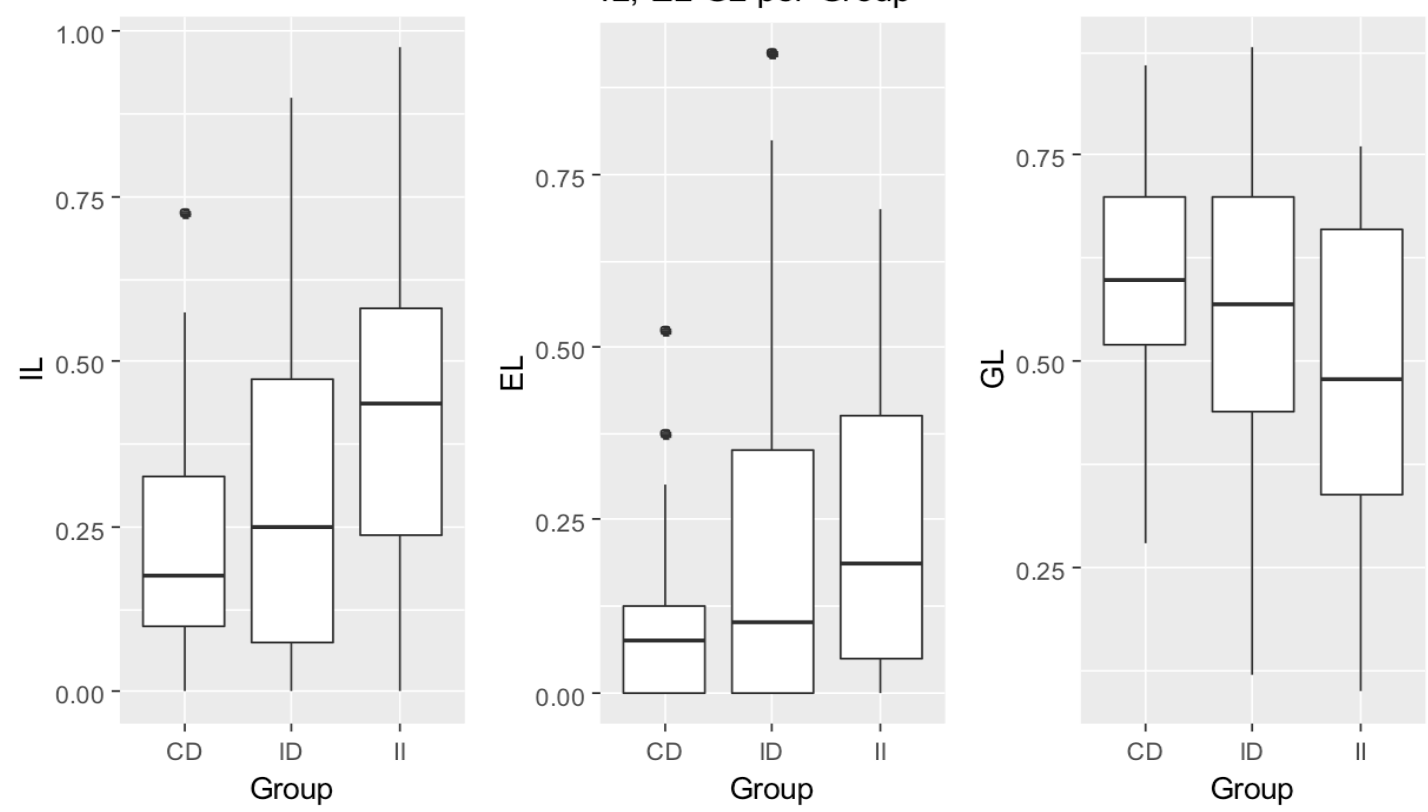

Figure 1: The invested cognitive load per group. IL: intrinsic load, EL: extraneous load, GL: germane load, CD: collaborative deductive, ID: independent deductive and II: independent inductive. 
The results of the six efficiency measures: EILKA, EELKA, EILKR, EELKR, EILKT, and EELKT are presented per group and gender in Figure 2. There is a general trend of higher scores for the CD group than for the ID and II groups.
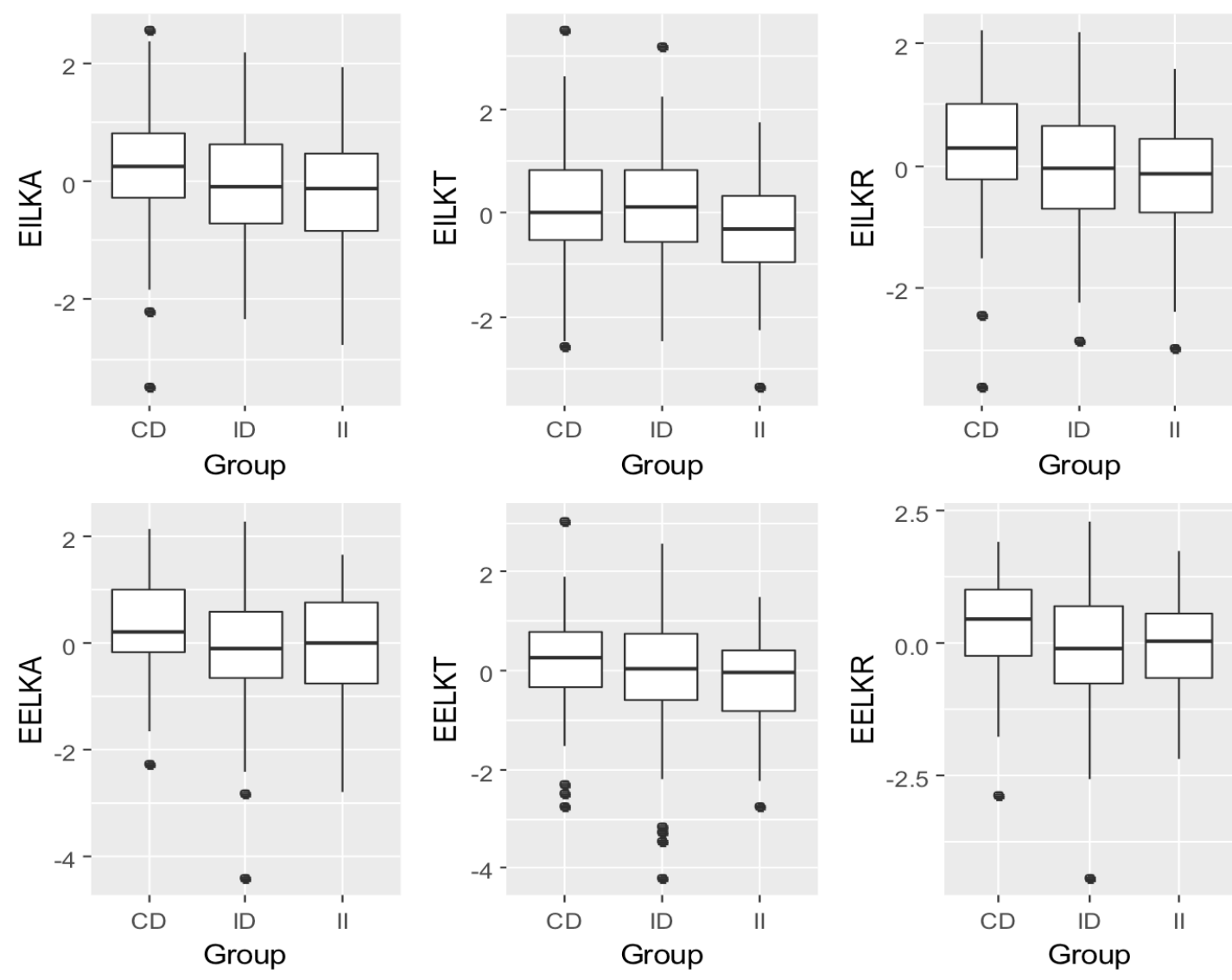

Figure 2: The efficiency of different instructions per group. KA: knowledge acquisition, KT: knowledge transfer and KR: knowledge retention.

Mixed effect analysis showed a significant change in IL, EL and GL when the CD learning approach is compared with both ID and II approaches. Comparing CD to ID resulted in a significantly higher IL $(0.116 \pm 0.026)$ and EL $(0.147 \pm 0.026)$, while a significantly lower GL $(-0.086 \pm 0.021)$ in the ID group. The same was true for comparing CD to II, as there was a significantly higher IL $(0.262 \pm 0.036)$ and EL $(0.230 \pm 0.035)$, while a significantly lower GL $(-0.202 \pm 0.029)$ in the II group (Table 2). The model fits for IL, EL and GL were reasonable (AICs were -188.2, 211.1 and -377.1 respectively, Marginal $R^{2} \mathrm{~s}$ were $0.14,0.14$ and 0.15 , conditional $\mathrm{R}^{2} \mathrm{~s}$ were $0.63,0.48,0.56$, respectively). 
Table 2: Comparison of instructional methods and effects on different types of cognitive load.

\begin{tabular}{|l|c|c|c|c|}
\hline & CD -> ID & CD -> II & Chi-sq, Df & $p$-value \\
\hline IL & $0.116 \pm 0.026$ & $0.262 \pm 0.036$ & $48.61,2$ & $<0.001 *$ \\
\hline EL & $0.147 \pm 0.026$ & $0.230 \pm 0.035$ & $39.89,2$ & $<0.001 *$ \\
\hline GL & $-0.086 \pm 0.021$ & $-0.202 \pm 0.029$ & $47.68,2$ & $<0.001 *$ \\
\hline
\end{tabular}

* Significant as $p$ value is $<0.05$.

There was a significant change in the efficiency of instruction when CD learning approach is compared with both ID and II approaches. Comparison of ID and CD showed a significantly higher efficiency for the CD group. The same effect was found when CD is compared to II (Table 3). The model fits for the efficiency measures were, however, not strong (AICs ranged from 881 to 929 , marginal $\mathrm{R}^{2} \mathrm{~S}$ between 0.08 and 0.14 , but conditional $\mathrm{R}^{2} \mathrm{~s}$ varied. For EELKA and EIKLA, conditional $\mathrm{R}^{2}$ was 0.44 and 0.49 , for the other measures, the conditional $\mathrm{R}^{2}$ ranged between 0.20 and 0.30 ).

Table 3: Comparison of instructional methods and effects on different scores of instructional efficiency.

\begin{tabular}{|l|c|c|c|c|}
\hline & CD -> ID & CD -> II & Chi-sq, Df & $p$-value \\
\hline EELKA & $-0.642 \pm 0.127$ & $-0.845 \pm 0.186$ & $18.13,2$ & $0.0012^{*}$ \\
\hline EILKA & $-0.503 \pm 0.131$ & $-0.913 \pm 0.178$ & $19.01,2$ & $0.0001^{*}$ \\
\hline EELKR & $-0.619 \pm 0.146$ & $-0.742 \pm 0.196$ & $14.10,2$ & $0.0008^{*}$ \\
\hline EILKR & $-0.501 \pm 0.141$ & $-0.835 \pm 0.189$ & $14.29,2$ & $0.0008^{*}$ \\
\hline EELKT & $-0.356 \pm 0.156$ & $-0.775 \pm 0.211$ & $8.59,2$ & $0.0136^{*}$ \\
\hline EILKT & $-0.227 \pm 0.156$ & $-0.848 \pm 0.212$ & $14.08,2$ & $0.0008^{*}$ \\
\hline
\end{tabular}

* Significant as $p$ value is $<0.05$.

\section{Discussion}

The current study investigated the efficiency of instructional methods that involved three different applications of VPs with lecture, which are collaborative deductive, independent deductive, and independent inductive.

The findings show that the collaborative deductive approach was the most efficient instructional design with significantly higher scores in knowledge acquisition, retention and transfer, as compared with independent deductive and 
independent inductive approaches. Furthermore, the collaborative deductive group experienced significantly lower intrinsic and extraneous load and higher germane load when compared to the independent deductive and independent inductive groups. Our results agree with previous work that showed an inverse relationship between transfer test performance and intrinsic and extraneous cognitive load for the students who learned in groups (Kirschner et al. 2009b).

It was mentioned that novice learners experienced a high cognitive load when handing complex tasks with several interacting elements (Van Merrienboer and Sweller 2010). However, such high cognitive load can be reduced by sharing it among learners as in the case of collaborative learning, because processing of information is divided across a larger reservoir of their cognitive capacity (Kirschner et al. 2009a). That is why collaborative learning, in our study, resulted in deeper processing of the information, more meaningful learning, and eventually better transfer of knowledge (Kirschner et al. 2009b). Therefore, our hypothesis is completely supported by the attained results.

Collaborative learning can take various forms such as in face-to-face problembased learning, or synchronous or asynchronous computer-mediated environments (Crook 1996). Our study involved students' collaboration while seated together in the classroom (face to face), but the virtual patient displayed by the computer data acted as a trigger for discussion. Working with computer-based simulated cases in small groups is not enough to increase the scope and depth of the elaboration of computer cases (de Leng et al. 2009). Tutors, therefore, should ensure the harmony among learners without having dominant or dormant members in the group.

Our study showed a significantly lower efficiency of an independent inductive learning approach on knowledge acquisition, retention and transfer. Such findings can be attributed to the high intrinsic load that was imposed on novice learners by complex VP problems. Previous studies showed that complex problems without any prior knowledge of the topic impose high load on working memory and leads to slow and inefficient learning (Clark et al. 2012). Moreover, the situation could be even worse if minimal guidance is provided to novice students, as was the case in the independent inductive approach (Kirschner et al. 2006). The amount of guidance, therefore, should be adjusted as per the expertise of the learner and the complexity of the given problem. 
Our findings might disagree with previous work by Alfieri et al. (2013). The authors in their study suggested that presenting principles and rules (theory) after case comparisons might better promote learning than presenting the principles before case comparisons. In case comparisons, the tutor asks the students to find similarities and differences between cases before encountering the theory. In our context, the students encounter patient problems (VPs) that require them to reach a diagnosis and treatment plan, which is different than finding similarities and differences between two worked examples. Therefore, deductive methods seem to be superior to inductive methods under some conditions but may be inferior under other conditions.

The study showed a negative correlation between intrinsic and extraneous load on one side and germane load on the other side. Such findings are consistent with the principles of cognitive load theory. Imposing high intrinsic and extraneous load results in leaving no or minimal cognitive resources. Working memory resources (germane load) are necessary to process elements related to previous tasks or to link knowledge already available in long-term memory with new knowledge leading to the construction of cognitive schemata (Van Merrienboer and Sweller 2010).

Our study is not without limitations. Due to the limited number of students per batch, we had to extend the study over two years on two different batches of students. Therefore, a complete randomization for all the students together was impossible to achieve. This probably also was a reason for not optimal fit in the models for the efficiency measures. The study has also hypothesized the inductive learning approach to presenting the VP (problem) before the lecture (direct instruction). In general, sequencing VP in an inductive or deductive approach should carry differences in the amount of guidance and complexity of both the VP and the lecture to optimally scaffold learning. However, our aim was to ensure consistency in the presented content between the inductive and deductive groups. Furthermore, the collaborative deductive method involved a tutor, which might be counted as a variable that is not present in the other two groups. However, we cannot isolate the tutor from the collaborative activity as it represents one of the elements of the collaborative activity in our context. The tutor role was more as a facilitator of the collaborative session than being a knowledge provider.

The study has provided some practical implications for both medical teachers and VPs designers. For medical teachers, the study has shown that the most efficient 
instructional method is a collaborative deductive approach: first present relevant theory in a lecture and then let students work collaboratively with the virtual patients. The study has confirmed previous work grounded on cognitive load theory that declared the significance of adapting the amount of guidance based on the complexity of the provided problem and the experience of the learners. Furthermore, the study has shown that any future selection of instructional methods involving VPs should consider a cognitive load measurement, as some VPs applications might be detrimental to learning.

The study has also provided a practical implication in regard to VPs design specificity: the VP design should be customized during development based on its intended use by the teacher and students. VP designers should ask medical teachers "how they are going to use the VPs?" before commencing the development process. A collaborative use of VPs requires a more complex design to trigger discussion and reflection during use, while an inductive independent use of VPs requires relatively simple VPs that are able to stimulate rather than hinder learners to close knowledge gaps that might have arisen during VP practice.

\section{Conclusion}

Collaborative use of VPs after a lecture is the most efficient instructional method, of those tested, as it leads to better learning and transfer combined with lower cognitive load, when compared with independent use of VPs, either before or after the lecture.

\section{Practice Points}

1. The relevant theory should be presented first and then followed by a collaborative use of VPs.

2. Future selection of instructional methods involving VPs should consider a cognitive load measurement, as some VPs applications might be detrimental to learning.

3. The amount of guidance offered during VPs practice should be based on the complexity of the provided problem and the experience of the learners.

4. The intended use of VPs should be incorporated and considered during the initial stages of VPs development. 


\section{References}

Alfieri L, Nokes-Malach T, \& Schunn C. 2013. Learning through case comparisons: A meta-analytic review. Educational Psychologist, 48(2): 87-113.

Bateman J, Allen M, Samani D, Kidd J, Davies D. 2013. Virtual patient design: Exploring what works and why. A grounded theory study. Medical education. 47(6):595-606.

Bates D, Mächler M, Bolker B, Walker S. 2014. Fitting linear mixed-effects models using lme4. arXiv preprint arXiv:14065823.

Berman N, Fall LH, Smith S, Levine DA, Maloney CG, Potts M, Siegel B, FosterJohnson L. 2009. Integration strategies for using virtual patients in clinical clerkships. Academic medicine : journal of the Association of American Medical Colleges. 84(7):942-949.

Brunken R, Plass JL, Leutner D. 2003. Direct measurement of cognitive load in multimedia learning. Educational Psychologist. 38(1):53-61.

Clark R, Kirschner PA, Sweller J. 2012. Putting students on the path to learning: The case for fully guided instruction. American Educ 36(1), 6-11.

Crook C. 1996. Computers and the collaborative experience of learning. Psychology Press.

de Leng BA, Muijtjens AM, van der Vleuten CP. 2009. The effect of face-to-face collaborative learning on the elaboration of computer-based simulated cases. Simulation in Healthcare. 4(4):217-222.

Edelbring S, Brostrom O, Henriksson P, Vassiliou D, Spaak J, Dahlgren LO, Fors U, Zary N. 2012. Integrating virtual patients into courses: Follow-up seminars and perceived benefit. Medical education. 46(4):417-425.

Ellaway, R., Candler, C., Greene, P., \& Smothers, V. 2006. An architectural model for medbiquitous virtual patients. Medbiquitous, baltimore. 2006. [accessed 2016/10/04].

http://groups.medbiq.org/medbiq/display/VPWG/Architecture+documents.

Ellaway R, Davies D. 2011. Design for learning: Deconstructing virtual patient activities. Medical teacher. 33(4):303-310.

Ellaway R, Topps D, Lee S, Armson H. 2015. Virtual patient activity patterns for clinical learning. Clinic Teach. 12(4):267-271. 
Huwendiek S, Duncker C, Reichert F, De Leng BA, Dolmans D, van der Vleuten CP, Haag M, Hoffmann GF, Tonshoff B. 2013. Learner preferences regarding integrating, sequencing and aligning virtual patients with other activities in the undergraduate medical curriculum: A focus group study. Med Teach. 35(11):920-929.

Huwendiek S, Reichert F, Bosse HM, de Leng BA, van der Vleuten CP, Haag M, Hoffmann GF, Tonshoff B. 2009. Design principles for virtual patients: A focus group study among students. Medical education. 43(6):580-588.

Kirschner F, Paas F, Kirschner PA. 2009a. A cognitive load approach to collaborative learning: United brains for complex tasks. Educational Psychology Review. 21(1):31-42

Kirschner F, Paas F, Kirschner PA. 2009b. Individual and group-based learning from complex cognitive tasks: Effects on retention and transfer efficiency. Computers in Human Behavior. 25(2):306-314.

Kirschner PA, Sweller J, Clark RE. 2006. Why minimal guidance during instruction does not work: An analysis of the failure of constructivist, discovery, problembased, experiential, and inquiry-based teaching. Educ psychol. 41(2):75-86.

Leppink J. 2016. Cognitive load measures mainly have meaning when they are combined with learning outcome measures. Medical education. 50(9):979.

Leppink J, Paas F, Van der Vleuten CP, Van Gog T, Van Merrienboer JJ. 2013. Development of an instrument for measuring different types of cognitive load. Behavior research methods. 45(4):1058-1072.

Leppink J, Paas F, van Gog T, van der Vleuten CPM, van Merriënboer JJG. 2014. Effects of pairs of problems and examples on task performance and different types of cognitive load. Learning and Instruction. 30(Supplement C):32-42.

Marei HF, Donkers J, Al-Eraky MM, van Merrienboer JJG. 2017. The effectiveness of sequencing virtual patients with lectures in a deductive or inductive learning approach. Medical teacher.1-7.

Paas FG, Van Merriënboer JJ. 1993. The efficiency of instructional conditions: An approach to combine mental effort and performance measures. Human factors. 35(4):737-743.

Team RC. 2017. A language and environment for statistical computing. R foundation for statistical computing, 2012. 
Tremblay ML, Lafleur A, Leppink J, Dolmans DH. 2017. The simulated clinical environment: Cognitive and emotional impact among undergraduates. Medical teacher. 39(2):181-187.

Van Gog T, Paas F. 2008. Instructional efficiency: Revisiting the original construct in educational research. Educational Psychologist. 43(1):16-26.

Van Merrienboer JJ, Sweller J. 2010. Cognitive load theory in health professional education: Design principles and strategies. Med Educ. 44(1):85-93.

Van Merrienboer JJG, Kirschner PA. 2018 Ten steps to complex learning ( $3^{\text {rd }}$ Rev. Ed.). New York, Routledge.

Vandewaetere M, Manhaeve D, Aertgeerts B, Clarebout G, Van Merrienboer JJ, Roex A. 2014. 4c/id in medical education: How to design an educational program based on whole-task learning: Amee guide no. 93. Med Teach.1-17.

Young JQ, Van Merrienboer J, Durning S, Ten Cate O. 2014. Cognitive load theory: Implications for medical education: Amee guide no. 86. Med Teach. 36(5):371-384. 


\section{Appendix1}

\begin{tabular}{|c|c|c|c|}
\hline Category & Factor & $\mathbf{1}^{\text {st }} \mathrm{VP}$ & $2^{\text {nd }} V P$ \\
\hline \multirow[t]{6}{*}{ General } & Title & Impacted wisdom teeth & $\begin{array}{l}\text { Impacted wisdom tooth } \\
\text { with a cystic lesion }\end{array}$ \\
\hline & Description & $\begin{array}{l}22 \text { years old female patient } \\
\text { presented with pain relevant to } \\
\text { her impacted wisdom teeth. }\end{array}$ & $\begin{array}{l}45 \text { years old male patient } \\
\text { presented for replacing his } \\
\text { multiple missing teeth. An } \\
\text { impacted wisdom tooth } \\
\text { with a cystic lesion was } \\
\text { incidentally discovered. }\end{array}$ \\
\hline & Language & \multicolumn{2}{|c|}{ English } \\
\hline & Identifier & VP002 & VP003 \\
\hline & Provenance & \multicolumn{2}{|c|}{ Marei HF, College of Dentistry, University of Dammam } \\
\hline & $\begin{array}{c}\text { Typical } \\
\text { study time }\end{array}$ & 20 minutes & 30 minutes \\
\hline \multirow[t]{4}{*}{ Educational } & $\begin{array}{c}\text { Educational } \\
\text { level }\end{array}$ & \multicolumn{2}{|c|}{ Undergraduates $4^{\text {th }}-5^{\text {th }}$ year dental students } \\
\hline & $\begin{array}{c}\text { Educational } \\
\text { modes }\end{array}$ & \multicolumn{2}{|c|}{ Learning and formative assessment } \\
\hline & Coverage & \multicolumn{2}{|c|}{ Oral and maxillofacial surgery - Impacted teeth } \\
\hline & $\begin{array}{l}\text { Objectives } \\
\text { and } \\
\text { outcomes }\end{array}$ & $\begin{array}{l}\text { 1. Formulate a treatment plan } \\
\text { for a patient with impacted } \\
\text { wisdom teeth. } \\
\text { 2. Identify the risk associated } \\
\text { with surgical removal of } \\
\text { impacted wisdom teeth. } \\
\text { 3. Identify factors that should } \\
\text { be considered for better } \\
\text { surgical outcomes. }\end{array}$ & $\begin{array}{l}\text { 1. Diagnose a patient with } \\
\text { a problem relevant to } \\
\text { impacted wisdom teeth. } \\
\text { 2. Classify impacted } \\
\text { wisdom teeth. } \\
\text { 3. Identify the risk } \\
\text { associated with surgical } \\
\text { removal of impacted } \\
\text { wisdom teeth. } \\
\text { 4.Identify and manage }\end{array}$ \\
\hline
\end{tabular}




\begin{tabular}{|c|c|c|c|}
\hline & & & $\begin{array}{l}\text { complications associated } \\
\text { with surgical removal of } \\
\text { impacted teeth. }\end{array}$ \\
\hline \multirow{6}{*}{$\begin{array}{c}\text { Instructional } \\
\text { design }\end{array}$} & Path type & \multicolumn{2}{|c|}{ Branching ends at two different nodes } \\
\hline & $\begin{array}{c}\text { User } \\
\text { modality }\end{array}$ & \multicolumn{2}{|c|}{$\begin{array}{l}\text { Single user plays the role of a general dentist in the dental } \\
\text { office }\end{array}$} \\
\hline & $\begin{array}{c}\text { Media } \\
\text { resources }\end{array}$ & \multicolumn{2}{|c|}{ Text, images, video, and sound } \\
\hline & $\begin{array}{c}\text { Narrative } \\
\text { use and } \\
\text { patient } \\
\text { focus }\end{array}$ & \multicolumn{2}{|c|}{$\begin{array}{l}\text { Told from the patient's voices, while the decision taken are } \\
\text { told from dentist's voices }\end{array}$} \\
\hline & $\begin{array}{c}\text { Interactive } \\
\text { use }\end{array}$ & $\begin{array}{l}\text { Clickable text options for the } \\
\text { different decision points in the } \\
\text { scenario and Multiple choice } \\
\text { questions - Overall number of } \\
\text { cognitive interactions: } 12\end{array}$ & $\begin{array}{l}\text { Clickable text options for } \\
\text { the different decision } \\
\text { points in the scenario and } \\
\text { Multiple choice questions - } \\
\text { Overall number of } \\
\text { cognitive interactions: } 25\end{array}$ \\
\hline & $\begin{array}{l}\text { Feedback } \\
\text { use }\end{array}$ & $\begin{array}{l}\text { Feedback is given to each } \\
\text { decision by displaying text. A } \\
\text { reason why a decision is } \\
\text { wrong is provided. Feedback } \\
\text { is provided immediately and } \\
\text { statistically summarized at the } \\
\text { end of the VP. }\end{array}$ & $\begin{array}{c}\text { Feedback is not given. } \\
\text { Only score at the end of the } \\
\text { VP. }\end{array}$ \\
\hline \multirow[t]{3}{*}{ Technical } & $\begin{array}{l}\text { Operating } \\
\text { system }\end{array}$ & \multicolumn{2}{|c|}{ Disc-based media } \\
\hline & Format & \multicolumn{2}{|c|}{$\begin{array}{l}\text { SCORM package for uploading on LMS and } \\
\text { Application/EXE for disc-based media. }\end{array}$} \\
\hline & $\begin{array}{l}\text { Integration } \\
\text { and } \\
\text { dependence }\end{array}$ & \multicolumn{2}{|c|}{ Requires Windows to run as an independent application } \\
\hline
\end{tabular}




\begin{tabular}{|c|c|c|c|}
\hline Category & Factor & $3^{\text {rd }} \mathbf{V P}$ & $4^{\text {th }} V P$ \\
\hline \multirow[t]{6}{*}{ General } & Title & Maxillofacial Trauma 1 & Maxillofacial Trauma 2 \\
\hline & Description & $\begin{array}{l}\text { A road traffic accident } \\
\text { resulted in } 3 \text { injured patients }\end{array}$ & $\begin{array}{c}\text { A road traffic accident } \\
\text { resulted in } 2 \text { injured } \\
\text { patients }\end{array}$ \\
\hline & Language & \multicolumn{2}{|c|}{ English } \\
\hline & Identifier & VP004 & VP005 \\
\hline & Provenance & \multicolumn{2}{|c|}{ Marei HF, College of Dentistry, University of Dammam } \\
\hline & $\begin{array}{c}\text { Typical } \\
\text { study time }\end{array}$ & 30 minutes & 30 minutes \\
\hline \multirow[t]{4}{*}{ Educational } & $\begin{array}{c}\text { Educational } \\
\text { level }\end{array}$ & \multicolumn{2}{|c|}{ Undergraduates $4^{\text {th }}-5^{\text {th }}$ year dental students } \\
\hline & $\begin{array}{c}\text { Educational } \\
\text { modes }\end{array}$ & \multicolumn{2}{|c|}{ Learning and formative assessment } \\
\hline & Coverage & \multicolumn{2}{|c|}{ Oral and maxillofacial surgery - Maxillofacial Trauma } \\
\hline & $\begin{array}{l}\text { Objectives } \\
\text { and } \\
\text { outcomes }\end{array}$ & $\begin{array}{l}\text { 1. Diagnose different } \\
\text { maxillofacial fractures. } \\
\text { 2.Request the most } \\
\text { appropriate radiographs for } \\
\text { trauma patients. } \\
\text { 3.Formulate an appropriate } \\
\text { treatment plan for patient with } \\
\text { different maxillofacial } \\
\text { injuries. risks and } \\
\text { 4.Recognize different } \\
\text { complications of } \\
\text { surgical procedures. }\end{array}$ & $\begin{array}{l}\text { 1. Diagnose different } \\
\text { maxillofacial fractures. } \\
\text { 2.Request the most } \\
\text { appropriate radiographs for } \\
\text { trauma patients. } \\
\text { 3.Formulate an appropriate } \\
\text { treatment plan for patient } \\
\text { with different maxillofacial } \\
\text { injuries. } \\
\text { 4.Recognize risks and } \\
\text { complications of different } \\
\text { surgical procedures. }\end{array}$ \\
\hline Instructional & Path type & \multicolumn{2}{|c|}{ Branching ends at one end node } \\
\hline design & $\begin{array}{c}\text { User } \\
\text { modality }\end{array}$ & \multicolumn{2}{|c|}{$\begin{array}{l}\text { Single user plays the role of a general dentist in the } \\
\text { emergency department }\end{array}$} \\
\hline
\end{tabular}




\begin{tabular}{|c|c|c|c|}
\hline & $\begin{array}{c}\text { Media } \\
\text { resources }\end{array}$ & \multicolumn{2}{|c|}{ Text, images, video, and sound } \\
\hline & $\begin{array}{l}\text { Narrative } \\
\text { use and } \\
\text { patient } \\
\text { focus }\end{array}$ & \multicolumn{2}{|c|}{$\begin{array}{l}\text { Told from the patient's voices, while the decision taken are } \\
\text { told from dentist's voices }\end{array}$} \\
\hline & $\begin{array}{c}\text { Interactive } \\
\text { use }\end{array}$ & $\begin{array}{l}\text { Clickable text options for the } \\
\text { different decision points in the } \\
\text { scenario and Multiple choice } \\
\text { questions - Overall number of } \\
\text { cognitive interactions: } 25\end{array}$ & $\begin{array}{l}\text { Clickable text options for } \\
\text { the different decision } \\
\text { points in the scenario and } \\
\text { Multiple choice questions - } \\
\text { Overall number of } \\
\text { cognitive interactions: } 25\end{array}$ \\
\hline & $\begin{array}{c}\text { Feedback } \\
\text { use }\end{array}$ & $\begin{array}{c}\text { Feedback is given to each } \\
\text { decision by displaying text. A } \\
\text { Feedback is provided } \\
\text { immediately and statistically } \\
\text { summarized at the end of the } \\
\text { VP. }\end{array}$ & $\begin{array}{l}\text { Feedback is not given. } \\
\text { Only score at the end of the } \\
\text { VP. }\end{array}$ \\
\hline Technical & $\begin{array}{l}\text { Operating } \\
\text { system }\end{array}$ & \multicolumn{2}{|c|}{ Disc-based media } \\
\hline & Format & \multicolumn{2}{|c|}{$\begin{array}{l}\text { SCORM package for uploading on LMS and } \\
\text { Application/EXE for disc-based media. }\end{array}$} \\
\hline & $\begin{array}{c}\text { Integration } \\
\text { and } \\
\text { dependence }\end{array}$ & \multicolumn{2}{|c|}{ Requires Windows to run as an independent application } \\
\hline
\end{tabular}




\section{Appendix 2}

1. Which of the following characteristics would indicate a disease free wisdom tooth?
A. Frequent history of percoronitis.
B. Probing depth of $3 \mathrm{~mm}$ mesial to the tooth.
C. Absence of attached gingiva around the tooth.
D. Enlarged tooth follicle

2. Based on the best scientific evidence, which of the following strategies are more helpful in operative management of impacted third molars?

A. Performing envelope flap without vertical releasing incision posterior to the second molar.

B. Chlorhexidine mouthwash on the day of surgery only.

C. Prophylactic antibiotics for 2 days preoperative.

D. Prophylactic antibiotics immediately before the surgery.

3. 22 years old patient, who is medically fit and well presented with facial swelling 3 days following surgical removal of disto-angular impacted wisdom tooth. Clinical examination shows normal looking mucosa, trismus, and soft edematous swelling. The patient is already taking Amoxicillin 500mg TID since the operation. The best management for this patient is:
A. Change the antibiotic to Metronidazole.
B. Double the dose of the antibiotic.
C. Arrange for a review appointment after 5 days
D. Curettage of the socket.

4. Direct trauma to the left side of angle would result in left angle fracture and most properly a contralateral fracture at:
A. Left body
B. Left subcondylar
C. Right subcondylar
D. Right coronoid

5. 15 years old male patient presented with pain and tenderness following right subcondylar fracture. Which of the following signs could be found during clinical examination?
A. Anterior open bite deformity
B. Deviation of the mandible during opening toward the right side
C. Deviation of the mandible during opening toward the left side
D. No Deviation during opening the mouth

6. 6 years child presented with pain and tenderness related to the right joint. CT showed intra-capsular condylar fracture. Which of the following is the best treatment option?
A. Open reduction and internal fixation of the fractured segments.
B. Closed reduction and IMF for 4 weeks.
C. Conservative treatment that involves pain killer, soft diet, follow up.
D. Closed reduction and IMF for 10 days. 
Chapter 6: General discussion 
This final chapter consists of four sections, namely: (1) contributions of our thesis to the different learning theories the reported studies were based on, (2) strengths and limitations of the studies reported in the thesis, (3) practical implications in the form of messages to stakeholders, and, finally, (4) the main conclusion.

\section{Contributions to Learning Theories}

The aim of this thesis was to provide a rational on how to effectively integrate VPs in a curriculum. VPs are an expensive E-learning simulation tool that requires for its development a great effort, time investment and collaboration between faculty members. Therefore, it is crucial to know how to use such tools in order to achieve the intended learning outcomes, while respecting learners' preferences. Multiple studies evaluated the use of VPs, and they have reported that their use and integration within a curriculum is subjected to many moderating variables, such as: (a) design features of VPs to make them engaging to learners (Botezatu, Hult, \& Fors, 2010; Huwendiek, Reichert, et al., 2009), (b) learners' acceptance of specific VP integration scenarios (Edelbring et al., 2012; Huwendiek et al., 2013), (c) reported effectiveness of VPs in comparison with other instructional methods with regard to specific learning outcomes (Botezatu, Hult, Tessma, \& Fors, 2010; Cook, Erwin, \& Triola, 2010; Cook \& Triola, 2009), (d) the reported effectiveness of different VP integration scenarios in comparison with one another (T. Johnson et al., 2014), (e) awareness and extent of internal motivation of faculty members towards developing VPs (Botezatu, Hult, Kassaye Tessma, \& Fors, 2010; Round, Conradi, \& Poulton, 2009), and (f) the level of support offered by decision makers, education leaders and administrators to medical teachers, who are designing and sharing VPs (Cook \& Triola, 2009).

The current thesis was concerned with the effect of different VP integration scenarios on knowledge acquisition, retention and transfer. Furthermore, one study in this thesis evaluated the integration of VPs with respect to teaching and learning professionalism. The design of different interventions within our thesis was based on three main learning theories, which are social-constructivist theory, situated learning theory, and cognitive load theory. 


\section{Contributions to Social-Constructivist Theory}

Social-constructivist theories were the pillar for designing our instructional interventions in Studies 1 and 2. Social-constructivism advocates that learning is not only linking new knowledge to old knowledge for schema construction to occur, but also requires interaction among learners and between learners and tutors when they tackle a problem or perform a learning task (Colliver, 2002; Gokhale, 1995; Philpott \& Batty, 2009). Such interaction allows students with high abilities to provide scaffolding to students with lower abilities. It has been documented that low abilitystudents can only cross the zone of proximal development (ZPD) when help and scaffolding are provided at the appropriate time, either by peer learners or by a tutor. ZPD is the difference between what a learner can do without help and what he or she can do with help (Vygotsky, 1980).

Study 1 hypothesized that the use of VPs in a collaborative learning activity would be more effective than its use as an independent, individual learning activity. Our hypothesis was partially supported, as the higher effectiveness of collaborative learning was only found in the female campus. Our results were consistent with $\mathrm{T}$. Johnson et al. (2014) study, who found students who interacted with VPs as members of three-person teams correctly diagnosed cranial nerve palsies more often than did students who interacted with VPs as individuals.

Our study was different from T. Johnson's et al. (2014) study with regard to the group composition, due to the cultural background of our study setting. Our study involved single-gender group, while the other study involved mixed gender groups. It has been reported in the literature that heterogeneous groups with respect to learners' abilities, gender, socio-economic status, and race lead to greater degrees of elaborative thinking, providing and receiving explanations, and perspective taking in discussing the problem, which leads to deeper understanding, better reasoning abilities, and accuracy in long-term retention (D. Johnson \& Johnson, 1987). Future studies might investigate differences in patterns of communication and collaboration between single-gender groups versus mixed-gender groups.

The message that we would like to convey from Study 1 is that the collaborative use of VPs by itself is not enough to produce consistent results among different groups of students. We anticipate that consistent results in Study 1 between the male and female campus might have been achieved if structuring of different 
groups in the male campus was conductive to students' interaction. Having high ability-male students with low ability-male students in the same group might have provided a positive effect of collaborative practice in the male campus. Secondly, composing student groups based on their self-efficacy (students' beliefs about their capability to perform a task) might have even provided larger differences in scores in favor of collaborative practice. It was reported that high self-efficacy groups use more high-level cognitive skills in group discussion than low self-efficacy groups, which is reflected positively on discussion behaviors and group performance (Wang \& Lin, 2007). Therefore, future studies investigating collaborative VP practice might intentionally compose student groups in a way that considers different factors affecting collaborative learning.

Other than group composition, the complexity of the problems provided in the VPs might be another factor that could have influenced group discussion and student interactions. VPs of Topic 1 were much easier than VPs of Topic 2. Stimulation of discussion, debates and reflection on different choices (decision points/nodes) are reinforced when collaborative learning is applied to ill-structured, complex tasks embedded in an authentic context (Jonassen, 1994). Ill-structured problems are problems that contain unknown elements, have multiple acceptable solutions (or no solution at all), possess multiple criteria for evaluating solutions, and often require learners to make judgments (Van Merrienboer, 2013). Solving ill-structured problems requires the interpretation of domain knowledge and/or previously encountered cases to come up with possible solution steps. Such a method of problem solving is known as a knowledge-based method. It allows one to solve problems in a particular domain of learning but does not guarantee that an acceptable solution is reached (Van Merrienboer, 2013).

On the other side, well-structured problems that have only one correct answer can be solved by strong problem-solving methods, that is, the straightforward application of rules under appropriate conditions (Van Merrienboer, 2013). Therefore, well-structured problems, in contrast to ill-structured problems, might more easily allow learners to think independently and apply rules in isolation of other members of the group. Though group work on a well structured problems may be tagged as collaborative, such practice is not really collaborative in the social-constructivist meaning because it lacks any social interaction (Kreijns, Kirschner, \& Jochems, 
2003). Therefore, we could benefit from future research that compares between collaborative and independent VP practice, when VPs are based on either challenging ill-structured problems or more straightforward well-structured problems.

In Study 2, we found no difference between the deductive and inductive learning approaches on knowledge acquisition, retention and transfer. The inductive approach involved a presentation of a problem followed by direct instruction (i.e., a lecture). The lecture covered both the knowledge gaps and the areas that were known to students and did not give students the chance to search the literature and integrate knowledge from different resources, which might lead to deeper learning. Therefore, the lecture in our context can be considered as direct instruction rather than a scaffolding tool helping students with deep learning. Schwartz and Bransford (1998) advocated that lectures that provide on-time scaffolding are more helpful for students, and hence were more meaningful than similar lectures presented not as scaffolding for inquiry but as direct instruction. Future studies that investigate the use of VPs in an inductive approach should provide learners the opportunity to generate their own learning objectives after the VP session. The tutor should discuss these learning objectives with the students in order to discover the knowledge gaps that need to be targeted by just-in-time instruction. It has been reported that just-in-time direct instruction promotes knowledge construction in a way that makes knowledge available for future use in relevant contexts (Edelson, 2001).

\section{Contributions to Situated Learning Theory}

In Study 3, the students perceived the use of VPs as part of a collaborative activity as an effective tool for the development of ethical reasoning skills. Students' perception was aligned with the principles of situated learning theory, which represents the cornerstone in designing instructions on professionalism (Birden et al., 2013). The study suggested that VPs intended for teaching professionalism need to have high physical and functional fidelity, follow a specific dramatic structure and should include multiple plausible endings to match the complexity of the nature of professionalism, where usually there is no one correct answer or decision.

Students' preferences in Study 3 were consistent with those of previous studies (Botezatu, Hult, Kassaye Tessma, et al., 2010; Huwendiek, Reichert, et al., 2009), which showed a student preference for VPs that are interactive, rich in media, 
authentic, have appropriate difficulty and are based on real-life scenarios relevant to their future practice. In our study, we intentionally recruited senior students, who were able to be engaged in social interactions and reflective sessions during and after VP encounters. Al-Eraky (2015) advocated that the capacity of learners to internalize professional values and reflect on experience varies according to their educational stages and professional maturity. Therefore, learners at early years would appreciate VPs that focus mainly on knowledge acquisition with respect to the codes of ethics, while more mature learners would benefit more from VPs that present situations in which there is no clear cut between correct and wrong answers, which could stimulate their reflection on the advantages and limitations of different courses of action (Murphy S, Imam B, \& Whitehouse L, 2016).

Study 3 added two new features to VP design, especially when VPs are used for teaching professionalism, which are the dramatic structure and the nature of the ending. The dramatic structure has been previously described by Reeve (2009) in serious game development, where he advocated that the good narrative of a game reinforces engagement and encourages longer involvement in the learning process. Therefore, it is crucial to maintain a balance between storytelling and the free exploratory activity in order to keep the learner actions integral to the story. Others advocated that the VPs should not be designed to focus directly on professionalism dilemmas, as the dilemmas have to be incorporated in the whole scenario as one step toward the comprehensive treatment of the patient. In other words, if the learning objective of a VP is to show the student how to consent a patient before surgery, the consenting process should be incorporated in the VP as a step in the treatment plan rather than being the main focus (Murphy S et al., 2016). The second feature in the VP design for professionalism is about the nature of the ending. Ethical dilemmas should have more than one correct answer and this needs to be reflected in a set of possible endings (Al-Eraky, Donkers, Wajid, \& Van Merrienboer, 2015)

Our findings of Study 1 with regard to the effectiveness of collaborative practice of VPs on knowledge transfer suggest that the same positive results of collaboration could be reached when learning ethical reasoning skills, especially after our findings of Study 3 that showed the high acceptance of students to the use of VPs as a driver for collaboration, interaction and reflection. When future studies investigate the effectiveness of the collaborative learning approach on learning ethical 
reasoning skills, not only social constructivism but also situated learning theories should be considered. Designing the instructional interventions should involve VPs that are based on ill-structured problems to stimulate more social interactions, richer discussion and suggestions in the reflection session. Furthermore, authenticity of the problems could be increased by providing ethical dilemmas within the broader context of clinical problems rather than being the main focus of the VP scenarios.

\section{Contributions to Cognitive Load Theory}

Study 4 hypothesized that the collaborative deductive learning approach is the most efficient instructional approach when compared with the other two learning approaches, namely: independent deductive and independent inductive. Our hypothesis was fully supported by the attained results, as the collaborative deductive group experienced significantly lower intrinsic and extraneous load and higher germane load when compared to the independent deductive and independent inductive groups. Such cognitive load was reflected positively on students' scores in different tests. Our results were consistent with the principles of cognitive load theory (Young, Van Merrienboer, Durning, \& Ten Cate, 2014), and previous work that showed an inverse relationship between transfer test performance and intrinsic and extraneous cognitive load for students who were involved in collaborative learning (Kirschner, Paas, \& Kirschner, 2009b).

The results of Study 4 can be explained by cognitive load theory and social constructivism. Reducing the cognitive load during VP practice was a mean to allow students to process and link new information generated by their interaction and discussion during their collaborative practice to already constructed schemas.

The collaborative deductive learning approach has offered the learners two ways for taking the load off their working memory. The first was obtaining the supportive information from the lecture and encoding it in schemas in long-term memory so that it could be subsequently activated in working memory when needed to perform the task, which is working on the VP (Van Merrienboer \& Kirschner, 2018). Supportive information is typically complex in nature, as it involves multiple elements and high interactivity between these elements. High-complexity information should preferably be delivered before the learning task, as it imposes a high cognitive 
load if delivered during task performance (Van Merrienboer, Kirschner, \& Kester, 2003).

The second way to decrease cognitive load was the division of information processing across a larger reservoir of 'collective' working memory, leading to lower load per learner (Kirschner, Paas, \& Kirschner, 2009a). For each individual learner, this relieved processing capacity for deeper processing of information and eventually better transfer of knowledge (Kirschner et al., 2009b).

Also in line with social-constructivist learning theory, lower load per learner in the collaborative deductive group might have helped students to construct richer cognitive schemas during VP practice. Taking-off the cognitive load through managing the gained information by two ways in collaborative deductive learning was more efficient than doing it in only one way in independent deductive learning, or not doing it all in independent inductive learning. Future studies might link students' scores with cognitive load measurements during assessment rather than during learning using new VPs or real patients. Such investigations could explore the richness of cognitive schemas as a result of different instructional interventions.

\section{Strengths and Limitations}

The current thesis has salient qualities, but not without limitations. To the best of our knowledge, this is the first comprehensive study on the integration of VPs in undergraduate dental education. Furthermore, the thesis has investigated VP design with relevance to teaching professionalism, which is rarely examined in the dental education literature. The studies recruited undergraduate dental students across three consecutive batches. Randomization of students to different groups was implemented in Studies 1 and 2, although it was not possible to combine male and female students. Students of each gender were randomly distributed to two groups, each of which has practiced the two different interventions implemented on every batch of students. Furthermore, we managed to overcome the logistic barriers with respect to division of students in two separate campuses and schedule the sessions within their busy schedule. Yet, to generalize our results of VP integration to different cultures, future studies could investigate the integration of VPs with gender-mixed groups using more advanced assessments tools such as assessing the students' knowledge transfer to real patient encounters. 
The thesis has examined three VP integration scenarios only, namely: collaborative deductive, independent deductive, and independent inductive. There is a fourth possibility, yet the effectiveness and efficiency of the collaborative inductive learning approach were not examined in our thesis. We intentionally tried our best to limit the number of interventions, because each one dictates further randomization of students, which would result in smaller numbers of students per group. Future studies might compare between the collaborative deductive and collaborative inductive learning approaches in regard to cognitive load measures and knowledge transfer to real patient encounters. Another limitation is the amount and time of exposures to VPs. In our studies, VP exposure was limited to only one session, while we could have measured the effectiveness of VPs across multiple encounters. Future studies could measure knowledge transfer after exposing students to VPs over a whole semester or even a whole academic year.

Another limitation relevant to Study 2, is that the lecture might have masked positive effects of the inductive approach, because the breadth and depth of students' knowledge gaps after their practice with VPs was unknown to the tutor. Furthermore, the students did not discuss together the knowledge gaps or engaged in inquiry activities after facing the problems, which is known to be effective in motivating students toward deep learning in the inductive approach (Schmidt, Rotgans, \& Yew, 2011). Future investigation of the use of VPs in an inductive approach needs to provide the students the opportunity of exploring and formulating their own learning objectives. Then, the tutor would be aware of the breadth and depth of the knowledge that should be provided to the students to close these gaps.

Study 3 has investigated only the perception of students on VP design for teaching professionalism, which is the first layer in Kirkpatrick's model. The effectiveness of using VPs on learning the cognitive base of professionalism or its impact on students' behaviors are interesting venues for future research. Future studies could compare between the effectiveness of using VPs in a collaborative learning activity versus the students' clinical rotations with different medical teachers in different clinical encounters over a longer period of time.

The thesis has not only examined the effectiveness of different VP integration scenarios, but also investigated the efficiency of different interventions. Measuring different types of cognitive load was performed using a reliable instrument that has 
been used in multiple educational studies. However, future studies could also triangulate cognitive load measures using a dual-task method or physiological measures of cognitive load.

\section{Practical Implications in the Form of 'Letters to Stakeholders'}

A number of practical implications and recommendations can be suggested, with respect to integration of VPs within a curriculum, in the format of personal letters to five key stakeholders: VP designers, medical teachers, students, deans, and executives of e-learning companies.

Dear VP Designer,

The value of VPs depends on the ability of the medical teacher to integrate them within the curriculum. Therefore, you should communicate with medical teachers before development and check how they plan to use your VPs. Remember that effective use and integration requires specific features to be incorporated during design and development. VPs that are used for formative assessment require feedback to be incorporated within the design at each step, while VPs that are used for summative assessment might benefit from a summary report once VPs have been completed. VPs that are intended as an independent learning activity need to tackle simple problems and might benefit from links to extra resources, while VPs that are going to be integrated within a collaborative learning activity require more challenging ill-structured problem-solving to stimulate discussion between team members. Finally, VPs that are intended for teaching professionalism need to be of high physical and functional fidelity, follow a specific dramatic structure, and involve multiple plausible end nodes.

Since VPs are expensive e-learning simulation tools intended to be used over a long time and to be circulated between different medical teachers, it is important that every VP has its own Identification Card (ID). The VPs' ID card should involve information about the VPs name, design features, intended use (learning \& assessment) and preferable integration scenario. Huwendiek, de Leng, et al. (2009) proposed a VP typology framework that involves the features that should be described for every VP. The typology framework involves general features (title, description and language, unique ID, provenance, typical study time), educational design features (educational level, modes, topic covered, objectives), instructional design features 
(path type, number of users, media used, way of presenting data), and technical features (interactive use, feedback, technical format, integration).

Dear Medical Teacher,

VPs can help you in running an interactive engaging teaching session within the classroom. There are many VP activities that are described in the literature. However, you can build your own VP activity. Practicing a new VP activity requires piloting its effect and gathering information on student perceptions before its official use, as some integration scenarios might impose high cognitive load that hinders learning.

VPs can facilitate exposing the students to clinical cases at early years in their academic program. Furthermore, integration of different subjects that are sometimes difficult to be achieved and implemented in a discipline-based curriculum can be achieved by using VPs. You can still teach different dental and medical subjects as planned in your discipline-based curriculum and then at the end of a month, one or more VP sessions can be arranged to wrap up the learned materials by covering the learning objectives of different subjects through a comprehensive patient problem. The VPs used in these sessions could be custom-made and very specific to a particular discipline-based curriculum.

The good teacher is more than a lecturer. One of your recognized roles is being a resource developer (Harden \& Crosby, 2000). Therefore, sharing your knowledge as a subject matter expert with a team that is designing and developing VPs is one of your basic roles as a medical teacher. With every new VP design, you are actually not providing your time and effort only, but you are also gaining more experience in implementing one of the roles that is a core competency of the future medical teacher.

Dear Students,

The problem that you are going to face in a VP is a real problem that you are definitely going to face later in clinical practice. Therefore, it is better for you to make mistakes on VPs rather than on real patients. No one would blame you for making mistakes on a VP, while you cannot imagine the psychological impact that you would feel as a result of making serious mistakes on a real patient. Learning from mistakes 
on VPs would be highly retained in your memory, so you would be able to avoid them in the future.

Practicing VPs after attending a lecture would allow you to apply the gained knowledge on an authentic context that is similar to a real-life scenario. Extensive application and practice of VPs will facilitate the structuring of your knowledge in a shape known as an "illness script". Such shape of knowledge would enhance your ability in reaching a correct diagnosis and formulating the most appropriate treatment plan for a specific problem.

VPs can provide you with informative feedback on your performance or some of them might give you a summative report and score at the end of your practice, which would allow you to diagnose gaps of knowledge and skills relevant to your intended learning objectives. Such gaps can be closed by other methods of instruction such as reading, attending lectures and watching educational videos and tutorials.

Dear Deans of Medical and Dental Colleges,

The use of VPs by students will make them better prepared to deal with patients in the clinical years of their educational program, which would be reflected positively on patient satisfaction at your institute. Furthermore, you might find a drop in the incidence reports relevant to ethical and professional behavior, as the students recognized VPs as an effective tool for developing ethical reasoning skills that are needed for decision-making in situations in which they are facing professional dilemmas.

It is important that you create an environment that supports innovation in instructional design. You have to allocate time and financial resources to your staff so they can design and test VPs. Moreover, you should reward teachers who are able to create and integrate VPs within their courses.

The description of your educational program needs to include VPs as a recognized instructional method; so medical teachers would begin exploring this method. In the same vein, you should involve VP design and integration as an essential competency that needs to be developed within your faculty members. Therefore, multiple faculty development sessions on VP design and integration should be a priority in your faculty development program. 
Dear Chief Executives of E-learning companies,

The future of your industry depends on the degree of customization that is incorporated in different E-learning tools, and the ability of these E-learning tools to facilitate information processing rather than being just information provider. You might need to direct your investment toward creating mobile applications of VPs that can be used on students' own devices, which will spread VP use with a high return on investment. Moreover, the future of VP design depends on the ability of your company to integrate it with artificial intelligence. Through the use of artificial intelligence, VPs can respond directly to all students' verbal questions without the need of answers being programmed in advance. Such a development might open a wide gate for using VPs in many medical and dental colleges.

Another application of artificial intelligence is the production of VPs that can suggest solutions for low-achieving students. In other words, linking between VPs and the science of learning analytics might extend the role of VPs from only diagnosing deficiencies of students' knowledge and skills to suggesting a customized learning pathway that involves customized contents and activities.

\section{Conclusion}

This thesis added further evidence that incorporating VPs in a collaborative learning activity, which is part of a deductive learning approach is an effective and efficient method of integrating VPs within a dental curriculum. The studies presented in this thesis also showed that this learning approach is well perceived by students for learning ethical reasoning skills, which are necessary for decision-making when facing professionalism dilemmas. 


\section{References}

Al-Eraky, M. M. (2015). Twelve Tips for teaching medical professionalism at all levels of medical education. Med Teach, 37(11), 1018-1025.

Al-Eraky, M. M., Donkers, J., Wajid, G., \& Van Merrienboer, J. J. (2015). Faculty development for learning and teaching of medical professionalism. Med Teach, 37 Suppl 1, S40-46.

Birden, H., Glass, N., Wilson, I., Harrison, M., Usherwood, T., \& Nass, D. (2013). Teaching professionalism in medical education: a Best Evidence Medical Education (BEME) systematic review. BEME Guide No. 25. Med Teach, 35(7), e1252-1266.

Botezatu, M., Hult, H., \& Fors, U. G. (2010). Virtual patient simulation: what do students make of it? A focus group study. BMC Med Educ, 10, 91.

Botezatu, M., Hult, H., Kassaye Tessma, M., \& Fors, U. G. (2010). As time goes by: Stakeholder opinions on the implementation and use of a virtual patient simulation system. Med Teach, 32(11), e509-516.

Botezatu, M., Hult, H., Tessma, M. K., \& Fors, U. (2010). Virtual patient simulation: knowledge gain or knowledge loss? Med Teach, 32(7), 562-568.

Colliver, J. A. (2002). Constructivism: the view of knowledge that ended philosophy or a theory of learning and instruction? Teach Learn Med, 14(1), 49-51.

Cook, D. A., Erwin, P. J., \& Triola, M. M. (2010). Computerized virtual patients in health professions education: a systematic review and meta-analysis. Academic Medicine, 85(10), 1589-1602.

Cook, D. A., \& Triola, M. M. (2009). Virtual patients: a critical literature review and proposed next steps. Med Educ., 43(4), 303-311.

Edelbring, S., Brostrom, O., Henriksson, P., Vassiliou, D., Spaak, J., Dahlgren, L. O., ... Zary, N. (2012). Integrating virtual patients into courses: follow-up seminars and perceived benefit. Med Educ, 46(4), 417-425.

Edelson, D. (2001). Learning-for-use: a framework for integration content and process learning in the design of inquiry activities. J Res Sci Teach, 8, 355385 .

Gokhale, A. A. (1995). Collaborative learning enhances critical thinking.

Harden, R., \& Crosby, J. (2000). AMEE Guide No 20: The good teacher is more than a lecturer-the twelve roles of the teacher. Med Teach, 22(4), 334-347. 
Huwendiek, S., de Leng, B. A., Zary, N., Fischer, M. R., Ruiz, J. G., \& Ellaway, R. (2009). Towards a typology of virtual patients. Med Teach, 31(8), 743-748.

Huwendiek, S., Duncker, C., Reichert, F., de Leng, B. A., Dolmans, D., van der Vleuten, C. P., . . Tonshoff, B. (2013). Learner preferences regarding integrating, sequencing and aligning virtual patients with other activities in the undergraduate medical curriculum: A focus group study. Med Teach, 35(11), 920-929.

Huwendiek, S., Reichert, F., Bosse, H. M., de Leng, B. A., van der Vleuten, C. P., Haag, M., . . . Tonshoff, B. (2009). Design principles for virtual patients: a focus group study among students. Med Educ, 43(6), 580-588.

Johnson, D., \& Johnson, R. (1987). Learning together and alone: Cooperative, competitive, and individualistic learning: Prentice-Hall, Inc.

Johnson, T., Lyons, R., Kopper, R., Johnsen, K., Lok, B., \& Cendan, J. (2014). Virtual patient simulations and optimal social learning context: a replication of an aptitude-treatment interaction effect. Med Teach, 36(6), 486-494.

Jonassen, D. H. (1994). Thinking technology: Toward a constructivist design model. Educational technology, 34(4), 34-37.

Kirschner, F., Paas, F., \& Kirschner, P. A. (2009a). A cognitive load approach to collaborative learning: United brains for complex tasks. Educational Psychology Review, 21(1), 31-42.

Kirschner, F., Paas, F., \& Kirschner, P. A. (2009b). Individual and group-based learning from complex cognitive tasks: Effects on retention and transfer efficiency. Computers in Human Behavior, 25(2), 306-314.

Kreijns, K., Kirschner, P. A., \& Jochems, W. (2003). Identifying the pitfalls for social interaction in computer-supported collaborative learning environments: a review of the research. Computers in Human Behavior, 19(3), 335-353.

Murphy S, Imam B, \& Whitehouse L. (2016). Twelve Tips for Utilizing Virtual Patients to Teach Professionalism. MedEdPublish, 5(3), 1-9.

Philpott, J., \& Batty, H. (2009). Learning best together: social constructivism and global partnerships in medical education. Med Educ, 43(9), 923-924.

Reeve, C. (2009). Narrative-Based Serious Games. In O. Petrovic \& A. Brand (Eds.), Serious Games on the Move (pp. 73-89). Vienna: Springer Vienna. 
Round, J., Conradi, E., \& Poulton, T. (2009). Training staff to create simple interactive virtual patients: the impact on a medical and healthcare institution. Med Teach, 31(8), 764-769.

Schmidt, H. G., Rotgans, J. I., \& Yew, E. H. (2011). The process of problem-based learning: what works and why. Med Educ, 45(8), 792-806.

Schwartz, D. L., \& Bransford, J. D. (1998). A time for telling. Cognition and instruction, 16(4), 475-5223.

Van Merrienboer, J. J. (2013). Perspectives on problem solving and instruction. Computers \& Education, 64, 153-160.

Van Merrienboer, J. J., \& Kirschner, P. A. (2018). Ten steps to complex learning: A systematic approach to four-component instructional design: Routledge.

Van Merrienboer, J. J., Kirschner, P. A., \& Kester, L. (2003). Taking the load off a learner's mind: Instructional design for complex learning. Educational Psychologist, 38(1), 5-13.

Vygotsky, L. S. (1980). Mind in society: The development of higher psychological processes: Harvard university press.

Wang, S.-L., \& Lin, S. S. J. (2007). The effects of group composition of self-efficacy and collective efficacy on computer-supported collaborative learning. Computers in Human Behavior, 23(5), 2256-2268.

Young, J. Q., Van Merrienboer, J. J., Durning, S., \& Ten Cate, O. (2014). Cognitive Load Theory: implications for medical education: AMEE Guide No. 86. Med Teach., 36(5), 371-384. 
Chapter 7: English summary 
Virtual Patients have been gaining interest in educational research over the last 10 years. A VP is an interactive computer simulation of a real-life clinical scenario for the purpose of teaching, learning and assessment. VPs can bridge a gap that might exist between theoretical and clinical training, facilitate knowledge acquisition and the development of clinical reasoning skills. Moreover, learning with VPs provides a safe environment for students to learn from their mistakes. VPs differ in their design based on the use of images, presentation of stories, degree of interactivity and how they branch during practice.

Currently, there is a shift in the use of VPs from being a standalone E-learning object to a more holistic approach that involves their use in the classroom within one or more learning activities. The literature shows different learning activities that can be constructed around VPs. Two of them are independent and collaborative activities. In an independent activity, the learner works individually with a VP, where learning depends mainly on the intrinsic characteristics incorporated in the VP design. In a collaborative activity, the students work in groups of 3-5 members and take collective decisions after discussion while practicing the VP.

Furthermore, the literature has presented the use of VPs in different sequences with other instructional methods such as lectures, small group discussions, and real patients. VP activities can be sequenced before other instructional methods such as a lecture or a small group discussion, which is known as an inductive learning approach because it works from a concrete case to more general information. In this approach, students appreciate gaps in their knowledge, which raise their interest in the subsequent presented materials. On the other side, the VP activities can be sequenced after lectures or small group discussions, which is known as a deductive learning approach. In such approach the VP serves as a context for knowledge application, which promotes deep learning. The alignment of the VPs' session and the other instructional sessions to augment each other is known as a VP integration scenario. Although studies on students' perception of VP integration scenarios showed a preference for a VP that is followed by a lecture, small group discussion and then a real patient, still there is a gap of knowledge in regard to how VPs can be effectively integrated into a curriculum.

The studies reported in this $\mathrm{PhD}$ thesis were conducted in one governmental dental college in Saudi Arabia. The college involves two separate campuses for the 
male and female students. The studies targeted two topics that belong to an oral and maxillofacial surgery course, which is delivered annually to $4^{\text {th }}$ year dental students. The thesis aimed at investigating the effectiveness of different integration scenarios on students' knowledge acquisition, retention and transfer. Furthermore, it has explored how VPs can be integrated to teach ethical reasoning skills that are necessary for the students in taking decisions in ethical dilemmas as a part of teaching and learning professionalism.

This thesis involved four studies to answer four research questions, as follows: (1) Would the use of virtual patients as a collaborative learning activity, when compared with their use as an independent learning activity, enhance students' knowledge acquisition, retention, and transfer? (2) Does sequencing virtual patients with lectures through a deductive approach, when compared with an inductive approach, result in a difference in students' knowledge acquisition, retention, and transfer? (3) How can the use of VPs in the classroom help students in developing their ethical reasoning skills, and what are the VP design features that learners perceive as crucial for teaching professionalism? (4) Is the collaborative use of VPs after a lecture the most efficient instructional method, when compared with independent use of VPs either before or after the lecture?

Study 1 aimed at comparing the effect of using VPs in a collaborative learning activity and using VPs in an independent learning activity on students' knowledge acquisition, retention and transfer. Dental students across male and female campuses have been randomly assigned to condition (collaborative and independent), yielding four experimental groups. Each group received a lecture followed by a learning session using two VPs per topic. Students were administrated immediate and delayed written tests as well as transfer tests using two VPs to assess their knowledge in diagnosis and treatment relevant to the different problems that are presented in topics 1 and 2. The study showed that on the female campus, the use of VPs in a collaborative learning activity is more effective than its use as an independent learning activity in enhancing students' knowledge acquisition and retention. The study showed that putting the students together in groups to work on VPs is not enough to produce consistent results across different campuses, which underpins other factors, which are conductive to students' interaction such as abilities of different group members and the complexity of presented problems. Ill-structured problems 
that contain unknown elements, have multiple acceptable solutions (or no solution at all), and often require learners to make judgments are more stimulating to students' interactions than well-structured problems.

Study 2 explored the effect of sequencing VPs with lectures in a deductive approach, in comparison with an inductive approach, on students' knowledge acquisition, retention, and transfer. Study 2 followed the same methodology as Study 1, as students were randomly assigned into four groups namely: male/inductive, male/deductive, female/inductive and female/deductive. Each group received a lecture session and an independent VP learning activity, which either followed the lecture session in the deductive group or preceded it in the inductive group. Students were administrated knowledge acquisition and retention written tests as well as transfer tests using two new VPs. The study found no significant effect for the learning approach on knowledge acquisition or retention, while for knowledge transfer, males benefited from the inductive approach in topic 1 while in the more complex topic 2 , they benefited from the deductive approach, while females were largely unaffected by learning approach.

Study 2 concluded that sequencing VPs in inductive and deductive learning approaches leads to no significant differences on students' performance when full guidance is offered in the inductive approach. The study showed that full guidance in the form of providing a lecture that covers both the knowledge gaps and the areas that were known to students in the inductive approach does not enhance their knowledge acquisition and retention when compared with the deductive approach. Therefore, the lecture if needed should be used as a scaffolding tool rather than as direct instruction, which requires the tutor to discuss the learning objectives with the students after the VP session in order to discover the knowledge gaps that need to be targeted by justin-time instruction.

Study 3 investigated students' perception toward the use of VPs in a collaborative activity in learning ethical reasoning skills. Furthermore, the study explored features in VP design that are necessary to promote teaching professionalism. Sixty-five senior dental students participated in learning sessions that involved collaborative practice with five VPs (four high fidelity and one low fidelity), followed by reflection sessions. Fidelity is recognized in the field of simulation as the extent of reality in the thinking process perceived by the learners as a result of having 
physical appearance and interactivity within the simulator similar to that seen in real clinical setting with real patient. Students' perceptions were measured using a questionnaire that involved 10 closed and 3 open-ended questions. High-fidelity VPs were perceived as significantly better for developing ethical reasoning skills than lowfidelity VPs. Analyses of answers to open-ended questions disclosed two new features that are specific for VPs intended for teaching professionalism, which are VP dramatic structure and how the VP should end.

Study 3 concluded that VPs intended for teaching professionalism should be of high fidelity, follow a specific dramatic structure and include multiple plausible endings. Furthermore, the study found that the use of VPs as part of a collaborative activity that is followed by a reflection session is perceived as an effective tool for the development of ethical reasoning skills in dental education. Study 3 recommended future studies that investigate the effectiveness of VPs in a collaborative learning approach on learning ethical reasoning skills. The study argued that learners would benefit more from VPs that are based on ill-structured problems, in which there is no clear cut between correct and wrong answers to stimulate more social interactions, richer discussion and suggestions in the reflection session.

Study 4 investigated the efficiency of instructional methods that involved three different applications of VPs combined with lectures, which are collaborative deductive, independent deductive, and independent inductive learning approaches. Instructional efficiency considers the amount of cognitive load invested in order to achieve a specific performance: high efficiency relates to high performance combined with low load and low efficiency relates to low performance combined with high load. Cognitive load theory advocates the significance of managing the extraneous and intrinsic cognitive load, so the working memory can process novel information to construct schemas in long-term memory. The extraneous cognitive load refers to the cognitive load that is not necessary for learning and / or execution of the task. On the other side, intrinsic cognitive load is the load necessary for executing the learning tasks and it increases with the increase in the number of information elements and the extent to which these elements interact with each other. However, germane load refers to the cognitive resources allocated to deal with learning processes.

All participants of Studies 1 and 2 completed a cognitive load questionnaire, which measured intrinsic, extraneous and germane load after their learning sessions. 
The study found that the highest intrinsic and extraneous load was detected in the independent inductive group, while the lowest intrinsic and extraneous load was seen in the collaborative deductive group. Furthermore, comparisons showed a significantly higher efficiency, that is, higher performance in combination with lower cognitive load, for the collaborative deductive group than for the other two groups. The study concluded that collaborative use of virtual patients after a lecture is the most efficient instructional method, as it enhances learning with minimal investment of cognitive load.

The thesis in its last chapter invited peer researchers to investigate the integration of VPs with gender-mixed groups using more advanced assessments tools such as assessing the students' knowledge transfer to real patient encounters. The thesis has also suggested exploring the collaborative inductive learning approach in comparison with other learning approaches using VPs that are based on ill-structured problems. The thesis directed practical messages that might stimulate different stakeholders toward better application of VPs in dental education. Finally, this $\mathrm{PhD}$ project has added further evidence that incorporating VPs in a collaborative learning activity, which is part of a deductive learning approach, is an effective and efficient method of integrating VPs within a dental curriculum. 
Hoofdstuk 8: Samenvatting 
In het onderwijskundig onderzoek van de afgelopen 10 jaar zijn Virtuele Patiënten (VP's) steeds meer in de belangstelling komen te staan. Een VP is een interactieve computersimulatie van een echt scenario uit de klinische praktijk dat onderwijzen, leren en toetsen als doel heeft. VP's zijn in staat een mogelijk bestaand hiaat tussen theoretisch en klinisch opleiden te vullen en kennisverwerving en de ontwikkeling van klinisch redeneervaardigheden te bevorderen. Bovendien biedt het leren met VP's studenten een veilige omgeving waarin zij kunnen leren van hun fouten. Het ontwerp verschilt per VP qua gebruik van beelden, presentatie van verhalen, mate van interactiviteit en hoe zij zich in de praktijk ontwikkelen.

Momenteel vindt er een verschuiving plaats van het gebruik van VP's als standalone E-learning object naar een meer holistische aanpak waarbij de VP's binnen een of meerdere klassikale activiteiten worden ingezet. In de literatuur worden verschillende leeractiviteiten beschreven die om VP's kunnen worden heen gebouwd. Twee daarvan zijn zelfstandige en samenwerkingsactiviteiten. Bij een zelfstandige activiteit werkt de student individueel met een VP en hangt het leren voornamelijk af van de intrinsieke eigenschappen die in het VP-ontwerp zijn opgenomen. Bij een samenwerkingsactiviteit werken de studenten in groepen van 3-5 leden en nemen zij na de discussie gezamenlijke besluiten terwijl ze met de VP oefenen.

Voorts laat de literatuur zien dat VP's gebruikt worden in verschillende opeenvolgingen van onderwijsmethoden, zoals colleges, onderwijsgroepen en echte patiënten. VP-activiteiten kunnen plaatsvinden voorafgaand aan andere onderwijsmethoden zoals een college of onderwijsgroep. Dit wordt een inductieve leerbenadering genoemd, omdat er vanuit een concrete casus naar meer algemene informatie wordt toegewerkt. Bij deze benadering worden studenten zich bewust van hiaten in hun kennis, waardoor zij geïnteresseerd raken in de stof die zij vervolgens gepresenteerd krijgen. Aan de andere kant kunnen VPactiviteiten plaatsvinden na colleges of onderwijsgroepen, wat bekend staat als een deductieve leerbenadering. Bij deze benadering dient de VP als context voor het toepassen van kennis, wat het diepgaand leren bevordert. Het onderling zo afstemmen van de VP-sessie en de andere educatieve sessies dat zij elkaar versterken wordt een VP-integratiescenario genoemd. Hoewel studies over studentpercepties van VPintegratiescenario's een voorkeur lieten zien voor een VP gevolgd door een college, onderwijsgroep en vervolgens een echte patiënt, bestaat er nog steeds een lacune in 
kennis met betrekking tot de vraag hoe VP's effectief kunnen worden geïntegreerd in een curriculum.

De in dit proefschrift beschreven studies zijn in één publieke universiteit voor tandheelkunde in Saoedi-Arabië uitgevoerd. De universiteit beslaat twee afzonderlijke campussen voor mannelijke en vrouwelijke studenten. De studies richtten zich op twee onderwerpen die deel uitmaakten van een cursus mond-, kaaken aangezichtschirurgie die jaarlijks wordt gegeven aan vierdejaars studenten tandheelkunde. Het proefschrift beoogde te onderzoeken wat het effect was van verschillende integratiescenario's op de verwerving, retentie en overdracht van kennis door studenten. Voorts heeft het onderzocht hoe VP's geïntegreerd kunnen worden om studenten ethisch redeneervaardigheden aan te leren die zij nodig hebben voor het nemen van besluiten omtrent ethische dilemma's als onderdeel van het leren en onderwijzen van professionaliteit.

Dit proefschrift omvatte vier studies ter beantwoording van de volgende vier onderzoeksvragen: (1) Zou het gebruik van virtuele patiënten als een gezamenlijke leeractiviteit, vergeleken met hun gebruik als een zelfstandige leeractiviteit, de verwerving, retentie en overdracht van kennis door studenten verbeteren? (2) Leidt de opeenvolging van colleges met virtuele patiënten middels een deductieve benadering, vergeleken met een inductieve benadering, tot een verschil in de verwerving, retentie en overdracht van kennis door studenten? (3) Hoe kan het klassikale gebruik van VP's studenten helpen hun ethisch redeneervaardigheden te ontwikkelen en welke aspecten van het VP-ontwerp beschouwen studenten als uiterst belangrijk voor het doceren van professionaliteit? (4) Is het gezamenlijk gebruik van VP's na een college de meest effectieve onderwijsmethode vergeleken met het zelfstandig gebruik van VP's, hetzij voor of na het college?

Studie 1 beoogde het effect van het gebruik van VP's bij een gezamenlijke leeractiviteit op de verwerving, retentie en overdracht van kennis door studenten te vergelijken met de effectiviteit van het gebruik van VP's bij een zelfstandige leeractiviteit. Studenten tandheelkunde van zowel de mannen- als vrouwencampus werden willekeurig ingedeeld bij een conditie (gezamenlijk en zelfstandig), wat vier experimentele groepen opleverde. Elke groep kreeg een college gevolgd door een leersessie waarbij twee VP's per onderwerp werden gebruikt. Bij de studenten werden direct en na een tussenperiode schriftelijke toetsen afgenomen 
alsook transfertoetsen waarbij twee VP's werden gebruikt om hun kennis ten aanzien van diagnose en behandeling met betrekking tot de verschillende bij onderwerp 1 en 2 gepresenteerde problemen te toetsen. De studie toonde aan dat studenten op de vrouwencampus meer kennis verwierven en behielden wanneer VP's gebruikt werden bij een gezamenlijke in plaats van een zelfstandige leeractiviteit. De studie liet zien dat het voor het verkrijgen van constante resultaten over verschillende campussen niet volstaat om studenten samen in groepen te plaatsen om aan VP's te werken en dat er dus andere factoren een rol spelen die zorgen voor meer interactie tussen studenten, zoals de capaciteiten van verschillende groepsleden en de moeilijkheidsgraad van de getoonde problemen. Slecht gestructureerde problemen die onbekende elementen bevatten, meerdere aanvaardbare oplossingen (of helemaal geen oplossing) hebben en vaak van studenten vragen een oordeel te uiten stimuleren de interactie tussen studenten meer dan goed gestructureerde problemen dat doen.

Studie 2 onderzocht het effect van de opeenvolging van colleges met VP's bij een deductieve benadering, in vergelijking met een inductieve benadering, op de verwerving, retentie en overdracht van kennis door studenten. Bij Studie 2 werd dezelfde methodologie aangehouden als bij Studie 1, aangezien studenten willekeurig werden ingedeeld in vier groepen, namelijk: mannen/inductief, mannen/deductief, vrouwen/inductief en vrouwen/deductief. Elke groep kreeg een collegesessie en een zelfstandige VP-leeractiviteit die ofwel op de collegesessie volgde bij de deductieve groep dan wel eraan vooraf ging bij de inductieve groep. Bij de studenten werden schriftelijke kennis- en retentietoetsen afgenomen alsook transfertoetsen waarbij twee nieuwe VP's werden gebruikt. De studie vond geen significant effect van de leerbenadering op de kennisverwerving en -retentie, maar wat de kennistransfer betreft hadden mannen voordeel bij de inductieve benadering bij onderwerp 1, terwijl ze bij het moeilijkere onderwerp 2 juist meer baat hadden bij de deductieve benadering; vrouwen werden over het algemeen niet beïnvloed door leerbenadering.

Studie 2 concludeerde dat het moment van VP-introductie bij de inductieve en deductieve benaderingen niet leidde tot significante verschillen in de prestaties van studenten wanneer er bij de inductieve benadering volledige begeleiding werd geboden. De studie liet zien dat volledige begeleiding in de vorm van een college waarin zowel de ontbrekende kennis als de al bij de inductieve benadering aanwezige kennis werd behandeld niet leidt tot een verbetering van 
kennisverwerving en -retentie vergeleken met de deductieve aanpak. Daarom zou het college indien nodig als ondersteuning moeten dienen in plaats van als directe instructie, wat betekent dat de tutor na de VP-sessie de leerdoelen moet bespreken met de studenten om erachter te komen op welke kennishiaten de just-in-time instructie gericht moet zijn.

Studie 3 onderzocht de perceptie van studenten ten aanzien van het gebruik van VP's bij een gezamenlijke activiteit bedoeld om ethisch redeneervaardigheden op te doen. Voorts onderzocht de studie welke aspecten van het VP-ontwerp nodig zijn om het aanleren van professionaliteit te bevorderen.

Vijfenzestig ouderejaarsstudenten tandheelkunde namen deel aan leersessies waarin gezamenlijk geoefend werd met vijf VP's (waarvan vier high fidelity en één low fidelity), gevolgd door reflectiesessies. In de simulatiepraktijk wordt onder "fidelity" verstaan de mate waarin studenten ervaren dat hun denkproces overeenkomt met de realiteit als gevolg van een fysiek voorkomen en interactiviteit binnen de simulator die lijken op die van een echte klinische setting met een echte patiënt. De percepties van studenten werden gemeten met behulp van een vragenlijst bestaande uit 10 gesloten en 3 open vragen. High-fidelity VP's werden als significant beter gezien voor het ontwikkelen van ethisch redeneervaardigheden dan low-fidelity VP's. Uit de analyse van de antwoorden op de open vragen kwamen twee nieuwe aspecten naar voren die kenmerkend zijn voor VP's bedoeld om professionaliteit aan te leren, te weten de dramatische structuur van de VP en hoe de VP moet aflopen.

Studie 3 concludeerde dat VP's bedoeld voor het aanleren van professionaliteit high fidelity moeten zijn, een specifieke dramatische structuur moeten volgen en op meerdere aannemelijke manieren moeten kunnen eindigen. Voorts bleek uit de studie dat het gebruik van VP's als onderdeel van een gezamenlijke activiteit gevolgd door een reflectiesessie gezien wordt als een effectieve manier om ethisch redeneervaardigheden te ontwikkelen in het tandheelkundig onderwijs. Studie 3 beval toekomstige studies aan die het effect van VP-gebruik bij een gezamenlijke leerbenadering op het aanleren van ethisch redeneervaardigheden onderzoeken. De studie stelde dat studenten meer voordeel zouden hebben bij VP's die gebaseerd zijn op slecht gestructureerde problemen waarbij het onderscheid tussen goede en slechte antwoorden niet duidelijk is en die 
daardoor zorgen voor meer sociale interactie, een rijkere discussie en meer suggesties in de reflectiesessie.

Studie 4 onderzocht de doelmatigheid van onderwijsmethoden waarbij VP's op drie verschillende manieren in combinatie met colleges werden gebruikt, namelijk de gezamenlijk deductieve, zelfstandig deductieve en zelfstandig inductieve leerbenadering. Bij doelmatigheid van het onderwijs wordt gekeken naar de mate van cognitieve belasting bij het leveren van een bepaalde prestatie: er is sprake van een hoge doelmatigheid wanneer met een lage belasting een hoge prestatie geleverd wordt en van een lage doelmatigheid wanneer de belasting hoog is en de prestatie laag. Cognitieve belastingstheorie benadrukt hoe belangrijk het is dat extraneous (irrelevante) en intrinsic (inherente) cognitieve belasting gereguleerd worden, opdat het werkgeheugen nieuwe informatie kan verwerken om schemata in het langetermijngeheugen te construeren. De irrelevante cognitieve belasting betreft de cognitieve belasting die niet nodig is voor het leren en/of uitvoeren van de taak. De inherente cognitieve belasting daarentegen is de belasting die nodig is voor het uitvoeren van de leertaken en neemt toe naarmate het aantal informatie-elementen en hun onderlinge interactie toeneemt. Germane (nuttige) belasting verwijst echter naar de cognitieve middelen die worden ingezet om met leerprocessen om te gaan.

Alle deelnemers van Studie 1 en 2 vulden een vragenlijst over cognitieve belasting in die de inherente, irrelevante en nuttige belasting na hun leersessies mat. Met behulp van het statistisch programma " $\mathrm{R}$ ” werd een mixedeffects analyse uitgevoerd van de cognitieve belasting en doelmatigheid. Uit de studie bleek dat de hoogste inherente en irrelevante belasting werd waargenomen in de zelfstandig inductieve groep, terwijl de laagste inherente en irrelevante belasting werd gezien in de gezamenlijk deductieve groep. De vergelijkingen toonden voorts een significant hogere doelmatigheid, d.w.z. een hogere prestatie in combinatie met een lagere cognitieve belasting, voor de gezamenlijk deductieve groep dan voor de andere twee groepen. De studie concludeerde dat het gezamenlijk gebruik van virtuele patiënten na een college de meest doelmatige onderwijsmethode is, omdat deze het leren bevordert met een minimale cognitieve belasting.

In het laatste hoofdstuk nodigde het proefschrift collega-onderzoekers uit om de integratie van VP's te onderzoeken met groepen van gemengd geslacht met behulp van meer geavanceerde toetsinstrumenten, zoals het toetsen van de 
kennisoverdracht door studenten naar contacten met echte patiënten. Het proefschrift stelde ook voor de gezamenlijk inductieve leerbenadering in vergelijking met andere leerbenaderingen te onderzoeken, daarbij gebruikmakend van VP's die op slecht gestructureerde problemen gebaseerd zijn. Het proefschrift had enkele praktische tips die verschillende belanghebbenden zouden kunnen aanzetten tot een beter gebruik van VP's in het tandheelkundig onderwijs. Tot slot heeft dit PhD-project aanvullend bewijs geleverd voor de bevinding dat de inbedding van VP's in een gezamenlijke leeractiviteit die deel uitmaakt van een deductieve leerbenadering een effectieve en doelmatige methode is om VP's te integreren in een tandheelkundig curriculum. 
Valorisation 
This valorization section aims to provide recommendations for creating value from the research work reported in this thesis. The knowledge presented in the four studies of the thesis can serve as the basis for the development of VPs that are better customized to specific uses. It can also serve for a better integration of VP activities in instructional designs.

The four studies presented in the current thesis underpin the relation between development, different ways of using VPs, and effectiveness in terms of learning outcomes. Effective use of VPs leads to a wide adoption of VPs by a large number of medical, dental and nursing schools with a high Return on Investment (RoI) for different stakeholders (i.e., students, teachers and management). VPs can be a valuable tool in the teacher toolbox, as they can facilitate running highly interactive teaching sessions. VPs can also be used as a tool for facilitating inter-disciplinary integration, as they can be designed to wrap up the learned materials by covering the learning objectives of different subjects through comprehensive patient problems. The use of VPs can even reduce the number of incident reports, as they can better prepare students for a variety of clinical encounters.

Study 1 showed, on the one hand, that for effective collaborative use of VPs, it is important to develop VPs that are challenging enough to stimulate social interactions between learners. Study 2, on the other hand, showed that the independent use of VPs, especially when applied before any other form of instruction, requires VPs that (a) are simple, (b) stimulate learners' interest in the topic, and (c) motivate them to search in the literature for information that closes any existing knowledge gap. VPs in such a context could be of high value if they make use of artificial intelligence. Through the use of student modelling, future VPs could suggest for every student a customized learning pathway that involves customized contents and activities.

Study 3 opened the gate for VP developers toward a new application, namely, teaching professionalism. Such a new application will increase the breadth of use of VPs. The required core values and attitudes to practice medicine, dentistry and nursing are the same, with only little variations in priorities across different health professions and specialties. Therefore, the same professionalism VPs could be used across a wide spectrum of learners. VP designers might need to incorporate the essential design features that have been presented in Study 3 such as high fidelity, the 
need for multiple end nodes, and a strong dramatic structure in VPs that are intended for teaching professionalism.

Study 4 sent the message to VP developers that certain VP designs might impose a high cognitive load if sequenced inappropriately with other instructional methods. Therefore, VP developers might need to attach a manual or information sheet to every VP, giving recommendations and guidelines that govern different types of use. Then, given particular conditions and particular intended learning outcomes, the VPs could still be effectively used if the recommendations are well taken into account. This will lead to a growth in their practice with a high return on investment for different stakeholders.

VPs could be used much more often than they are currently used, both to teach professional competencies and more generic competencies such as professionalism, and that they can help to make learning more attractive, more collaborative, and, when used for independent learning, more personalized. 


\section{Acknowledgment}

I would like to thank Prof. dr. Jeroen Van Merrienboer for sharing his pearls of wisdom and knowledge with me throughout the course of my $\mathrm{PhD}$. I extend my gratitude to Dr. Jeroen Donkers for his continuous support and eye opening comments. Further, I am indebted to Dr. Mohamed Al-Eraky for his ongoing motivation and guidance on the personal and professional levels. 


\section{Dedication}

I heartily dedicate my thesis ...

To the soul of my father, who inspired me to preserve integrality and pursue excellence,

To the soul of my mother, who used to keep me in her prayers to be successful in my life,

To my wife (Eman), who sweetened my life and supported me throughout the journey of my studies.

To my kids (Shahd, Omar and Karam), who have high expectations from their father.

To my professors and mentors from Egypt and UK (Prof. Tarek ElSharkawy, Prof. Said Hamed, Dr. Andrew Cronin, Prof. David Tomas, Prof. Hossam Hamdy and Dr. Gohar Wajid), who inspired me to pursue excellence during my whole career.

Finally, to everyone who finds this thesis helpful in influencing the future of dental education. 


\section{Curriculum Vitae}

Hesham Fathi Marei is an Associate Professor \& Consultant of Oral and Maxillofacial Surgery. He is affiliated to the Faculty of Dentistry, Suez Canal University, Egypt. He is currently working in the College

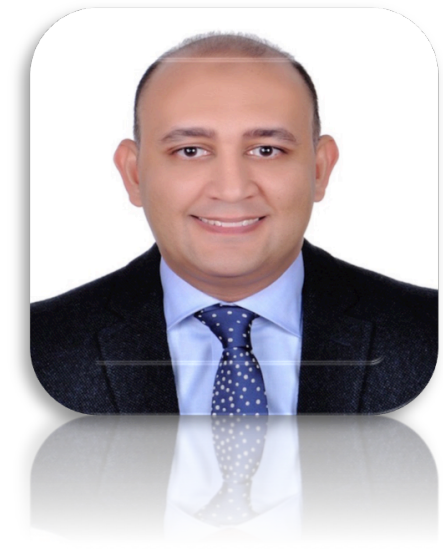
Saudi Arabia.

Dr. Marei graduated at Cairo University in 1997, and then received his Master (2003) and Doctoral (2008) Degrees in oral and maxillofacial surgery from Suez Canal University, Egypt. Moreover, he has done his clinical training at Cardiff Dental School, University Hospital of Wales, UK, and obtained his Fellowship in Dental Surgery from the Royal College of Surgeons in London, 2006.

In 2010, Dr. Marei developed a passion for medical education. This passion inspired him to obtain a Master Degree in medical education in 2012, and as you are reading these lines, he has almost concluded his $\mathrm{PhD}$ in medical education in the School of Health Professions Education (SHE) at Maastricht University, the Netherlands.

Dr. Marei has actively contributed with presentations, workshops and courses in both specialties (Oral and Maxillofacial Surgery \& Medical Education) at a number of national and international events in Egypt, Saudi Arabia, Bahrain, Pakistan, UAE, the Netherlands, and the UK. 


\section{Marei HF Publications}

\section{- Medical and Dental Education}

Marei HF, Donkers J, Al-Eraky MM, Van Merrienboer JJG. Collaborative use of virtual patients after a lecture enhances learning with minimal investment of cognitive load. Med Teach. 2018 May 25:1-8. doi: 10.1080/0142159X.2018.1472372. [Epub ahead of print]

Marei HF, Donkers J, Van Merrienboer JJG. The effectiveness of integration of virtual patients in a collaborative learning activity. Med Teach. 2018 May 7:1-8. doi: 10.1080/0142159X.2018.1465534. [Epub ahead of print]

Marei HF, Donkers J, Al-Eraky MM, van Merrienboer JJG. The effectiveness of sequencing virtual patients with lectures in a deductive or inductive learning approach. Med Teach. 2017 Dec;39(12):1268-1274.

Marei HF, Al-Eraky MM, Almasoud NN, Donkers J, Van Merrienboer JJG. The use of virtual patient as a vehicle for teaching professionalism. Eur J Dent Educ. 2018 May;22 (2):e253-e260.

Al-Eraky MM, Marei HF. Fresh Look at Miller's Pyramid. Assessment at the 'is' and 'do' levels. Med Educ. 2016 Dec; 50(12):1253-1257.

Al-Eraky MM, Marei HF. Pattern, Trends, and thinking 'inside' the box in medical education. Med Educ. 2015 Dec;49(12):1176-8.

Al-Eraky MM, Marei HF. Medical professionalism: When in Rome, Romans should help visitors. Med Teach. 2016;38(2):214.

Marei HF, Al-Khalifa KS. Pattern of online communication in teaching a blended oral surgery course. Eur J Dent Educ. 2016 Nov; 20(4): 213-217. 
Marei HF, Al-Jandan BA. Simulation-based local anaesthesia teaching enhances learning outcomes. Eur J Dent Educ. 2013 Feb;17 (1):e44-8.

\section{- Oral and Maxillofacial Surgery}

Al-Jandan B, Marei HF, Abuohashish H, Zakaria O, Al-Mahalawy H. Effects of sunitinib targeted chemotherapy on the osseointegration of titanium implants. Biomed Pharmacother. 2018 Apr;100:433-440.

Marei HF, Mahmood K, Almas K. Critical size defects for bone regeneration experiments in dog mandible: Systematic review. Implant Dent. 2018 Feb;27(1):135141.

Al-Jandan B, Syed FA, Zeidan A, Marei HF, Farooq I. Pharyngeal pack placement in minor oral surgery: A prospective randomized controlled study. Ear Nose Throat J. 2018 Mar;97(3):E18-E21.

Almasoud NN, Tanneru N, Marei HF. Alveolar bone density and its clinical implication in the placement of dental implants and orthodontic mini-implants. Saudi Med J. 2016 Jun;37(6):684-9.

Al-Mahalawy H, Marei HF, Abuohashish H, Alhawaj H, Alrefaee M, Al-Jandan B. Effects of Cisplatin chemotherapy on the osseointegration of titanium implants. J Craniomaxillofac Surg. 2016 Apr;44(4):337-46.

\section{BA Al-jandan, A Al-Harkan, J Pompura, LZ Lim, JS Guerrero, HF Marei.}

Evaluation of deproteinized bone mineral (DBM) as an onlay bone-graft in the rabbit mandible. The Saudi Journal for Dental Research 6 (2), 133-139

Shujaat S, Abouelkheir HM, Al-Khalifa KS, Al-Jandan B, Marei HF. Pre-operative assessment of relationship between inferior dental nerve canal and mandibular impacted third molar in Saudi population. Saudi Dent J. 2014 Jul;26(3):103-7. 
Marei HF. Medical litigation in oral surgery practice. Lessons learned from 20 lawsuits. J Forensic Leg Med. 2013 May;20(4):223-5.

Al-Jandan BA, Al-Sulaiman AA, Marei HF, Syed FA, Almana M. Thickness of buccal bone in the mandible and its clinical significance in mono-cortical screws placement. A CBCT analysis. Int J Oral Maxillofac Surg. 2013 Jan;42(1):77-81.

Hassan KS, Marei HF, Alagl AS. Does grafting of third molar extraction sockets enhance periodontal measures in 30- to 35-year-old patients? J Oral Maxillofac Surg. 2012 Apr;70(4):757-64.

Hassan KS, Marei HF, Alagl AS. Composite bone grafts for treatment of osseous defects after surgical removal of impacted third and second molars: case report and review of the literature. Oral Surg Oral Med Oral Pathol Oral Radiol Endod. 2011 Dec;112(6):e8-15. 


\section{SHE dissertations series}

The SHE Dissertation Series publishes dissertations of $\mathrm{PhD}$ candidates from the School of Health Professions Education (SHE) who defended their PhD theses at Maastricht University. The most recent ones are listed below. For more information go to: https://she.mumc.maastrichtuniversity.nl

Waterval, D. (26-04-2018) Copy but not paste, an exploration of crossborder medical curriculum partnerships

Smirnova, A. (04-04-2018) Unpacking quality in residency training and health care delivery

Hikspoor, J. (05-12-2017) Development of the heart and vessels in the caudal part of the human body

Boymans, T. (06-10-2017) Hip arthroplasty in the very elderly: anatomical and clinical considerations

Zaidi, Z. (04-10-2017) Cultural hegemony in medical education: exploring the visibility of culture in health professions

Harrison, C. (20-09-2017) Feedback in the context of high-stakes assessment: can summative be formative?

Mekonen, H. (30-06-2017) Development of the axial musculo-skeletal system in humans

Taylor, T. (29-03-2017) Exploring Fatigue as a Social Construct: Implications for Work Hour Reform in Postgraduate Medical Education

McLellan, L. (29-03-2017) Prescribing the right medicine: Perspectives on education and practice

Ignacio, J. (09-02-2017) Stress Management in Crisis Event Simulations for Enhancing Performance

Bolink, S. (19-01-2017) Functional outcome assessment following total hip and knee arthroplasty; Implementing wearable motion sensors

Beckers, J. (09-12-2016) With a little help from my e-portfolio. Supporting students' self-directed learning in senior vocational education 
Giroldi, E. (07-12-2016) Towards skilled doctor-patient communication. Putting goaldirected and context-specific communication into (educational) practice

Huwendiek, S. (25-11-2016) Virtual patients for learning of clinical reasoning

Bohle-Carbonell, K. (28-09-2016) May I ask you...? The influence of individual, dyadic \& network factors on the emergence of information exchange in teams

Ginsburg, S. (01-09-2016) Hidden in plain sight, the untapped potential of written assessment comments

Koops, W. (08-06-2016) Computer-supported collaborative learning in clinical clerkships

Schlegel, C. (08-06-2016) Simulated and standardized patients in health profession education: the impact of quality improvement

Sorensen, J. 01-06-2016 Obstetric simulation: designing simulation-based medical education and the role of physical fidelity

Kok, E. (01-04-2016 Developing visual expertise: from shades of grey to diagnostic reasoning in radiology

Van den Eertwegh, V. (11-11-2015) Unravelling postgraduate communication learning; from transfer to transformative learning

Gingerich, A. (03-09-2015) Questioning the rater idiosyncrasy explanation for error variance, by searching for multiple signals within the noise

Goldszmidt, M. (02-09-2015) Communication and reasoning on clinical teaching teams, the genres that shape care and education

Slootweg, I. (19-06-2015) Teamwork of Clinical Teachers in Postgraduate Medical Training 
Al-Eraky, M. (21.05.15) Faculty development for medical professionalism in an Arabian context

Wearne, S. (08-04-2015) Is it remotely possible? Remote supervision of general practice registrars

Embo, M. (13-03-2015) Integrating workplace learning, assessment and supervision in health care education

Zwanikken, P. (23-01-2015) Public health and international health educational programmes for low- and middle-income countries: questioning their outcomes and impact 